NIST Technical Note 1904

\title{
Burning Velocity Measurements and Simulations for Understanding the Performance of Fire Suppressants in Aircraft
}

Gregory T. Linteris

John L. Pagliaro

This publication is available free of charge from: http://dx.doi.org/10.6028/NIST.TN.1904 


\title{
Burning Velocity Measurements and Simulations for Understanding the Performance of Fire Suppressants in Aircraft
}

\author{
Gregory T. Linteris \\ John L. Pagliaro \\ Energy and Environment Division \\ Engineering Laboratory
}

This publication is available free of charge from:

http://dx.doi.org/10.6028/NIST.TN.1904

January 2016

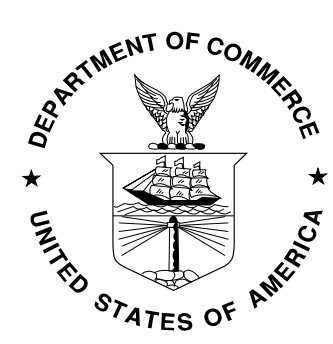

U.S. Department of Commerce Penny Pritzker, Secretary 
Certain commercial entities, equipment, or materials may be identified in this document in order to describe an experimental procedure or concept adequately. Such identification is not intended to imply recommendation or endorsement by the National Institute of Standards and Technology, nor is it intended to imply that the entities, materials, or equipment are necessarily the best available for the purpose.

National Institute of Standards and Technology Technical Note 1904 Natl. Inst. Stand. Technol. Tech. Note 1904, 42 pages (January 2016) CODEN: NTNOEF

This publication is available free of charge from: http://dx.doi.org/10.6028/NIST.TN.1904 


\title{
Burning Velocity Measurements and Simulations for Understanding the Performance of Fire Suppressants in Aircraft ${ }^{1}$
}

\section{Letter Report Prepared for Meggitt}

\author{
Gregory T. Linteris \\ Energy and Environment Division \\ Engineering Laboratory \\ NIST \\ John L. Pagliaro \\ MSSI Consultant
}

November 20, 2015

\subsection{Introduction}

As described by Reinhardt and co-workers [1], overpressure in the Federal Aviation Administration (FAA) Aerosol Can Test (FAA-ACT) has been observed for the halon replacements HFC-125, Novec 1230, and 2-BTP when added at sub-inerting concentrations. Work by Linteris and co-workers [2-5] has involved measurements of the flammability limits, explosion pressure and burning velocity, together with equilibrium, stirred-reactor, and premixed flame speed simulations to interpret this

overpressure. Additional investigations were performed to validate the kinetic mechanisms and understand the chemical reaction pathways for the pure agents in air [6-11].

The goal of the present work is to predict the overpressure behavior of two proprietary blends (each a $50 \%$ mass fraction of $\mathrm{CO}_{2}$ with either Novec $\left(\mathrm{C}_{6} \mathrm{~F}_{12} \mathrm{O}\right.$, Novec 1230$)$ or 2-BTP $\left(\mathrm{C}_{3} \mathrm{H}_{2} \mathrm{~F}_{3} \mathrm{Br}\right.$, 2-Bromo-3,3,3trifluoropropene), hereafter referred to as Blend $\mathrm{A}$ or Blend $\mathrm{D}$, respectively) using the techniques and understanding developed in the previous work. To this end, experimental measurements of the flammability limits, explosion pressure, and premixed flame speed have been made, under conditions believed to provide the most insight into the blends' behavior in the FAA-ACT. Following the approaches developed in prior work, equilibrium, stirred reactor, and premixed flame speed simulations have also been performed to interpret and predict the behavior of the agents in the FAAACT. Reviews of the concepts and experimental approaches are also provided to aid in the interpretation of the results.

\subsection{Background}

The exothermic reaction of halogenated hydrocarbons in combustion conditions has been described (sparsely) in the literature, for select compounds and experiments, as briefly reviewed by Linteris et al. [3]. As a result of the findings using the FAA-ACT, however, the potential for fire suppressants per se to react exothermically has recently been explored more comprehensively [2-11]. While the pure agents in air usually are not flammable themselves, when in the vicinity of a diffusion flame, they can react exothermically and contribute to the heat release (and hence, pressure rise if there is containment). For example, recent simulations [9] have predicted that HFC-125 added to the air stream in co-flow diffusion (e.g., cup-burner) flames (just below the extinguishing concentration) will increase the total heat release by a factor of up to three. This is the undesirable behavior leading to

\footnotetext{
${ }^{1}$ Official contribution of NIST, not subject to copyright in the United States.
} 
the overpressure in the FAA-ACT. Moreover, it has been shown that since the agents (premixed in the oxidizer) themselves are reactive, their presence in the oxidizer stream increases the volume of oxidizer required for stoichiometric reaction of the fuel and agent. This also contributes to a higher overpressure.

For premixed systems, it has also been found that some fire suppressants (e.g., Novec, HFC-125, etc.), when added to a premixed flame below its flammability limit, can actually increase the flame speed above the uninhibited condition, bringing the flame into the flammable regime. That is, the mixture becomes more reactive with the addition of the fire suppressant. Finally, the explosion pressure of lean mixtures can be higher with fire suppressant added to the air stream than without it.

For example, Table 1 lists the effect of $\mathrm{CF}_{3} \mathrm{Br}, \mathrm{C}_{2} \mathrm{HF}_{5}, \mathrm{C}_{6} \mathrm{~F}_{12} \mathrm{O}$, and $\mathrm{CH}_{2} \mathrm{CBrCF}_{3}$ on the: 1 . calculated heat release in a cup burner, 2. stoichiometric air requirement, 3. explosion pressure, and 4. laminar burning velocity. Undesirable behavior contributing to overpressure in the FAA-ACT is indicated by a red up arrow, while desirable behavior is indicated by the green down arrow.

Table 1 - Effect of agent addition on various test parameters related to overpressure in the FAA-ACT ( $\downarrow$ decreased; $\uparrow$ increased; 0: unaffected).

\begin{tabular}{|c|c|c|c|c|c|}
\hline Test Parameter: & & $\mathrm{CF}_{3} \mathrm{Br}$ & $\mathrm{C}_{2} \mathrm{HF}_{5}$ & $\mathrm{C}_{6} \mathrm{~F}_{12} \mathrm{O}$ & $\mathrm{CH}_{2} \mathrm{CBrCF}_{3}$ \\
\hline Diffusion Flames & & & & & \\
\hline Cup-Burner Heat Release & & $\downarrow$ & $\uparrow$ & No data & $\uparrow$ \\
\hline Stoichiometric Air Requirement & & 0 & $\uparrow$ & $\uparrow$ & $\uparrow$ \\
\hline & & & & & \\
\hline Premixed Flames & $\phi$ & & & & \\
\hline Explosion Pressure & 1.0 & $\downarrow$ & $\uparrow$ & $\uparrow$ & $\downarrow$ \\
& 0.6 & $\downarrow$ & $\uparrow$ & $\uparrow$ & $\uparrow$ \\
\hline Laminar Burning Velocity & 1.0 & $\downarrow$ & $\downarrow$ & $\downarrow$ & $\downarrow$ \\
& 0.6 & $\downarrow$ & $\uparrow$ & $\uparrow$ & $?$ \\
\hline
\end{tabular}

Our experimental approach for evaluating possible overpressure in the FAA-ACT by Blend A and Blend D is these last two tests: 1.) Enhanced explosion pressure of lean premixed flames; and 2.) enhanced burning velocity of lean premixed flames. Our numerical approach includes simulations of the equilibrium temperature and pressure, the overall reaction rate (as determined with perfectlystirred reactor (PSR) simulations), and premixed flame burning velocity calculations. 
In previous work [3-5] equilibrium and perfectly stirred reactor simulations were used to understand the experimental behavior of $\mathrm{C}_{2} \mathrm{HF}_{5}, \mathrm{C}_{6} \mathrm{~F}_{12} \mathrm{O}$, and $\mathrm{CH}_{2} \mathrm{CBrCF}_{3}$ in the FAA-ACT. The equilibrium simulations allow one to estimate the overpressure that can occur if there are no kinetic limitations. This was found to be the case for pure $\mathrm{C}_{2} \mathrm{HF}_{5}, \mathrm{C}_{6} \mathrm{~F}_{12} \mathrm{O}$, and $\mathrm{CH}_{2} \mathrm{CBrCF}_{3}$ at all concentrations except the inerting value; i.e., the equilibrium simulations predicted the pressure rise for the pure agents $\left(\mathrm{C}_{2} \mathrm{HF}_{5}\right.$, $\mathrm{C}_{6} \mathrm{~F}_{12} \mathrm{O}$, and $\mathrm{CH}_{2} \mathrm{CBrCF}_{3}$ ) at sub-inerting concentrations. For the blends $\mathrm{A}$ and $\mathrm{B}$, equilibrium calculations will again provide estimates of the fraction of chamber volume involved in the combustion and the maximum possible pressure rise.

For understanding flame extinction, a measure of the overall reaction rate is required. The perfectly stirred reactor simulations provided these for a range of inhibitor volume fractions $X_{a}$ and fueloxidizer mixing ratios. Since the actual FAA-ACT is a two-phase, turbulent explosive process, the mixing state of the fuel and oxidizer is unknown. However, by performing the simulations over a range of involved chamber oxidizer fraction $\eta$, the overall reaction rate as a function of mixing state can be obtained. This is useful since in previous work [5], the values of the overall reaction rate required for flame extinguishment were determined. To extinguish the end-gases of a low-speed, post-explosion flame, the stirred-reactor overall rate must be reduced to about $20 \mathrm{~s}^{-1}$; if the end-gases are sufficiently non-flammable, however, then the flame to be extinguished is the turbulent jet near the impulsive release of the fuel (which is easier to extinguish and requires less agent), so that the overall reaction rate must be reduced to about $1700 \mathrm{~s}^{-1}$ [5]. The PSR simulations provide insight into the value of $\omega_{p s r}$ as a function of mixing state and inhibitor volume fraction, aiding in extrapolation from the premixed experiments to the diffusion flames of the FAA-ACT.

\subsection{Experimental Methods}

\subsection{Apparatus and procedure}

The experimental apparatus for the flammability limits and explosion pressure, as well as for the burning velocity measurements, is a constant-volume combustion device with an internal volume of about $2 \mathrm{~L}$ (referred to as the 2-L chamber), which has been described in previous work [10] and is outlined below. A schematic diagram is shown in Figure 1, and a photograph in Figure 2. Plumbing and electrical schematics are shown in Figure 3 and Figure 4. The stainless steel (316) spherical vessel is similar to previous designs [12-15], with an inner diameter of $15.24 \mathrm{~cm}$, volume of $1.85 \mathrm{~L}$ and wall thickness of $2.54 \mathrm{~cm}$, and is equipped with an ignition system, an absolute pressure gage, a dynamic pressure sensor, and a thermocouple. The experiment can provide the flammability limits, explosion pressure (constant-volume), and rate of pressure rise; further processing of the latter can be used to obtain the laminar burning velocity (1-D spherical) as a function of initial pressure and temperature (which increase as the unburned gases are compressed). 


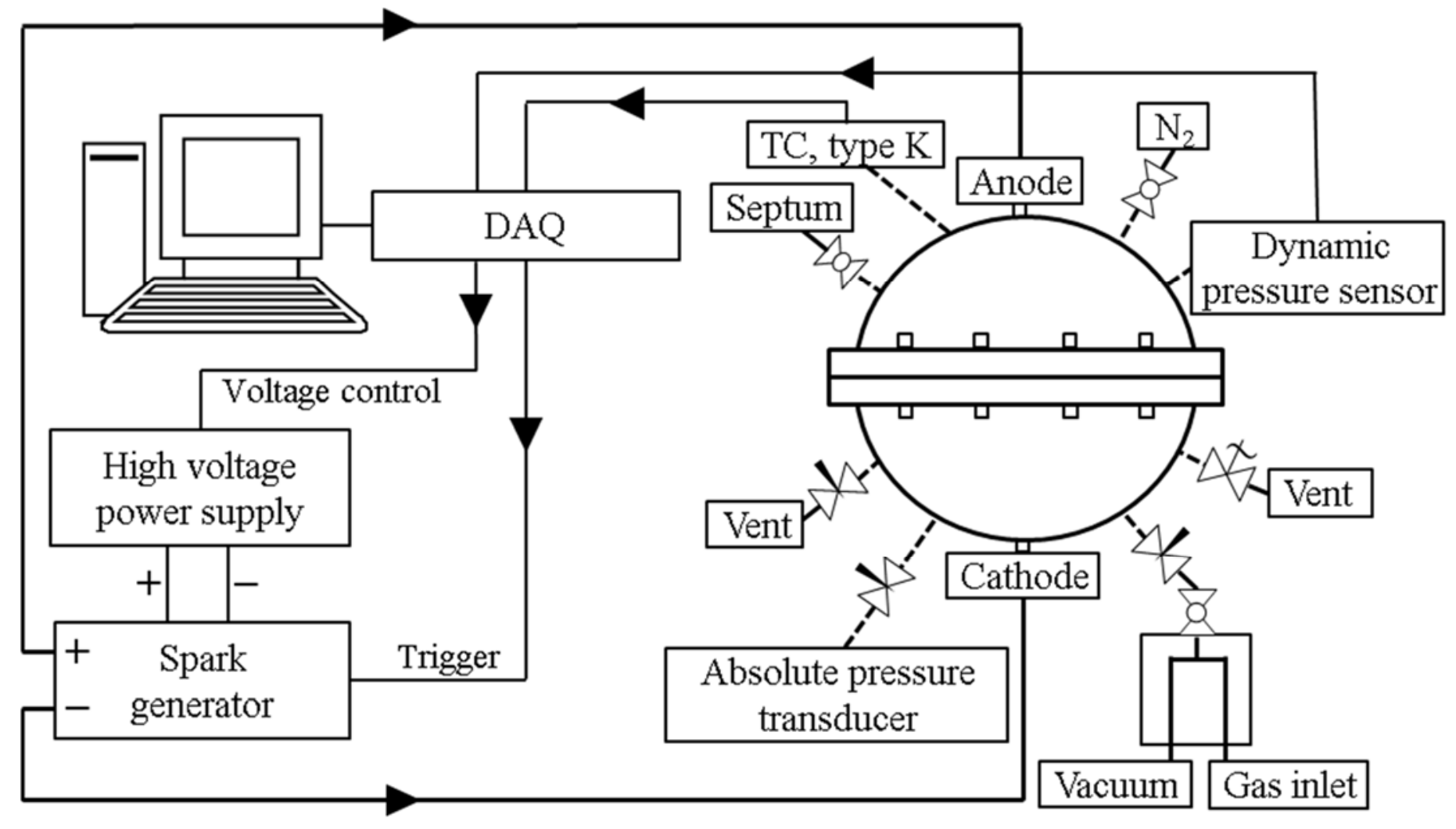

Figure 1: Schematic diagram of the 2-L experimental apparatus.

A vacuum pump reduces chamber pressure below 13.3 Pa prior to reactant addition. Test mixtures are prepared in the chamber using the partial pressure method, following injection of first liquid then gaseous reactants. Component partial pressures are determined with an absolute pressure transducer (Omega, PX811; claimed accuracy of $0.1 \%$ of reading) that is periodically calibrated against a Baratron 627D (claimed accuracy of $0.12 \%$ ) and a Wallace \& Tiernan 1500 pressure gage (claimed accuracy of $0.066 \%$ ). Liquid suppressants $\left(\mathrm{C}_{6} \mathrm{~F}_{12} \mathrm{O}\right.$ and $\left.\mathrm{C}_{3} \mathrm{H}_{2} \mathrm{~F}_{3} \mathrm{Br}\right)$ are injected using a syringe and a gas-tight septum separated from the chamber by a ball valve (to ensure leak-free operation during the experiment). 


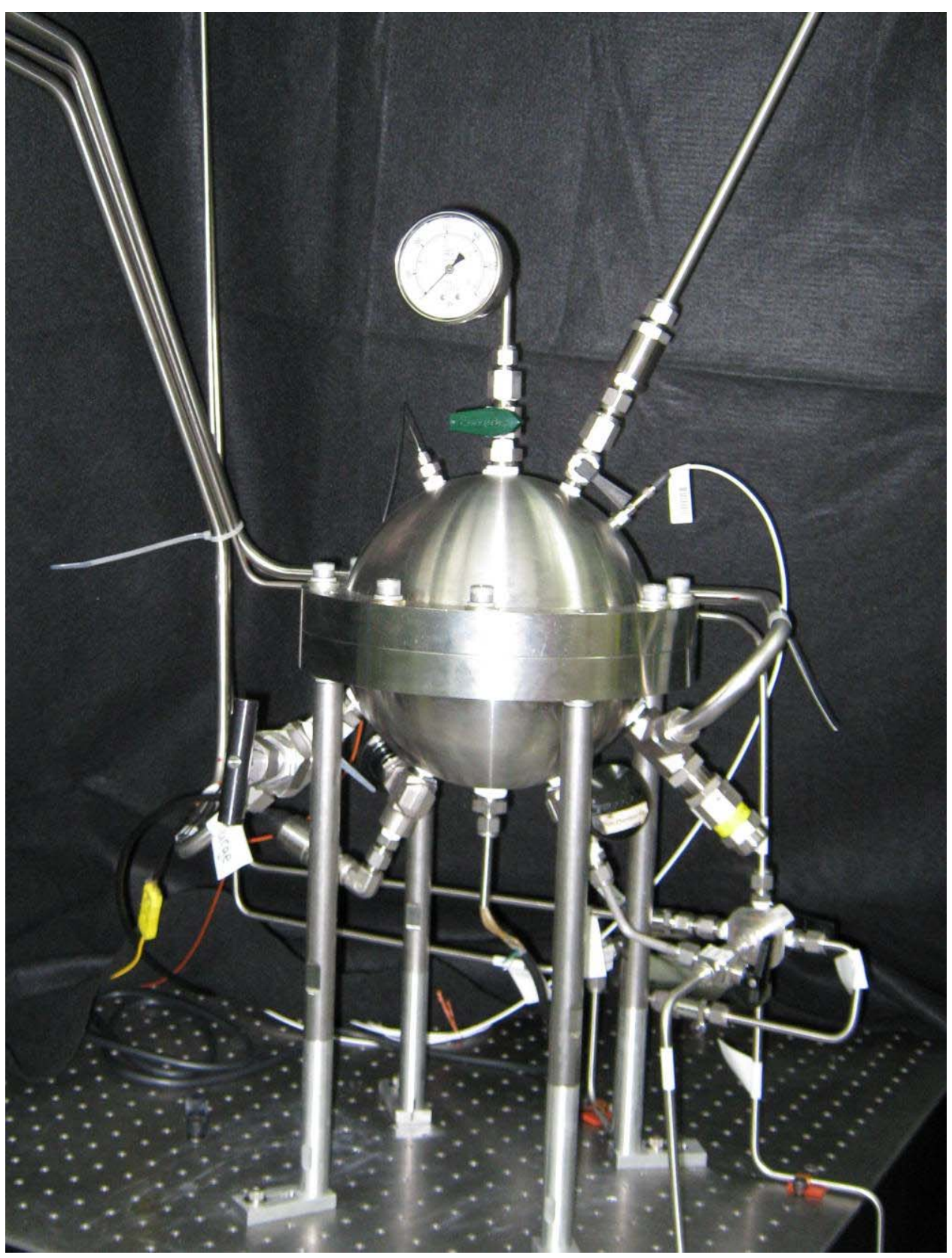

Figure 2 - 2-L chamber. 


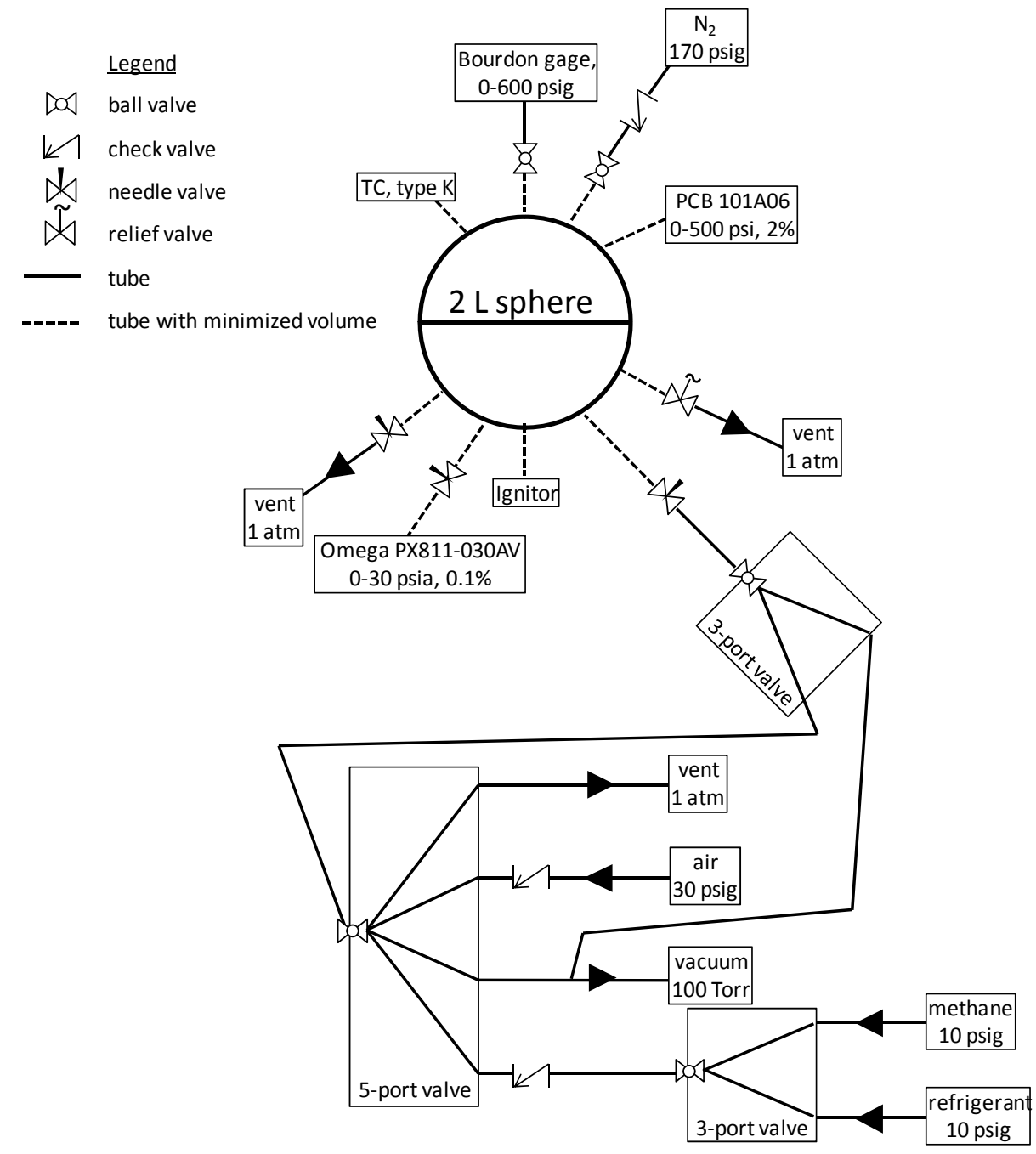

Figure 3 - Plumbing schematic diagram of 2-L chamber. 


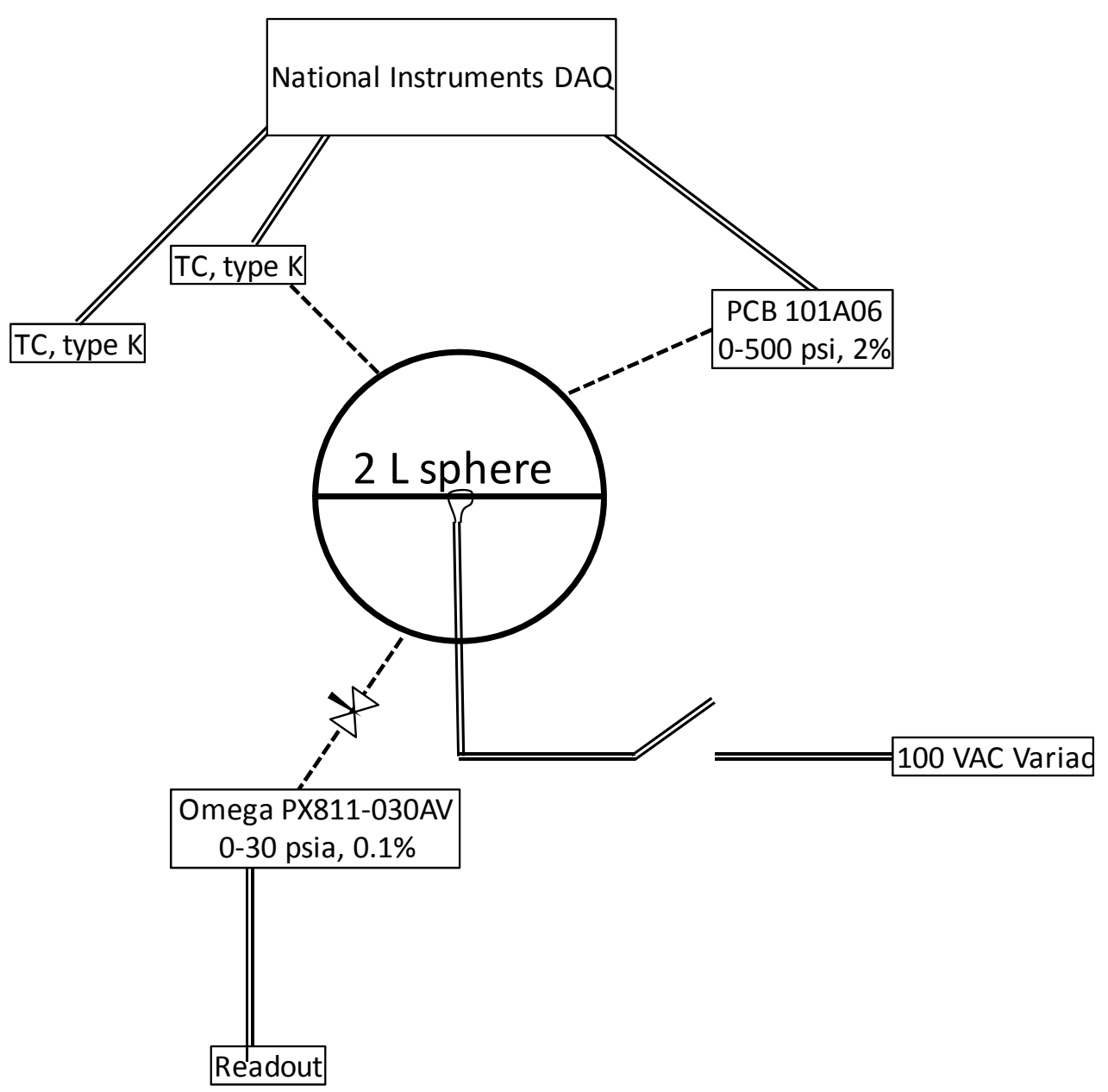

Figure 4 - Electrical schematic diagram of 2-L chamber.

The sample gases are $\mathrm{CH}_{4}$ (Matheson Tri-Gas, $99.97 \%$ purity), $\mathrm{C}_{3} \mathrm{H}_{8}$ (Scott Specialty Gases, $99.0 \%$ purity), $\mathrm{CF}_{3} \mathrm{Br}$ (Great Lakes Chemical Corp., $99.6 \%$ purity), $\mathrm{C}_{6} \mathrm{~F}_{12} \mathrm{O}\left(3 \mathrm{M},>99 \%\right.$ purity), $\mathrm{C}_{3} \mathrm{H}_{2} \mathrm{~F}_{3} \mathrm{Br}$ (American Pacific Corp., > $99 \%$ purity), and carbon dioxide (MG Industries). The air is house compressed air (filtered and dried) that is additionally conditioned with a $0.01 \mu \mathrm{m}$ filter, carbon filter, and a desiccant bed to remove small aerosols, organic vapors, and water vapor. The relative humidity r.h. of the house compressed air, measured with humidity gage (TSI VELOCICALC, 8386), is less than $2 \%$.

For tests with humid air, water vapor is added to the reactants by adding liquid water (house deionized) via the syringe, at the mass required to obtain the desired water vapor volume fraction in the air. After liquid water addition, the total pressure is monitored to insure that the partial pressure of water reached the vapor phase. In some cases (e.g., after tests with $\mathrm{C}_{3} \mathrm{H}_{2} \mathrm{~F}_{3} \mathrm{Br}$ ), the water is sometimes absorbed into deposits on the chamber wall surfaces, preventing the total pressure from achieving the calculated value. In these cases, somewhat more liquid water $(\approx 50 \%)$ is added until the correct value of the water partial pressure is achieved (corresponding to $100 \%$ r.h. at $20^{\circ} \mathrm{C}$, or a water volume fraction of 0.023). After addition of all reactants, a 5 min settling time is used to insure dissipation of any turbulence, as described in ref. [12]. 
Two ignition systems are used in the present work: an electrical spark and an exploding platinum wire. The spark ignition system is used for the burning velocity measurements, and some of the flammability limit and explosion pressure tests (as noted below). The electrical spark method is the more common ignition method, and provides the minimum disruption of the developing premixed flame (which is necessary for extracting the laminar burning velocity from the pressure rise data). The platinum igniter, based on the Japanese High Pressure Gas Law (JHPGL, a translation of which is available in ref. [16]), somewhat overdrives the ignition process, but is useful since it provides a much more conservative estimate of the flammability limits. It is used in some tests in the present work since it was found to more accurately represent the flammability limits of mixtures in FAA Aerosol Can Tests.

The electrical spark ignition system (capacitive) is based on the work of Shepherd et al. [17]). A $1 \mathrm{kV}$ to $15 \mathrm{kV}$ power supply (Acopian) and custom-made capacitor banks ( $1 \mathrm{nF}$ to $50 \mathrm{nF}$ ) provide variable ignition energies, with an estimated operating range of $0.05 \mathrm{~mJ}$ to $500 \mathrm{~mJ}$. Two tungsten electrodes form a gap in the center of the chamber. Thin electrodes $(0.4 \mathrm{~mm}$ diameter $)$ minimize heat loss from the flame, and the spark gap is adjustable $(2 \mathrm{~mm}$, typical). Ignition is attempted several times, while gradually increasing the capacitor charging voltage, until ignition occurs. This ensures the ignition energy is within an order of magnitude of the minimum value. (Note that for stoichiometric iso-octane-air mixtures, Marshall et al. [18] found that the burning velocity was insensitive to the ignition energy for values up to 1000 times the minimum ignition energy.)

The platinum wire ignition system is based on that in the JHPGL. A variable transformer AC power supply supplies $100 \mathrm{VAC}$, controlled by a manual switch, to a thin platinum wire. The platinum wire melts and ruptures violently during each ignition process, and is replaced for each test. The igniter configuration is modified slightly from that in the JHPGL. Rather than using igniter leads that enter the chamber from two locations at right angles to each other (per the JHPGL), the present igniter (shown in Figure 5) uses two parallel copper leads (57 mm long, $1 \mathrm{~mm}$ diameter) separated by $4 \mathrm{~mm}$, with crimp-on connections (Digi-Key A34501-ND and A2161-ND) between the copper and platinum wires instead of welds. Hence, the igniter could be inserted through a single 0.25 inch fitting, with easily replaceable fusible wire. The fusible portion of wire consists of a $20 \mathrm{~mm}$ length of Pt wire formed in a loop. In previous work [16], tests were conducted to explore the influence of the wire material and ignition energy, and showed that the platinum wire provided wider flammability limits, whereas the other materials (tungsten and copper) provided results more like those resulting from spark ignition. The difference was attributed to the catalytic action of the molten platinum droplets and the turbulence that they create in the explosion process.

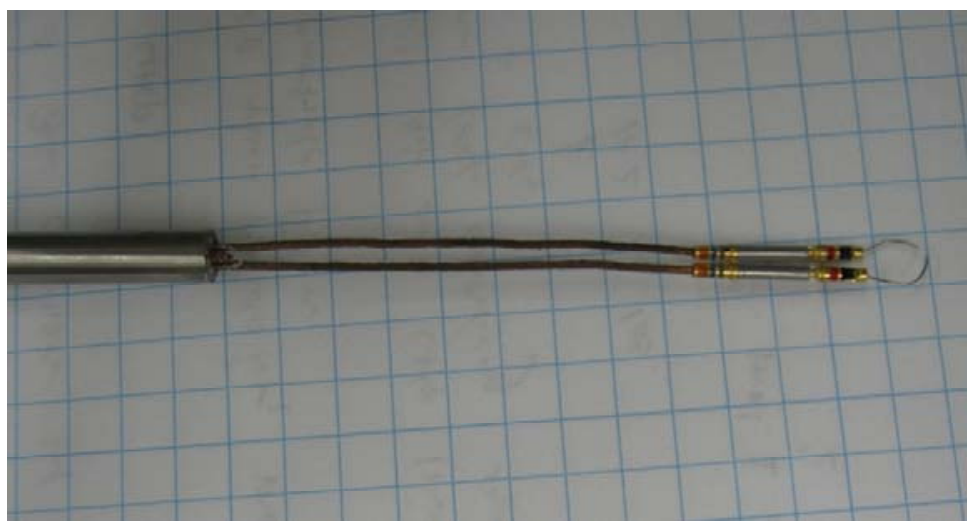

Figure 5 - Platinum igniter. 
With either igniter, the explosion pressure is recorded at $4000 \mathrm{~Hz}$. via a dynamic pressure sensor (PCB Piezotronics, 101A06; claimed accuracy of $0.1 \%$ of reading). The product gases are immediately purged to vacuum via a large flow of $\mathrm{N}_{2}$ (to minimize heating of the chamber and its exposure to acid gases), and the chamber is allowed to cool for 20 minutes between experiments. Figure 6 shows a typical pressure trace (curve labeled " $\mathrm{P}$ ") obtained from the experiment (other curves in the figure are described below). The laminar burning velocity is determined from the pressure trace using a thermodynamic model, developed by Metghalchi and Keck $[12,19]$ and further refined by others [13, 20]. A brief overview of the method follows.

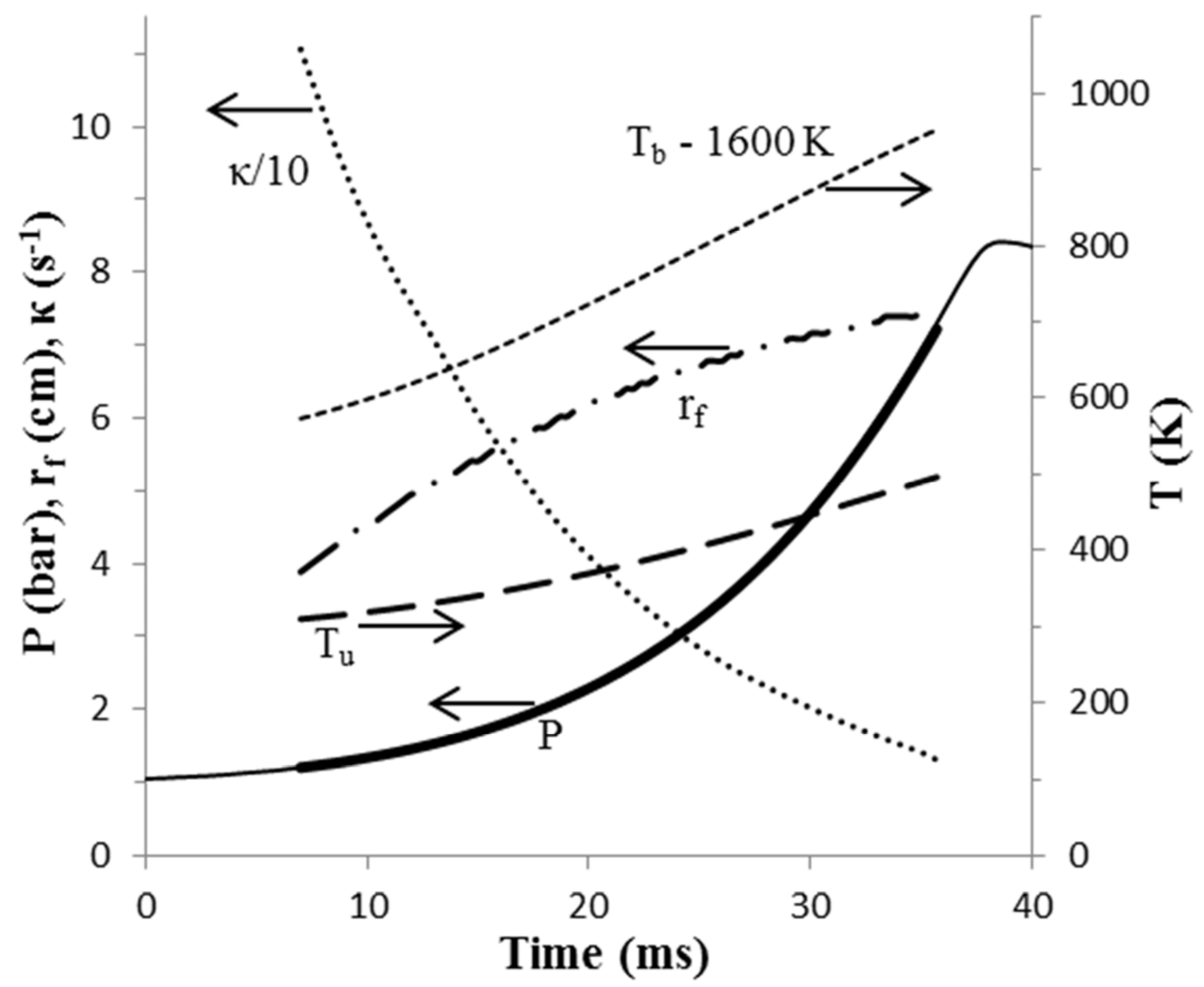

Figure 6: Experimental pressure trace $P$, flame radius $r_{f}$, flame stretch rate $\kappa$, and gas temperature (unburned $T_{u}$ and burned $T_{b}$ ) as a function of time.

\subsection{Burning velocity from the pressure trace}

In the analytical analysis of the propagation of the combustion wave in the chamber, the contents of the chamber are divided into burned and unburned zones separated by a reaction sheet, assumed to be of zero thickness, spherical, and smooth (no instabilities). Initially, the unburned gas is considered mixed and at rest. As the unburned gases react, a spatially uniform increase in pressure occurs. The burned gas is in chemical equilibrium and both the burned and unburned gases are 
considered as ideal, semi-perfect gases. Both zones are adiabatic, and the unburned gas is isentropically compressed as the mixture reacts in the flame sheet.

With these assumptions, the instantaneous flame radius and burning velocity can be expressed in terms of the chamber pressure by applying conservation of mass. The results are given in Eq. 1 and Eq. 2 (detailed formulation of the equations can be found in refs. [12, 20]),

$$
\begin{gathered}
r_{f}=R\left[1-\left(1-x_{b}\right)\left(P_{0} / P\right)^{1 / \gamma_{u}}\right]^{1 / 3} \\
S_{L}=R / 3\left(R / r_{f}\right)^{2}\left(P_{0} / P\right)^{1 / \gamma_{u}}\left(d x_{b} / d t\right)
\end{gathered}
$$

in which $r_{f}$ is the flame radius, $S_{u}$ is the laminar burning velocity, $R$ is the chamber radius, $x_{b}$ is the mass fraction of burned gas, $P$ is the instantaneous pressure, $P_{0}$ is the initial pressure, and $\gamma_{u}$ is the unburned gas specific heat ratio. To determine burning velocity, the mass fraction of burned gas $x_{b}$ must be related to the chamber pressure (for simplification, early studies applied a linear relationship [21]). Alternatively, a thermodynamic closed system analysis on the contents within the chamber can be performed. A two-zone approach is used in the present work. The burned gas zone also can be modeled using incremental shell volumes [22, 23], allowing burned gas density and temperature gradients; nonetheless, since previous studies have shown that inclusion of the gradients has negligible effect on the burning velocity $[19,20]$, we retain the two-zone model. The fraction of mass burned $x_{b}$ is found from simultaneous solution of the conservation of mass and energy equations given in Eq. 3 and Eq. 4, applied for the two zones,

$$
\begin{aligned}
& \frac{V}{M}=\int_{0}^{x_{b}} v_{b} d x+\int_{x_{b}}^{1} v_{u} d x \\
& \frac{E}{M}=\int_{0}^{x_{b}} e_{b} d x+\int_{x_{b}}^{1} e_{u} d x
\end{aligned}
$$

where $V$ is the volume of the chamber, $E$ is the total internal energy of the gases in the chamber, $M$ is the mass of the initial gas in the chamber, $e$ and $v$ are the internal energy and specific volume of the gas, and the subscripts $b$ and $u$ refer to the burned and unburned gas.

Thermodynamic data for the unburned and burned gases are required for model implementation. Data for hydrocarbon-air species $\left(\mathrm{CH}_{4}, \mathrm{O}_{2}, \mathrm{~N}_{2}, \mathrm{CO}_{2}, \mathrm{H}_{2} \mathrm{O}, \mathrm{CO}, \mathrm{NO}, \mathrm{OH}, \mathrm{H}_{2}\right.$, and $\left.\mathrm{O}\right)$ are taken from GRI-mech 3.0 [24], fluorinated species $\left(\mathrm{C}_{6} \mathrm{~F}_{12} \mathrm{O}, \mathrm{C}_{2} \mathrm{HF}_{5}, \mathrm{~F}, \mathrm{HF}, \mathrm{CF}_{4}\right.$, and $\left.\mathrm{CF}_{2} \mathrm{O}\right)$ from the National Institute of Standards and Technology (NIST) Hydrofluorocarbon (HFC) mechanism [25, 26], and brominated species $\left(\mathrm{CF}_{3} \mathrm{Br}, \mathrm{C}_{3} \mathrm{H}_{2} \mathrm{~F}_{3} \mathrm{Br}, \mathrm{Br}, \mathrm{HBr}\right.$, and $\left.\mathrm{Br}_{2}\right)$ from Babushok et al. [27, 28]. Hydrocarbonair product species are included for all mixtures, along with fluorinated products for test containing $\mathrm{C}_{6} \mathrm{~F}_{12} \mathrm{O}$. Additional brominated products are included for tests with $\mathrm{C}_{3} \mathrm{H}_{2} \mathrm{~F}_{3} \mathrm{Br}$.

The unburned gas properties are related to the chamber pressure through isentropic compression:

$$
T_{u}=T_{u 0}\left(\frac{P}{P_{0}}\right)^{\left(\gamma_{u}-1\right) / \gamma_{u}}
$$

where $T_{u 0}$ is the initial unburned temperature. Since $\gamma_{u}$ is a function of the unburned gas temperature $T_{u}$ and the initial mixture composition, $T_{u}$ and $\gamma_{u}$ are solved iteratively at each pressure increment. The properties of the unburned gas mixture, $v_{u}$ and $e_{u}$, are determined from the mixture composition and temperature. 
The remaining unknowns in the conservation equations $\left(v_{b}, e_{b}\right.$, and $\left.x_{b}\right)$ are found through iteration of $T_{b}\left(v_{b}\right.$ and $e_{b}$ are functions of temperature) and $x_{b}$ at each pressure increment, until the proper values of $T_{b}$ and $x_{b}$ are obtained. Burned gas species concentrations, required for the determination of $v_{b}$ and $e_{b}$, are estimated for each value of $T$ and $P$ using a constant volume equilibrium calculation performed via the CEA2 routine of Gordon and McBride [29]. The enthalpies of formation of $\mathrm{C}_{6} \mathrm{~F}_{12} \mathrm{O}, \mathrm{C}_{2} \mathrm{HF}_{5}$, and $\mathrm{C}_{3} \mathrm{H}_{2} \mathrm{~F}_{3} \mathrm{Br}$ (required for CEA2 calculation) are from refs. [3, 4, 25]. Once $x_{b}(P)$ is known, the burning velocity $S_{u}\left(P, T_{u}\right)$ is calculated over the experimental range of pressure and temperature using Eq. 2.

\subsection{Data reduction}

As described above, Figure 6 shows a typical pressure trace (solid line) from an experiment $\left(\mathrm{CH}_{4-}\right.$ air, $\phi=1.0)$. Also shown are $T_{b}, T_{u}$, and $r_{f}$, which are outputs of the two-zone model calculation. Only a portion of the pressure data is used for obtaining burning velocity, as denoted by the thick line on the pressure trace. For small $r_{f}$, the flame behavior is affected by flame stretch and the ignition process, and for large $r_{f}$, by heat losses to the walls and cellular instabilities; hence, typically only the central $75 \%$ of the pressure data are used. Spherically propagating flames are subject to stretch rates inversely proportional to the flame radius [30],

$$
\kappa=\frac{2}{r_{f}} \frac{\mathrm{d} r_{f}}{\mathrm{~d} t}
$$

where $\kappa$ is the stretch rate and $\mathrm{d} r_{f} / \mathrm{d} t$ is the flame front velocity. Figure 6 also shows the stretch rate for this experiment. To reduce stretch effects (as well as the transient caused by the ignition), data are neglected for small flame radii, $r_{f}<3.8 \mathrm{~cm}$ (i.e., $r_{f}<\mathrm{R} / 2$, as proposed by Elia et al. [31], and adopted by others $[18,22,32])$. For $r_{f} / R=0.5$, peak stretch rates range between $110 \mathrm{~s}^{-1}$ for uninhibited stoichiometric methane-air and $20 \mathrm{~s}^{-1}$ for inhibited cases with burning velocities near $6 \mathrm{~cm} / \mathrm{s}$. To avoid the effects of heat losses to the walls, only data up to $\mathrm{dP} / \mathrm{d} t_{\max }$ (i.e., the inflection point in the $P(t)$ curve in Figure 6) are used, following the recommendations in refs. [33, 34].

A single experiment provides burning velocity data for a range of pressure and temperature of the unburned gas, and these data are fit to the equation:

$$
S_{L}=S_{L, 0}\left(\frac{T}{T_{0}}\right)^{\alpha}
$$

where $S_{L}$ is the laminar burning velocity, $T_{0}$ is the initial temperature, $S_{L, 0}$ is the laminar burning velocity at the initial conditions; $\alpha$ and $S_{L, 0}$ are the fitting parameters. In the experiments performed, $T_{0}$ is $293 \pm 2 \mathrm{~K}$. Figure 7 shows the burning velocity of stoichiometric methane-air as a function of unburned gas temperature and chamber pressure (related through isentropic compression i.e., Eq. 5). The diamonds are the experimental data derived from Eq. 2, and the line is the fit to Eq. 7. In discussions following, $S_{L}$ is presented at ambient conditions as obtained from Eq. 7 (and shown as black dot in Figure 7). 


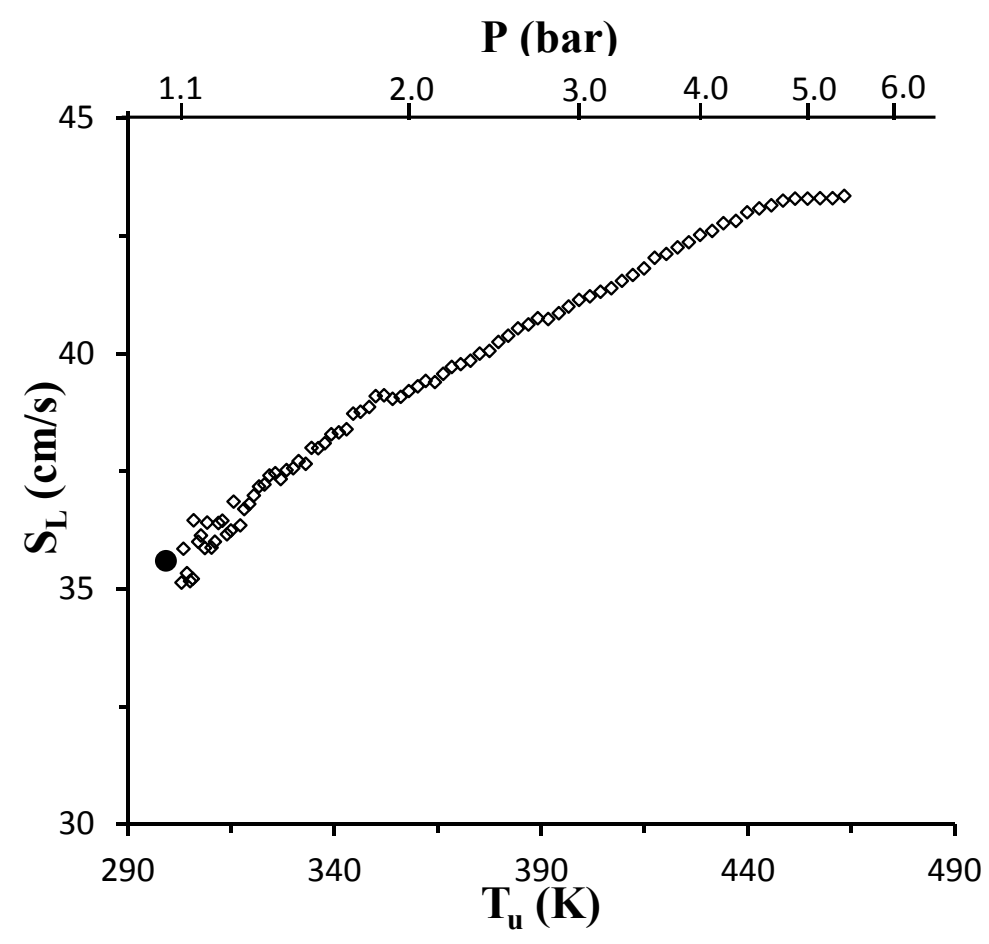

Figure 7: Plot of burning velocity as a function of pressure $P$ and unburned gas temperature $T_{u}$. The diamonds represent the data from an experiment, the line represents the fitted results using Eq. 7, and the black dot is the reported $S_{L}$ at ambient $\left(T_{0}=298 \mathrm{~K}, P_{0}=1\right.$ bar $)$ conditions.

In the present method, spherical flame propagation is a critical condition for accurate determination of $S_{L}$ from the pressure trace. Buoyancy can distort the shape of the flame, especially for slow burning mixtures (which are of particular interest in the present work). Takizawa et al. [13] estimated the minimum burning velocity measurable without error associated with buoyancy. They performed experiments in a spherical chamber, using the pressure rise to determine burning velocity. Separate experiments were performed in a cylindrical chamber with visual access to provide comparison. The shape of the flame front was recorded with high speed video and the burning velocity was calculated using the constant-pressure method [35, 36]. To minimize the effects of buoyancy, as recommended by Pfahl et al. [37], the rate of change of the flame radius with respect to time was traced in the two horizontal directions. Results [13] showed that burning velocities as low as $6 \mathrm{~cm} / \mathrm{s}$ could be measured with the constant-volume method. In the present work, cellular instabilities, which also invalidate the spherical flame assumption, are monitored through inspection of the $S_{L}$ data of individual test runs. The onset of cellular instabilities is typically detected via a distinct increase in $S_{L}[18,22]$, and these data (if occurring) are omitted during the experimental data fitting.

\subsection{Fuel Selection}

The fuel in the FAA_ACT is intended to simulate the contents of an aerosol spray can, and contains 5.87 moles of ethanol, 2.05 moles of propane, and 5 moles of liquid water. Although it would be most desirable to run experiments for the same conditions, it is not possible, since the water content of these tests is greater than $100 \% \mathrm{r.h}$. at room temperature. In order to overcome this limitation, yet collect data for a representative fuel system, we analyzed various surrogate fuels. The best option was to use propane-air mixtures at $100 \%$ r.h. This fuel system best approximated the adiabatic flame temperature, and the hydrogen atom content of the total fuel-air mixture in the FAA-ACT, and was 
adopted for the present experiments. Nonetheless, for the simulations, we used the actual FAA-ACT test fuel whenever modeling the FAA-ACT, and of course, for modeling experiments with the moist propane-air fuel, we used the propane and water vapor content as measured in the initial conditions of the experiment.

\subsection{Uncertainties}

The uncertainty analysis consists of individual uncertainty components and root-sum-of-squares (RSS) components [38]. Uncertainties in the measured parameters are reported as expanded uncertainties: $k u_{c}$, from a combined standard uncertainty (estimated standard deviation) $u_{c}$, and a coverage factor $k=2$ (level of confidence approximately $95 \%$ ). Likewise, when reported, the relative uncertainty is $k u_{c} / X$. Uncertainties in initial temperature and pressure, dynamic and peak pressure rise, agent volume fraction, equivalence ratio, and the burning velocity calculation and fitting to Eq. 7 are considered. The expanded relative uncertainties related to mixture composition are as follows: $0.5 \%$ for equivalence ratio; and $0.4 \%, 0.8 \%$, and $4 \%$ for the reactant mole fractions of air, $\mathrm{CH}_{4}$, and agent. Relative uncertainties of the dynamic and peak pressure rise, initial pressure, and initial temperature are $1.3 \%, 0.5 \%$, and $1 \%$. The expanded relative uncertainty for experimentally determined burning velocities is $12 \%$.

\subsection{Validation of Experimental Techniques}

\section{Flammability limits}

Using the present experimental technique, the flammability limits of $\mathrm{CH}_{4}$-air mixtures and $\mathrm{CH}_{2} \mathrm{~F}_{2}-$ air mixtures (as a function of stoichiometry) have been determined in previous work [16], and are shown in Figure 8. As illustrated for methane (left frame), the copper wire igniter reproduces the traditional flammability limits, and the platinum wire igniter provides slightly wider limits. For $\mathrm{CH}_{2} \mathrm{~F}_{2}$-air mixtures, the previously measured flammability limits are well reproduced by the tests with the exploding platinum wire.
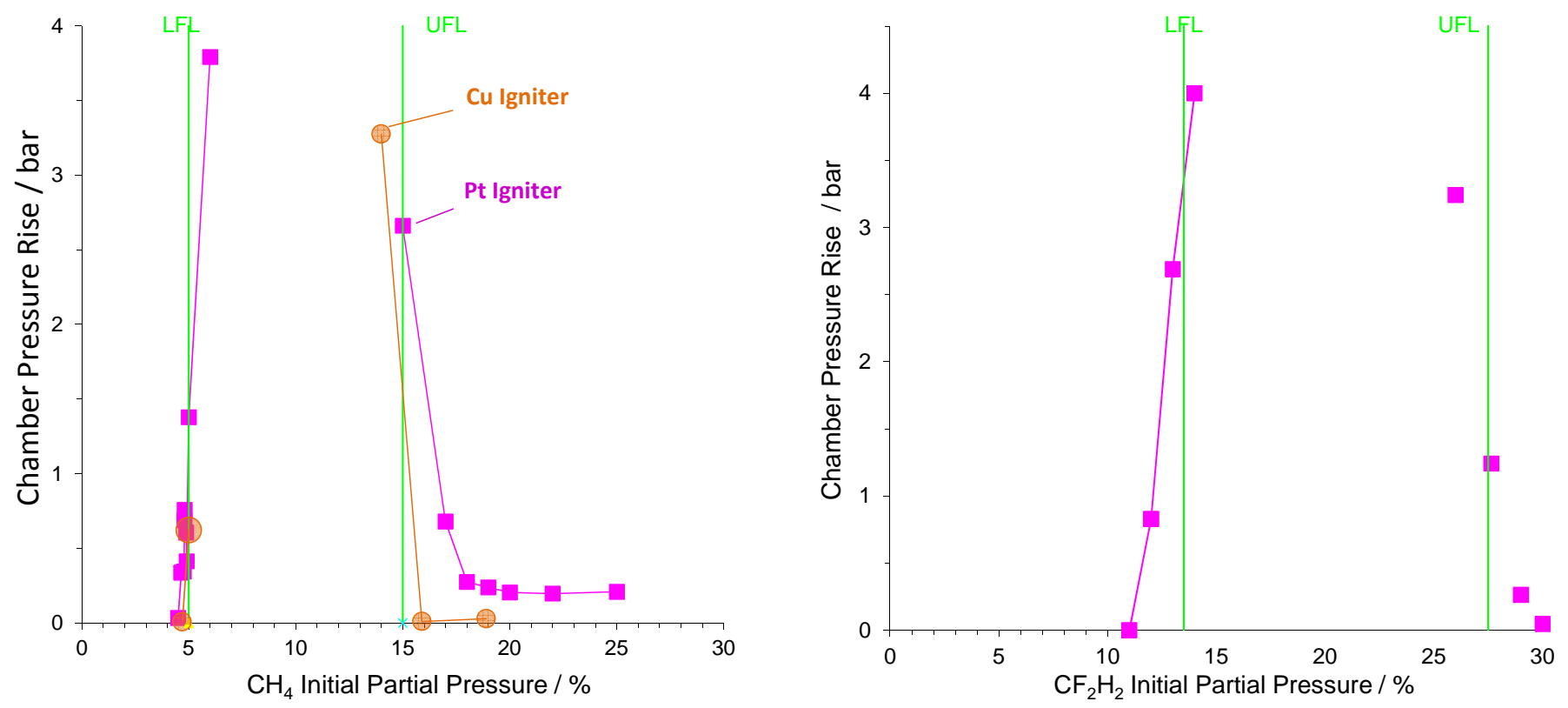

Figure 8 - Chamber pressure rise in the 2-L chamber as a function of fuel partial pressure, using either $\mathrm{Pt}$ or $\mathrm{Cu}$ wire igniter, together with literature values of the flammability limits (vertical lines) [39, 40]; left frame: $\mathrm{CH}_{4}$-air, right frame: $\mathrm{CH}_{2} \mathrm{~F}_{2}$-air. 


\section{Burning velocity}

To validate the accuracy of the experimental facility and the post-processing procedure, the burning velocity of methane-air flames was determined over a range of equivalence ratios (0.6 to 1.3). Figure 9 compares the present results to published data at standard ( $298 \mathrm{~K}, 1$ bar; lower curve) and compressed ( $400 \mathrm{~K}, 3$ bar; upper curve) conditions. The solid black squares show the present data, other black symbols show data collected using the same experimental technique $[13,14]$, blue symbols show stretch-corrected data from spherical flames [41-43], and red symbols show stretchcorrected data from counter-flow flames [44, 45].

For the initially ambient mixtures, the burning velocities are in excellent agreement with previous results using the constant-volume method with a similarly sized chamber and a two-zone model [13]. Values are within $1 \%$ at all equivalence ratios except for $\phi=0.7$ and $\phi=1.2$ where $S_{L}$ is $5 \%$ higher and $3 \%$ lower (the symbols in Figure 9 representing the data of ref. [13] are not visible because they are so closely aligned with the larger square symbols showing the present data). Results are within $5 \%$ of ref. [14], except at $\phi=1.2$ where $S_{L}$ is $8.5 \%$ lower. Burning velocities are also in satisfactory agreement with stretched-corrected spherically propagating [41-43] and counterflow [44, 45] flame data, within the scatter of reported values for the entire range of $\phi$. (For comparison, the same experimental $P$ vs. $t$ data were post-processed using the linear relationship between $P$ and $x_{b}$ [21]. This technique yielded burning velocities that were roughly $8 \%$ higher than the two-zone model approach, with $S_{L}=38.9 \mathrm{~cm} / \mathrm{s}$ at $\phi=1.0$. Similar findings were reported by refs. [34, 46]; thus, the twozone model approach was selected for post-processing the inhibited flame data.)

The upper set of symbols in Figure 9 compares burning velocities at the compressed conditions with previous results using the same constant-volume method. The present burning velocities are in excellent agreement with the results of Stone et al. [14] and in satisfactory (+-9\%) agreement with Takizawa et al. [13]. Overall, the methane validation results show that the present experimental approach provides burning velocities in agreement with those of other investigations at standard and compressed (400 K, 3 bar) conditions.

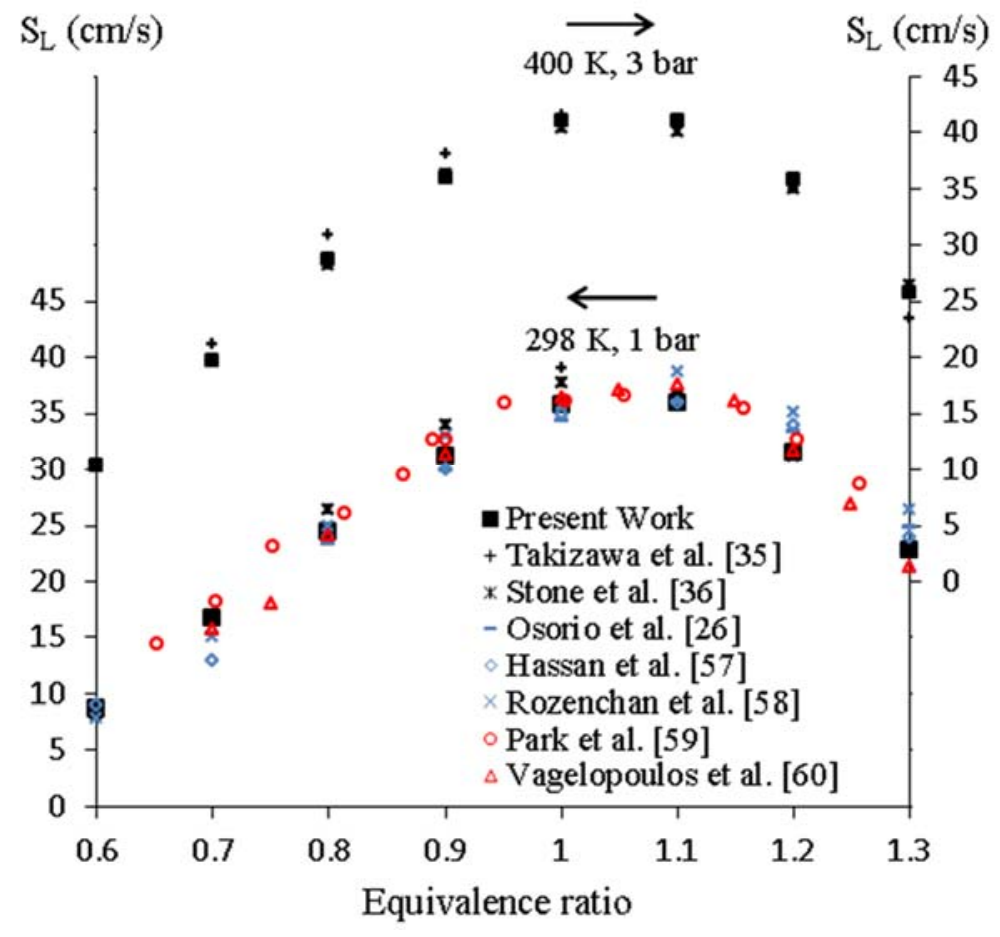

Figure 9: Burning velocity of premixed methane-air flames at $298 \mathrm{~K}$ and 1 bar (lower) and $400 \mathrm{~K}$ and 3 bar (upper) as a function of equivalence ratio, together with previously published results. 


\section{Numerical Methods}

\subsection{Overview}

Numerical simulations were performed to provide insight into the potential for pressure rise and the chemical reactivity of the system, as a function of fuel-air stoichiometry, as well as agent volume fraction. Simulations included chemical equilibrium, premixed steady 1-D planar laminar flame speed, and stirred reactor residence time just above blow-out. The National Aeronautics and Space Administration (NASA) equilibrium code CEA2 [29] and the SANDIA numerical codes PREMIX [47] and PSR [48] were used, along with the chemical kinetics [49] and transport [50] interpreters.

The equilibrium composition, temperature, and pressure for a mixture of gases at some given initial state can be calculated $[39,51]$. Automated numerical techniques are available, which use the method based on minimizing the Gibbs free energy, for a large number of species typically present in combustion systems. The equilibrium conditions of the aerosol can test were calculated using the CEA2 of Gordon and McBride [29]. The calculations were performed over a wide range of initial conditions including inhibitor volume fractions $\left(X_{i}\right)$ from 0 to 0.30 , with a water vapor volume fraction of 0.0125 , and fractions of chamber air involved $(\eta)$ of about 0.15 to 1.00 . The equilibrium simulations were used to predict the final temperature of the involved reactants, and from this, the maximum pressure of the FAA test chamber. The adiabatic combustion temperature and the predicted pressure rise were presented in a previous publication for pure $\mathrm{C}_{6} \mathrm{~F}_{12} \mathrm{O}, \mathrm{C}_{3} \mathrm{H}_{2} \mathrm{~F}_{3} \mathrm{Br}$, and $\mathrm{CF}_{3} \mathrm{Br}[10]$, and these previous results are presented in the present work for comparison.

PSR simulations were used to understand kinetic limitations associated with the explosion pressure predictions of the equilibrium simulations. Flame extinction caused by suppressants is controlled by the characteristic times for chemical reaction and transport, as described by the Damköhler number $\mathrm{Da}=\tau_{r} / \tau_{c}$, in which $\tau_{r}$ is the flow residence time, and $\tau_{c}$ is the chemical time [52]. Hence, an important step for understanding flame suppression is to estimate the overall reaction rate. Given the explosive, two-phase, turbulent mixing process occurring during release of the aerosol can test simulator fuel [53], the reaction zone might be simulated reasonably well by a PSR. Additionally, the PSR blow-out residence time has been correlated with both the laminar flame speed [54] and extinction of laminar diffusion flames with added inert suppressants [55], indicating its utility as a measure of overall combustion reaction rate. For example, to obtain the characteristic chemical time at extinction using a stirred-reactor model [48], the blow-out conditions are determined, as described previously $[3,55]$, and the overall chemical rate $\omega_{p s r}$ is the inverse of the chemical time. While any enhanced mixing in the FAA-ACT occurring due to turbulence cannot be modeled directly with the PSR simulations, the simulations can bracket the range of mixing conditions that might occur, and quantify the overall reaction rate therein. As with the equilibrium comparisons, the results of the PSR simulations for the pure compounds (Novec and 2-BTP) are compared with the blends.

As an illustration of the utility of stirred-reactor chemical rates for predicting flammability, Figure 10 plots, for a premixed methane-air system, the adiabatic flame temperature, stirred reactor overall rate, and the laminar burning velocity as a function of methane volume fraction in the mixture. As illustrated, good correlation is shown between the traditional flammability limits, and either the laminar burning velocity or the stirred reactor overall rate. 


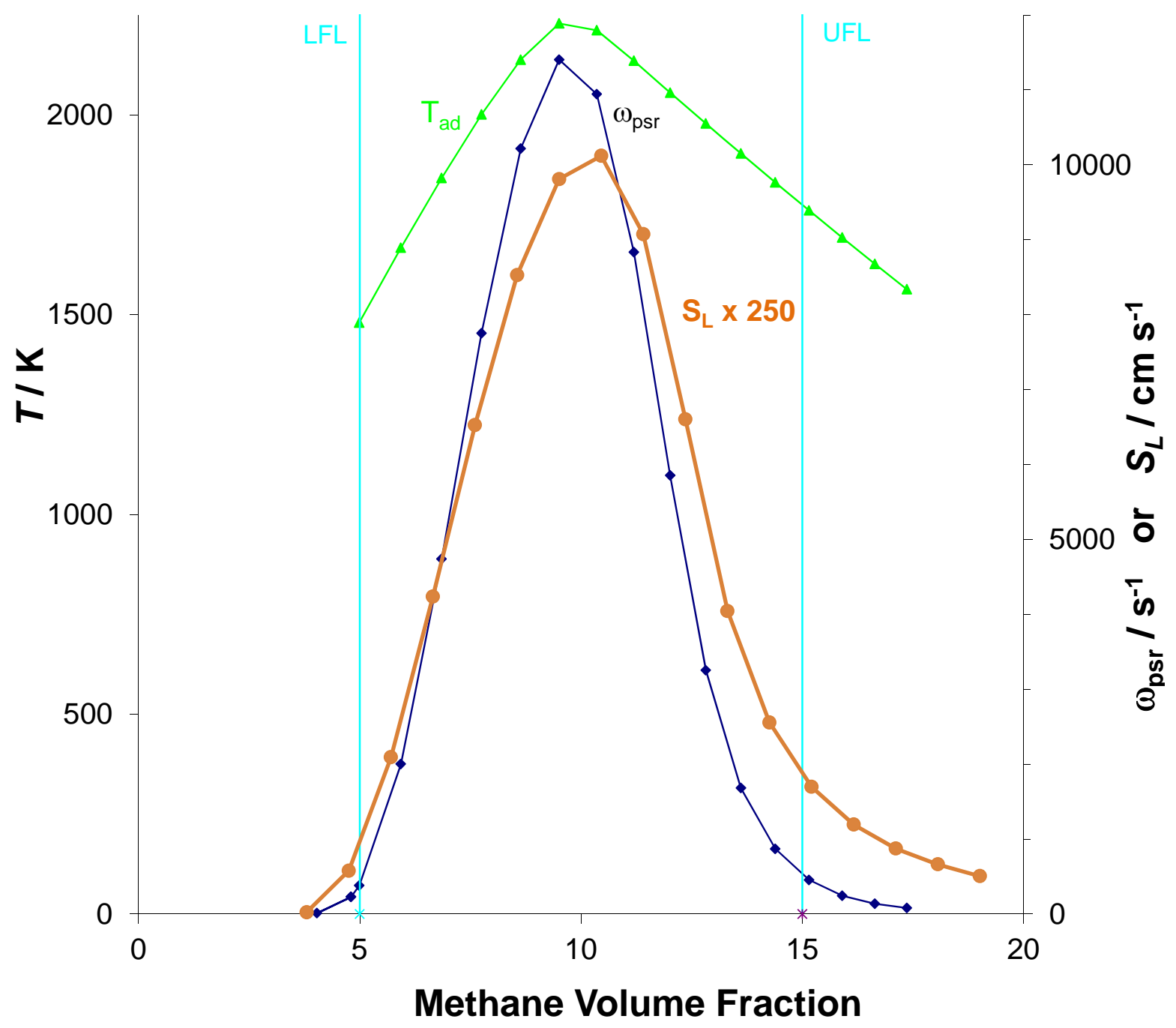

Figure 10 - Calculated overall chemical rate from stirred reactor simulations $\omega_{p s r}$, laminar burning velocity, and adiabatic flame temperature for methane-air mixtures as a function of methane volume fraction [16]. Vertical lines show the separately measured flammability limits of methane [39].

\subsection{Kinetic Mechanisms}

The kinetic mechanisms used for the simulations have been developed in separate work [4,5]. For both mechanisms, the hydrocarbon sub-mechanism is the $C_{1}-C_{4}$ model of Wang et al. [56] (111 species and 784 reactions), with the addition of 5 species and 36 reactions related to ethanol combustion, from Dryer and co-workers [57]. The starting mechanism to describe reactions of the hydrofluorocarbons in hydrocarbon flames is the NIST HFC mechanism [25], including modifications suggested in more recent work [58, 59], also as summarized in Ref. [3]. In addition, more recent modeling of the combustion of pure fluorocarbon agents [60] suggests that relatively large concentrations of $\mathrm{F}$ atoms are observed in the reaction and post-flame zones. Thus, some formation of $\mathrm{F}_{2}$ is expected, and reactions related to its formation and consumption (not previously considered) have now been added [7].

The kinetic model for flame inhibition by $\mathrm{C}_{3} \mathrm{H}_{2} \mathrm{~F}_{3} \mathrm{Br}$ is based on a decomposition model developed at NIST [6], which describes the reactions down to Br-containing species of $\mathrm{C}_{2}$ species and smaller. 
Subsequent reaction of these species are from the kinetic model for $\mathrm{CF}_{3} \mathrm{Br}$ inhibition of hydrocarbonair flames [27] with more recent modifications. The complete $\mathrm{C}_{3} \mathrm{H}_{2} \mathrm{~F}_{3} \mathrm{Br}$ sub-model includes 96 reactions of Br-containing species, as presented in ref. [6]. Thermodynamic data for most of the $\mathrm{Br}-$ containing species are from ref. [27] or Burcat et al. [61], while data for the set of species related to the decomposition of 2-BTP are estimated or calculated, as described in ref. [6]. The complete kinetic model for the simulations with $\mathrm{C}_{3} \mathrm{H}_{2} \mathrm{~F}_{3} \mathrm{Br}$ has 1609 reactions and 188 species, and is available in ref. [6].

The kinetic model for $\mathrm{C}_{6} \mathrm{~F}_{12} \mathrm{O}$ flame inhibition is an approximate model, outlined in ref. [4]. The initial $\mathrm{C}_{6} \mathrm{~F}_{12} \mathrm{O}$ steps were modelled (which leads to $\mathrm{C}_{2} \mathrm{HF}_{5}$ and $\mathrm{C}_{3} \mathrm{HF}_{7}$ ), and the rest of the fluorinatedspecies mechanism was the same as in the $\mathrm{C}_{3} \mathrm{H}_{2} \mathrm{~F}_{3} \mathrm{Br}$ mechanism described above.

\subsection{Kinetic Model Validation}

As initial validation of the kinetic mechanisms for flame inhibition by pure $\mathrm{C}_{6} \mathrm{~F}_{12} \mathrm{O}$ and $\mathrm{C}_{3} \mathrm{H}_{2} \mathrm{~F}_{3} \mathrm{Br}$, the burning velocity of premixed $\mathrm{CH}_{4}$ - and $\mathrm{C}_{3} \mathrm{H}_{8}$-air flames inhibited by these compounds has been measured and predicted in separate work. For addition of pure $\mathrm{C}_{6} \mathrm{~F}_{12} \mathrm{O}$, Figure 11 shows the measured (points) and predicted (lines) unstretched laminar burning velocity for $\mathrm{C}_{3} \mathrm{H}_{8}$-air flames (of various equivalence ratios) with added $\mathrm{C}_{6} \mathrm{~F}_{12} \mathrm{O}$ [62]. As indicated, the model predictions are very close to the experimental results, except for the very lean flames $(\phi=0.6)$, for which the uncertainty in the measured burning velocity is large $( \pm 2 \mathrm{~cm} / \mathrm{s})$ relative to the measured burning velocity $(3 \mathrm{~cm} / \mathrm{s}$ to $10 \mathrm{~cm} / \mathrm{s}$ ) (likely due to radiative heat losses, buoyancy, and stretch effects, which become more important at low burning velocity). For $\mathrm{C}_{3} \mathrm{H}_{2} \mathrm{~F}_{3} \mathrm{Br}$ addition, Figure 12 shows equivalent results for $\mathrm{CH}_{4}$ - and $\mathrm{C}_{3} \mathrm{H}_{8}$-air flames [11]. Again, the agreement is generally excellent, except for the very lean flames $(\phi=0.6)$, which have higher uncertainty in the measured burning velocity. These results provide confidence in the predictive ability of the premixed flames simulations for addition of $\mathrm{C}_{6} \mathrm{~F}_{12} \mathrm{O}$ and $\mathrm{C}_{3} \mathrm{H}_{2} \mathrm{~F}_{3} \mathrm{Br}$ to hydrocarbon flames, since similar simulations are presented below for the blends of these agents with $\mathrm{CO}_{2}$. Similarly, the stirred reactor simulations are expected to be accurate, since they use the same kinetic mechanism. 

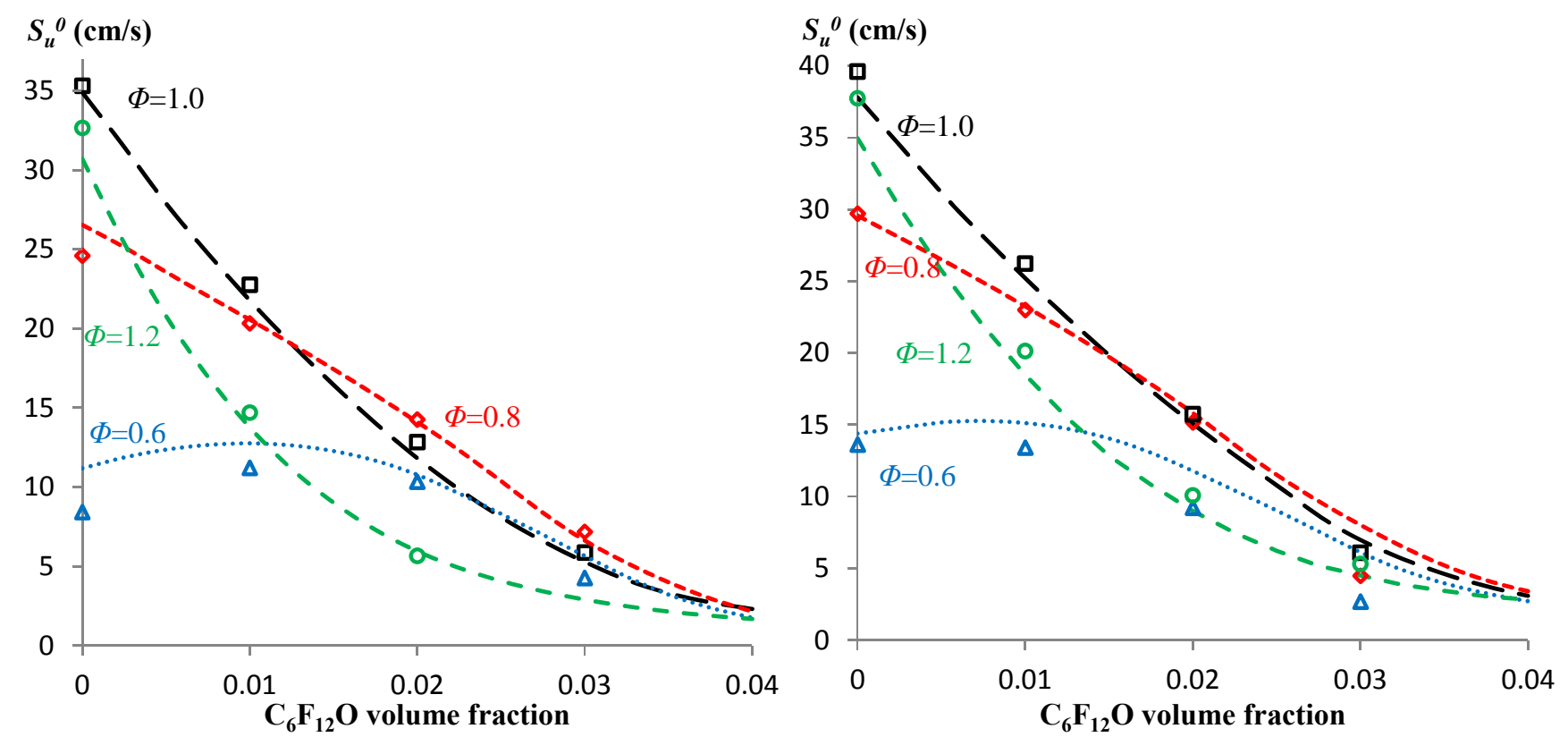

Figure 11 - Comparison of experimental (symbols) and numerical (lines) $S_{u}{ }^{0}$ for $\mathrm{C}_{6} \mathrm{~F}_{12} \mathrm{O}$ inhibited $\mathrm{CH}_{4}$-air (left frame) and $\mathrm{C}_{3} \mathrm{H}_{8}$-air (right frame) flames at $\phi=0.6,0.8,1.0$, and 1.2.
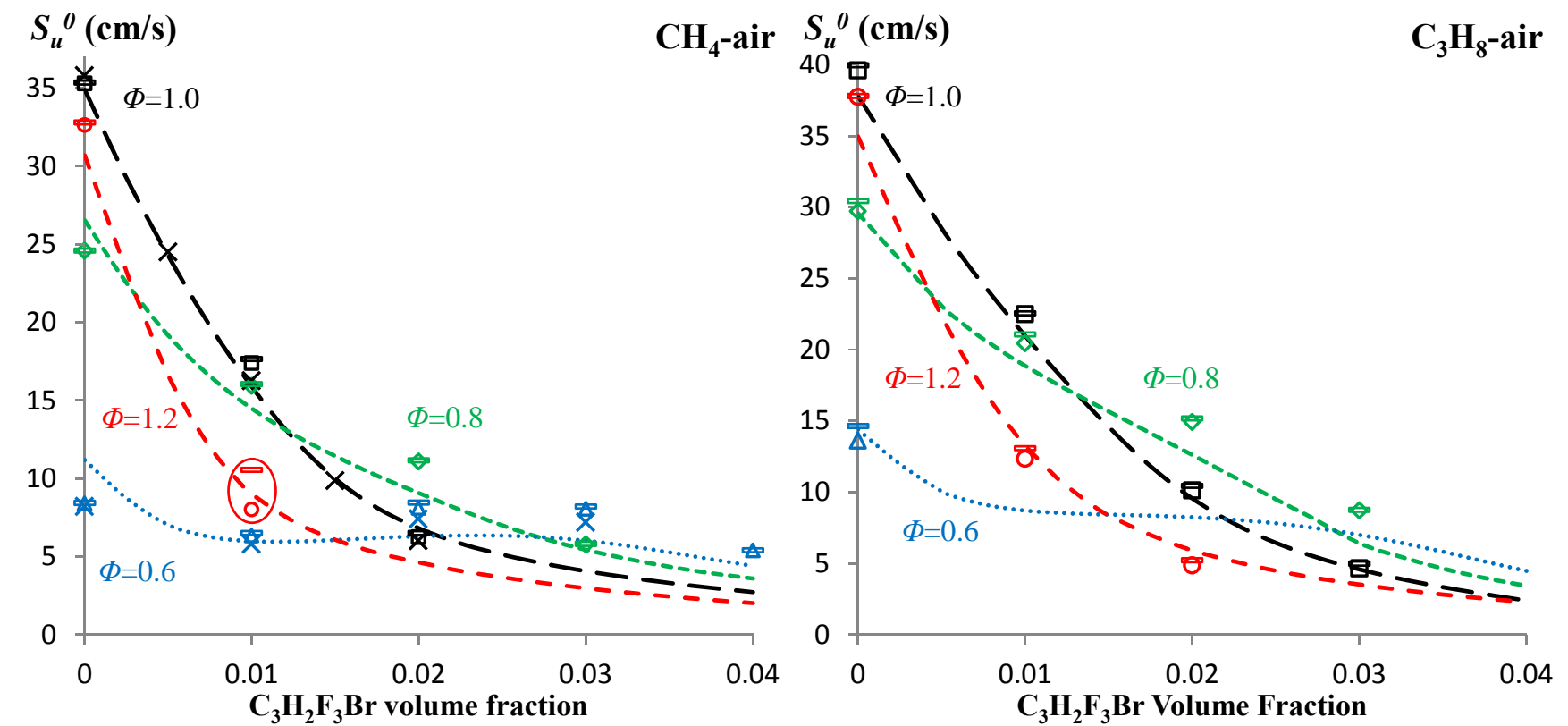

Figure 12 - Comparison of experimental (symbols) and numerical (lines) $S_{u}{ }^{0}$ for $\mathrm{C}_{3} \mathrm{H}_{2} \mathrm{~F}_{3} \mathrm{Br}$-inhibited $\mathrm{CH}_{4}$-air (left) and $\mathrm{C}_{3} \mathrm{H}_{8}$-air (right) flames at $\phi=0.6,0.8,1.0$, and 1.2 ; open symbols are non-linearly extracted, bars are linearly extracted, and crosses are from ref. [10]. 


\section{Results and Discussion}

\subsection{Experimental Results}

\subsubsection{Flammability of Agent-Air Mixtures}

Since the end-gases in the FAA-ACT may be nearly all air and suppressant (i.e., containing little of the fuel from the aerosol can contents), it is useful to explore the flammability of the air-agent mixtures (both for pure agents and their blends with $\mathrm{CO}_{2}$ ). Using the 2-L chamber, the flammability of both the pure agents and their blends were tested, using the platinum wire ignition system described above. For pure $\mathrm{C}_{6} \mathrm{~F}_{12} \mathrm{O}$ or $\mathrm{C}_{3} \mathrm{H}_{2} \mathrm{~F}_{3} \mathrm{Br}$ addition to humid air at stoichiometric conditions (agent volume fractions of 0.065 and 0.0775 and water vapor volume fraction of 0.023 ), the pressure did not rise above that caused by the igniter itself (about 0.07 bar); i.e., they were non-flammable, even with the energetic platinum igniter. The blends of the agents with $\mathrm{CO}_{2}$ were added at blend volume fractions of 0.30 ; for both blends, there was no significant pressure rise, again indicating no ignition. This is the highest concentration of agent expected, and is believed to be the most flammable concentration. Hence, like the pure agents themselves, at ambient conditions, the blends are non-flammable. This is not surprising since the inerting mole fraction of $\mathrm{CO}_{2}$ for hydrocarbon-air mixtures is around 0.30, and lean agent-air mixtures would be much less flammable. Nonetheless, under heated conditions the pure agents become flammable (as discussed below in Section 5.3.2. Pure Agent-Air Premixed Flames). Consequently, the potential flammability of the $\mathrm{CO}_{2}$ /agents blends at elevated temperatures is discussed in that section (we do not currently have capabilities to measure flammability limits at elevated temperatures).

\subsubsection{Explosion Pressures and Inerting Concentrations}

\subsubsection{Experimental Data}

As discussed in previous work [10], the explosion pressure of an agent/air mixture can describe the potential exacerbation of overpressure caused by agent addition, particularly if the experiments are conducted over a range of equivalence ratio $\phi$. For example, for the pure compounds $\mathrm{C}_{6} \mathrm{~F}_{12} \mathrm{O}$, $\mathrm{C}_{3} \mathrm{H}_{2} \mathrm{~F}_{3} \mathrm{Br}$, and $\mathrm{CF}_{3} \mathrm{Br}$, Figure 13 (right frame), Figure 14, (right frame) and Figure 15 [10] show the experimentally measured explosion pressure in the 2-L chamber for premixed mixtures of methaneor propane-air, for $\phi=1.0$ and 0.6. As indicated in Figure 15, $\mathrm{CF}_{3} \mathrm{Br}$ lowers the explosion pressure at all loadings and all values of $\phi$ that were tested. For $\mathrm{C}_{6} \mathrm{~F}_{12} \mathrm{O}$ (Figure 13, right frame), however, agent addition increases the explosion pressure somewhat (up to about $10 \%$ ) for stoichiometric flames $(\phi=1.0)$, and rather strongly (about $220 \%)$ for lean flames $(\phi=0.6)$. As has been discussed, this is due to the competition between the fuel effect of the agent (which increases the temperature and hence reaction rate with added $\mathrm{C}_{6} \mathrm{~F}_{12} \mathrm{O}$ to lean flames) and the slower kinetics of the fluorinated system (compared to the hydrocarbon system) [10]. For pure $\mathrm{C}_{3} \mathrm{H}_{2} \mathrm{~F}_{3} \mathrm{Br}$ addition (Figure 14, right frame), the explosion pressure of stoichiometric flames increases insignificantly (about $1 \%$ at $X_{a}=0.01$ ) and decreases for $X_{a}>0.01$. The lean flames $(\phi=0.6)$ are inhibited at low $\mathrm{C}_{3} \mathrm{H}_{2} \mathrm{~F}_{3} \mathrm{Br}$ volume fraction (around $X_{a}=0.01$ ) (due to the strong catalytic radical recombination by Br-species at lower temperatures [7]), but above this value of $X_{a}$, the explosion pressure rises (at $X_{a}=0.03$ ) to about $175 \%$ of the uninhibited value, and then drops for $X_{a}>0.03$.

The results for the Blend $\mathrm{A}$ are shown in Figure 13 (left frame). As indicated, the behavior (surprisingly) is similar to that of pure $\mathrm{C}_{6} \mathrm{~F}_{12} \mathrm{O}$ : leaner flames show enhancement of the explosion pressure with agent addition. At $\phi=1.0$, the explosion pressure is monotonically reduced for 
increasing $X_{a}$, but at lower values of $\phi$, the explosion pressure is increased with Blend A addition (up to about $X_{a}=0.10$ ), and then reduced. This figure can also be used to estimate the inerting concentration (the concentration of agent that will prevent explosion for all values of $\phi$ ). Slight extrapolation of the curves in Figure 13 indicates that a volume fraction of Blend A $X_{a}$ of 0.27 is sufficient to inert these mixtures.
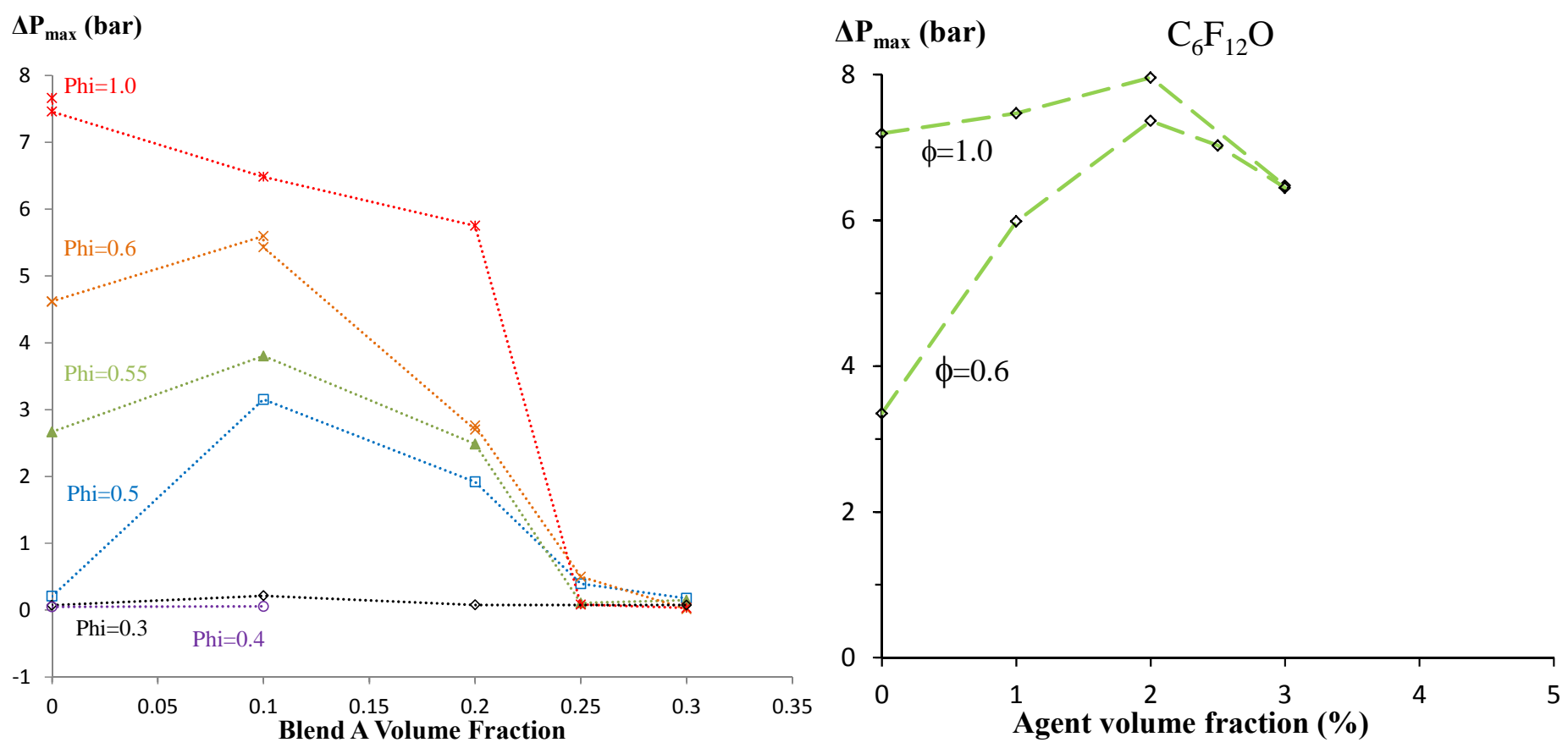

Figure 13 - Measured explosion pressure in the 2-L chamber for moist propane air flames of various $\phi$, as a function of the volume fraction of Blend $A$ in the initial mixture (left frame); or pure $\mathrm{C}_{6} \mathrm{~F}_{12} \mathrm{O}$ in dry methane-air flames (right frame) .
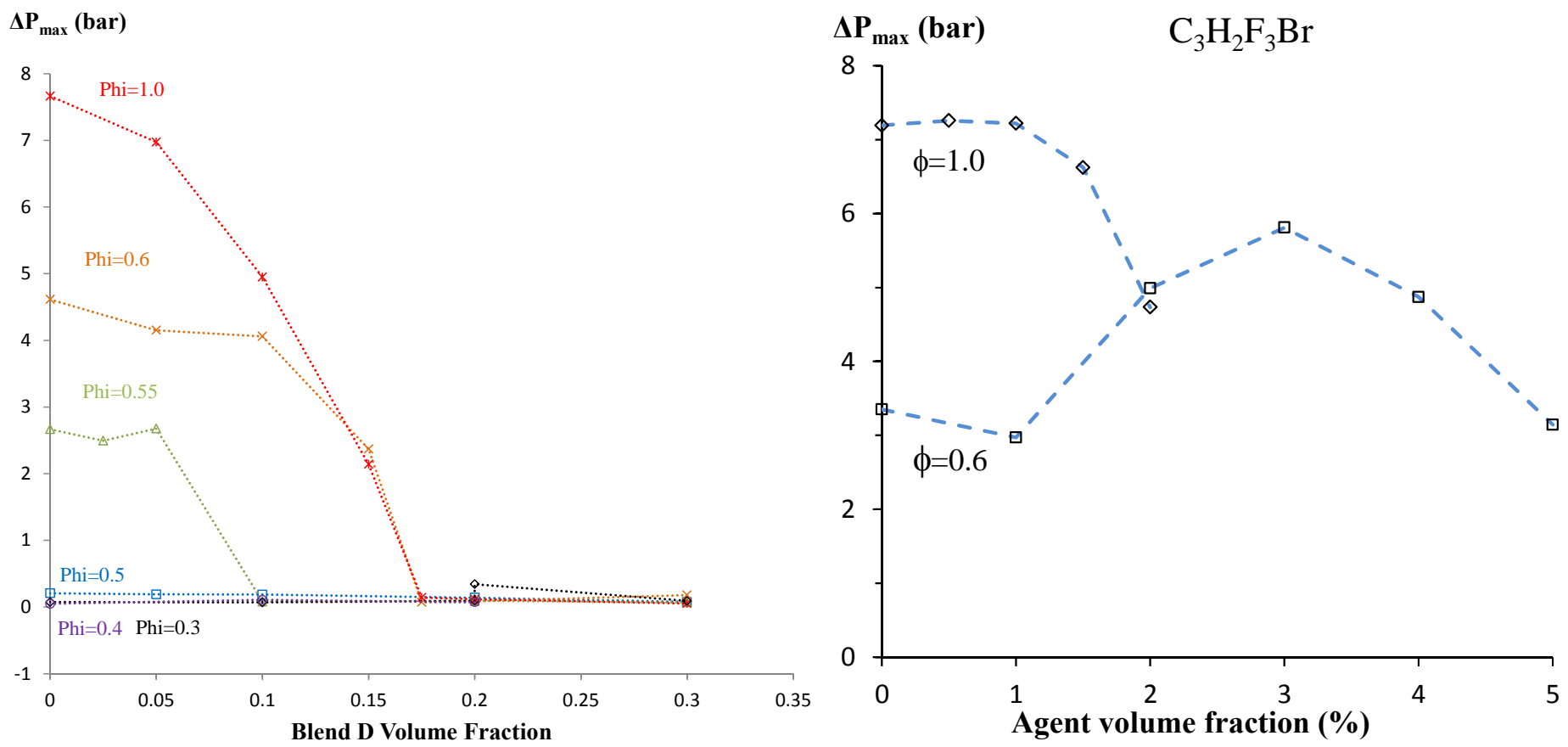

Figure 14 - Measured explosion pressure in the 2-L chamber for moist propane air flames of various $\phi$, as a function of the volume fraction of Blend $D$ in the initial mixture(left frame); or pure $\mathrm{C}_{3} \mathrm{H}_{2} \mathrm{~F}_{3} \mathrm{Br}$ in dry methane-air flames (right frame). 
The results for Blend D are shown in Figure 14 (left frame). For stoichiometric flames, the explosion pressure with added Blend $\mathrm{D}$ is monotonically reduced as $X_{a}$ increases. For the lean flames, while the shape of the curves mimics that of pure $\mathrm{C}_{3} \mathrm{H}_{2} \mathrm{~F}_{3} \mathrm{Br}$ (i.e., decreasing at very low agent loading, increasing for intermediate, and then decreasing again), the explosion pressure is never higher with added Blend D. That is, the explosion pressure behavior of Blend $\mathrm{D}$ is unlike $\mathrm{C}_{3} \mathrm{H}_{2} \mathrm{~F}_{3} \mathrm{Br}, \mathrm{C}_{6} \mathrm{~F}_{12} \mathrm{O}$, or Blend A, for which enhanced explosion pressure was observed. Apparently, the reduction in temperature caused by the $\mathrm{CO}_{2}$ addition sufficiently moderates temperature increase from reaction of the $\mathrm{C}_{3} \mathrm{H}_{2} \mathrm{~F}_{3} \mathrm{Br}$. Moreover, as discussed in ref. [7], the catalytic cycle for radical recombination from $\mathrm{Br}-$ species is more effective at lower temperature, and then becomes less effective as the temperature is increased with more agent. To explore these features in more detail, the experimental data in Figure 13 and Figure 14 are plotted in alternative form below, together with the results of equilibrium simulations for the conditions of these experiments. As with Blend A, the inerting concentration of Blend $\mathrm{D}$ for moist propane-air flames can be determined from the present explosion sphere experiments (Figure 14, left frame), and is found to be $X_{a}=0.18$.

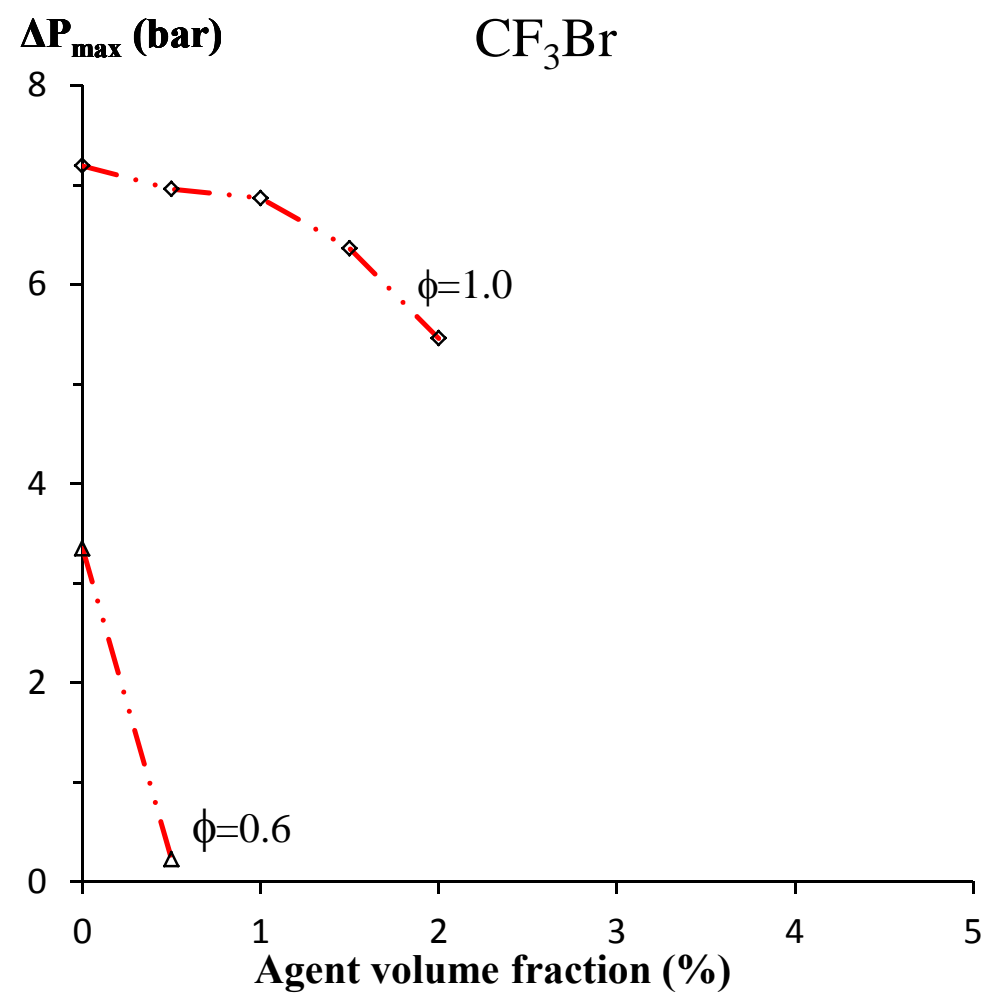

Figure 15 - Measured explosion pressure in the 2-L chamber (Pt-wire igniter) for methane-air flames $(\phi=1.0$, and 0.6$)$ as a function of the volume fraction of $\mathrm{CF}_{3} \mathrm{Br}$ in the initial mixture [10].

\subsubsection{Equilibrium Simulations and Experimental Data}

Figure 16 re-plots the measured explosion pressure data for methane-air flames from ref. [10] ( $\phi=1.0$ left frame, 0.6 right frame) with added $\mathrm{CF}_{3} \mathrm{Br}, \mathrm{C}_{6} \mathrm{~F}_{12} \mathrm{O}$, and $\mathrm{C}_{3} \mathrm{H}_{2} \mathrm{~F}_{3} \mathrm{Br}$. The top curves (right axes) show the calculated equilibrium adiabatic flame temperatures, while the middle curves (left axes) show the calculated equilibrium explosion pressure (lines) and the bottom curves, the measured values (points with connecting lines). As discussed previously [10], the potential for overpressure with added suppressant is illustrated by the equilibrium curves, and exists even for addition to 
stoichiometric flames $(\phi=1.0)$. Due to heat losses, kinetic limitations, and buoyancy-induced quenching, however, the experimental pressure rise is always lower than the equilibrium values. Most noteworthy is that the results for agent addition to the lean $(\phi=0.6)$ methane-air flames (right frame of Figure 16) indicate that a large enhancement of the explosion pressure is predicted (and experienced) with addition of any of the pure agents (except $\mathrm{CF}_{3} \mathrm{Br}$ ).
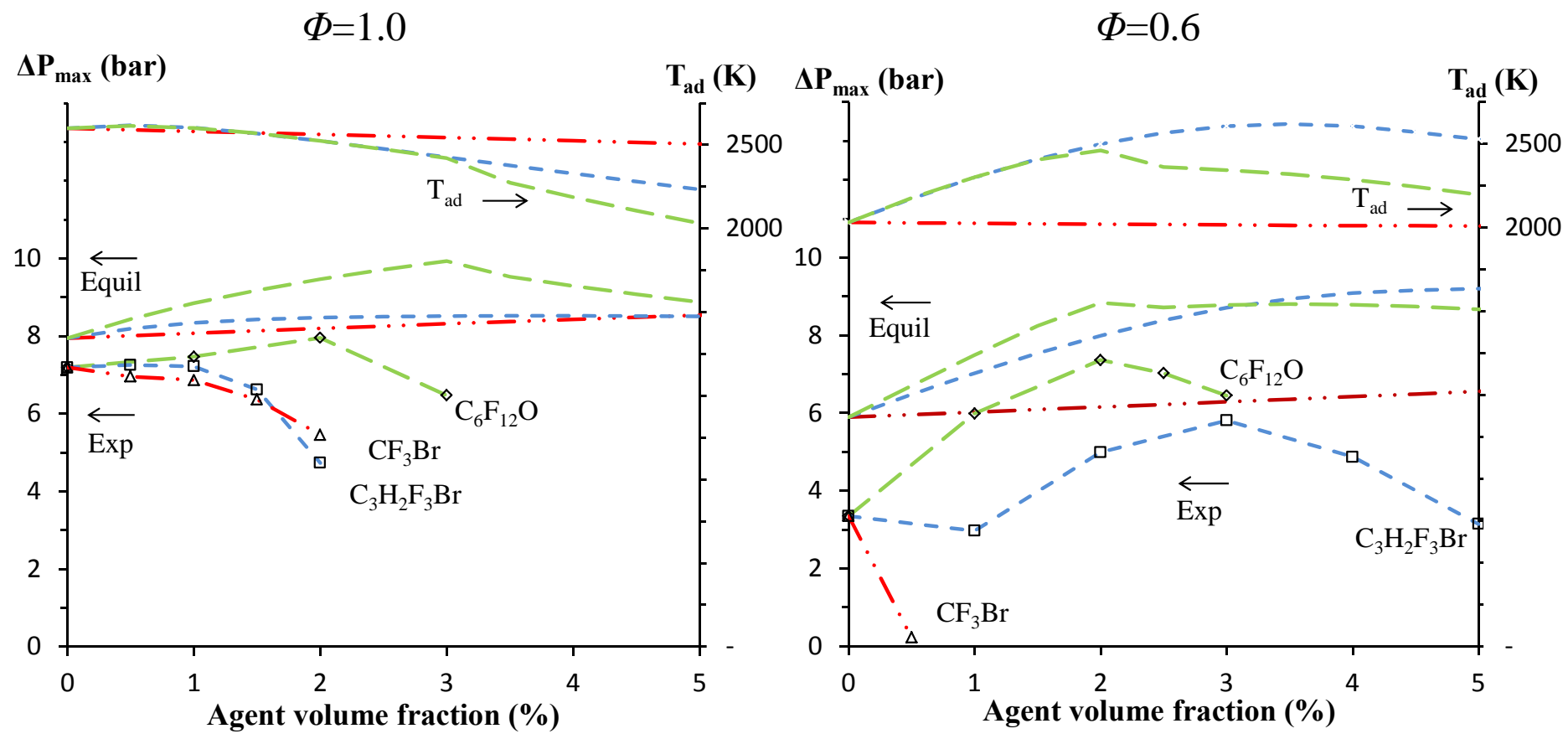

Figure 16 - Measured explosion pressure (Pt-wire igniter) in the 2-L chamber for methane-air flames ( $\phi=1.0$ left frame; $\phi=0.6$, right frame) as a function of the volume fraction of $\mathrm{CF}_{3} \mathrm{Br}, \mathrm{C}_{6} \mathrm{~F}_{12} \mathrm{O}$, and $\mathrm{C}_{3} \mathrm{H}_{2} \mathrm{~F}_{3} \mathrm{Br}$ volume fraction in the initial mixture [10]. Top curves show the calculated equilibrium temperature, and the bottom curves show the equilibrium and measured explosion pressure.

In Figure 17, data for Blend A and Blend D are presented (together) in the same format as in Figure 16. In Figure 17, different frames refer to different values of $\phi$, as indicated, and the blue solid lines refer to Blend A, while red, dotted lines refer to Blend D. As the figure shows, agent addition can either increase or decrease the equilibrium explosion pressure depending upon $X_{a}$ and $\phi$. Moreover, the predicted equilibrium explosion pressure (and adiabatic combustion temperature) of Blend A and Blend D are very close, with each sometimes higher than the other depending upon the $X_{a}$ and $\phi$. For the experimental explosion pressure, however, addition of Blend D always lowers the explosion pressure, and Blend D is always more effective than Blend A.

As noted, both the equilibrium adiabatic combustion temperature and the calculated equilibrium explosion pressure as a function of $X_{a}$ are similar for the two agents. Since the actual explosion pressure for addition of Blend $\mathrm{D}$ is always lower than for addition of Blend $\mathrm{A}$, Blend $\mathrm{D}$ has greater kinetic inhibition effect on the flames than does Blend A. In the 2-L spherical flame experiments, it is difficult to separate the effects of stretch-induced quenching (due to buoyancy-induced flow, which lowers the temperature) and purely kinetically-induced quenching (i.e., lowered extent of reaction 
due to slower chemistry of the halogen-containing system). A lowered overall reaction rate reduces the flame speed, allowing buoyancy more time to act, which then causes vortex formation and flowinduced quenching, further lowering the reaction rate. Nonetheless, the experimental results in Figure 17 can be used as rough estimates of the kinetic effects of agent addition; increased deviation of the experimental pressure rise from the equilibrium value (when agent is added) is due to kinetic effects of the agent. For example, for Blend $\mathrm{A}$ in lean flames, at $X_{a}=0.10$ the fuel effects dominates over any kinetic effects, and at $X_{a}=0.20$, the kinetic effects dominate. For Blend D, kinetic effects always dominate (adding agent to mixtures of any stoichiometry always increases the deviation of the actual pressure rise from the equilibrium results).

\subsection{Numerical Results}

The predicted performance of the blends in the FAA-ACT is explored via thermodynamic equilibrium simulations (for temperature and hence pressure rise), and perfectly-stirred reactor (PSR) simulations (to provide a measure of the overall reaction rate, which is related to the extinction condition). In the figures below (Figures 18 to 23), the left frames refer to the blends, and the right frames refer to the pure agents (for which the data and figures are from previous work for $\mathrm{C}_{6} \mathrm{~F}_{12} \mathrm{O}$ [4] and $\left.\mathrm{C}_{3} \mathrm{H}_{2} \mathrm{~F}_{3} \mathrm{Br}[5]\right)$.

\subsubsection{Equilibrium Simulations}

\subsubsection{Blend A}

Figure 18 shows the calculated equilibrium adiabatic combustion temperature $T_{a d}$ for the FAA-ACT as a function of the fraction of the chamber volume $\eta$ that is assumed to react with the fuel of the simulated aerosol can contents (ethanol, propane, water). For example, in the figure, the curve marked $X_{a}=0$ refers to the uninhibited oxidizer mixture (i.e., air at $50 \%$ r.h.), and shows that about a third of the chamber volume $\eta=0.29$ is required for peak temperature. As agent is added $\left(X_{a}\right.$ increases), the curves change as follows: 1 . shift down (due to the high fraction of $\mathrm{CO}_{2}$ in the blend, which lowers the temperature), 2. to the right (due to the oxygen demand of the $\mathrm{C}_{6} \mathrm{~F}_{12} \mathrm{O}$ in the blend and $\mathrm{O}_{2}$ displacement by the added agent, and 3. have less sharp of a peak (i.e., the mixture more resembles a premixed flame of air and agent, for which the curves would be flat, then diffusion flame of aerosol can fuel with air). For comparison, the pure $\mathrm{C}_{6} \mathrm{~F}_{12} \mathrm{O}$ flames (right frame) maintain their high $T_{a d}$ with agent addition, until $X_{a} \approx 0.027$, above which a steep drop occurs (due to insufficient hydrogen in the system to produce the stable product HF, as has been discussed [4]). For $X_{a}>0.075$, temperature again drops because the system (air-agent-fuel) is overall fuel rich. These features are captured in Figure 19, which shows the peak $T_{a d}$, and the value of $\eta$ at which the peak occurs. As indicated, the value of $\eta$ for peak $T_{a d}$ increases to about 1.0 as $X_{a}$ approaches the inertion value $(0.27$ for Blend $\mathrm{A}$, and around 0.07 to 0.08 for $\mathrm{C}_{6} \mathrm{~F}_{12} \mathrm{O}$ ).

The increase in $\eta$ with agent addition has ramifications for the potential pressure rise. Figure 20 shows the predicted pressure rise with addition of Blend $A$ or $\mathrm{C}_{6} \mathrm{~F}_{12} \mathrm{O}$ [4]. For increasing $X_{a}$, as $\eta$ increases (due to the increase of oxygen demand of the agent itself and displaced $\mathrm{O}_{2}$ ), the mass of reactants also increases (the chamber oxidizer volume contains both air and agent), increasing the potential pressure rise. Thus, at values of $X_{a}$ just below that required for inertion, there can be pressure rise of about 3.5 bar for Blend $\mathrm{A}$ addition, or 7 bar for $\mathrm{C}_{6} \mathrm{~F}_{12} \mathrm{O}$ addition. 

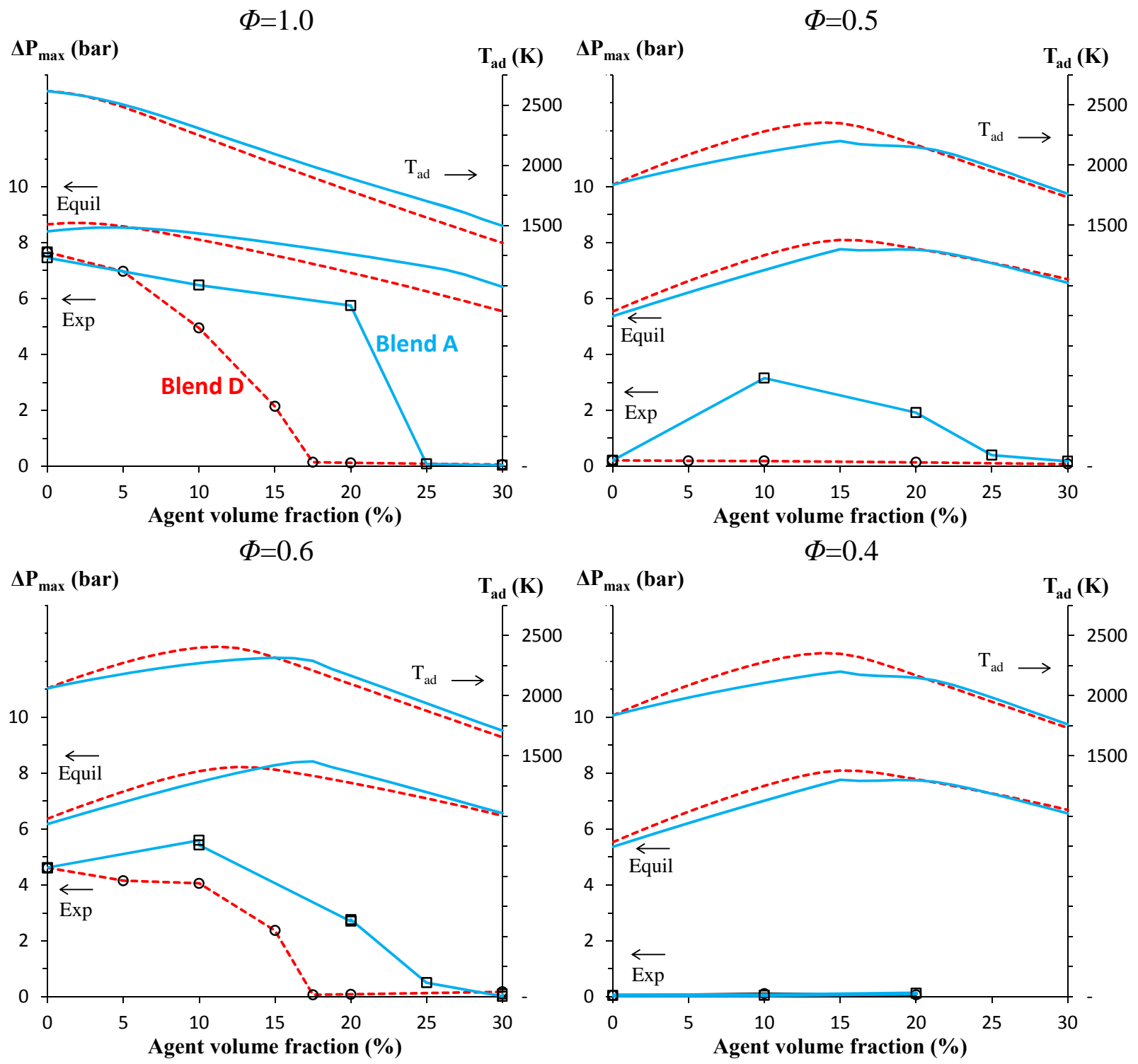

$$
\Phi=0.4
$$

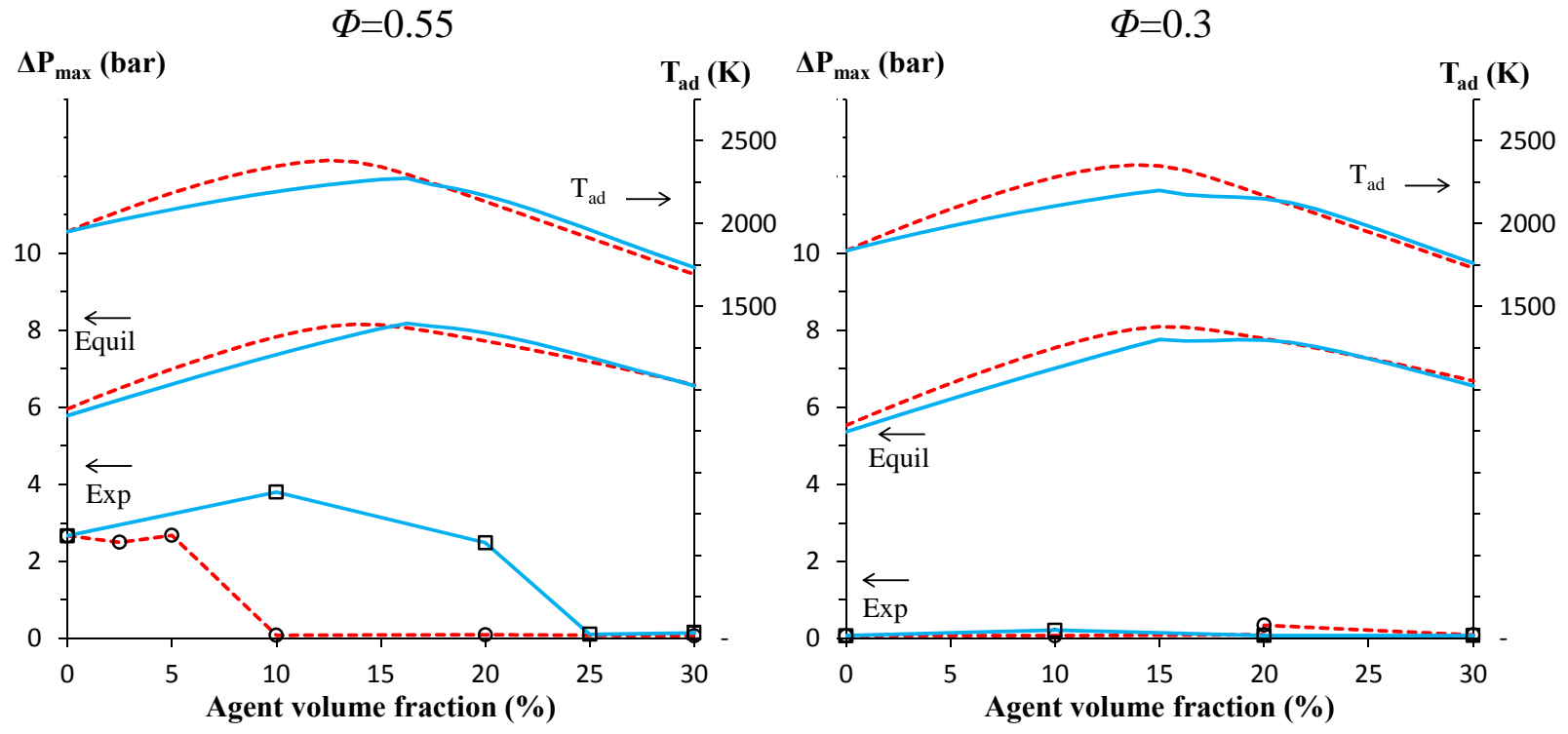

Figure 17 - Measured (bottom curve) and calculated equilibrium (middle curves) explosion pressure in the 2-L chamber for (Pt-wire igniter) for moist propane-air flames (various $\phi$ ) with 
added agent; calculated equilibrium adiabatic combustion temperature is shown by the top curves. Blue lines are Blend A; red (dotted) lines Blend D.
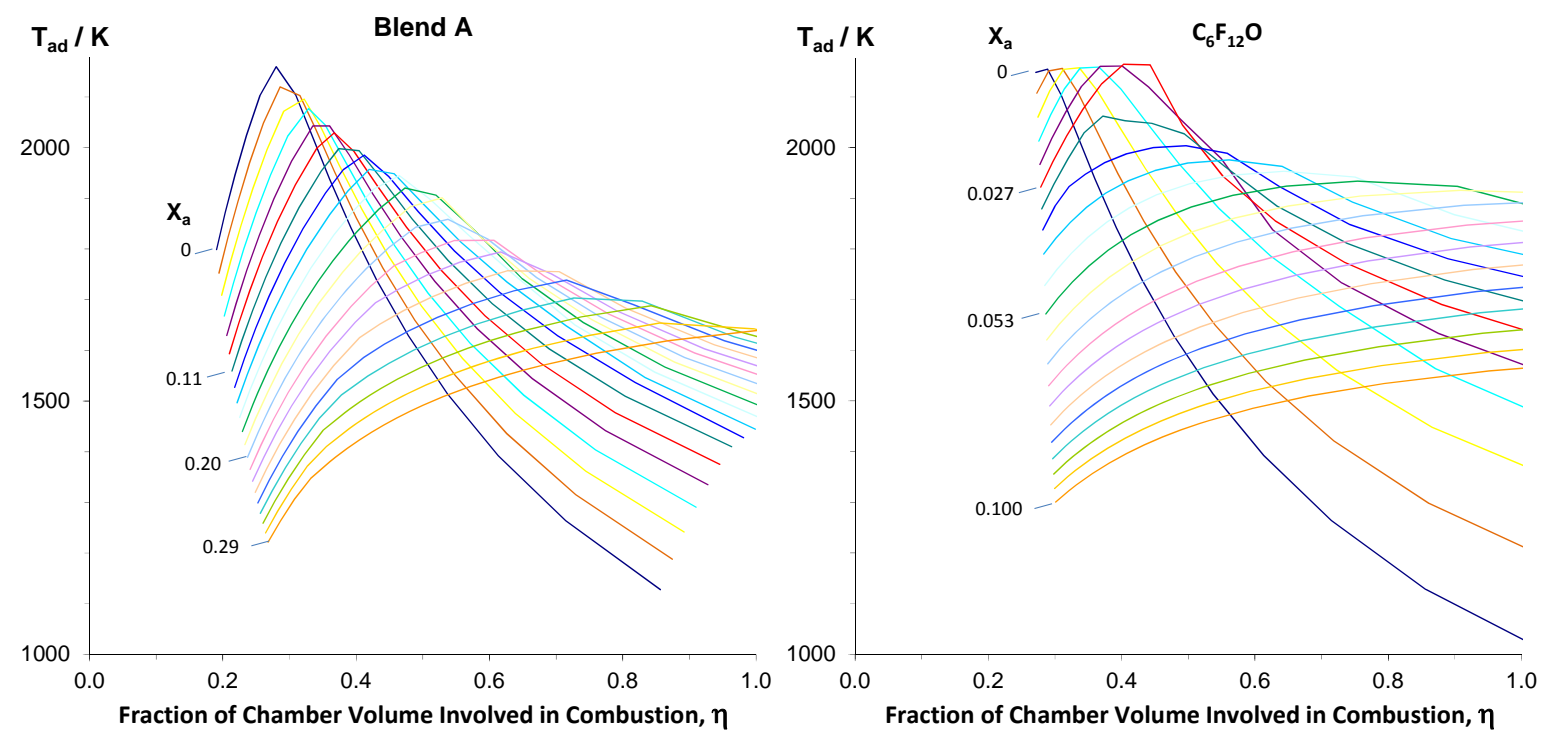

Figure 18 - Equilibrium adiabatic combustion temperature as a function of $\eta$, the fraction of chamber volume involved in combustion. Each curve refers to a different value of the agent volume fraction $X_{a}$ in the chamber (left frame: Blend $A$; right frame, $\mathrm{C}_{6} \mathrm{~F}_{12} \mathrm{O}$ [4]).
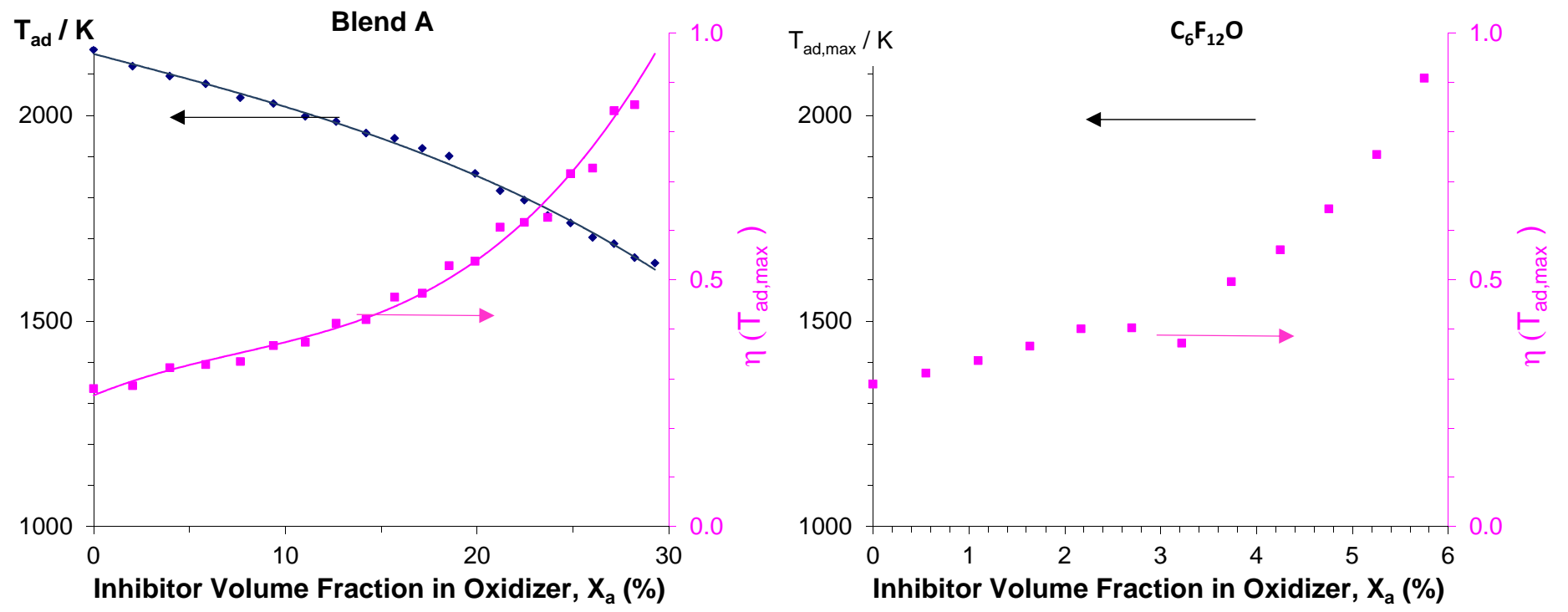

Figure 19 - Peak temperature (from Figure 18) and the value of $\eta$ at which the peak temperature occurs (left frame: Blend $\mathrm{A}$; right frame, $\mathrm{C}_{6} \mathrm{~F}_{12} \mathrm{O}$ [4]). 

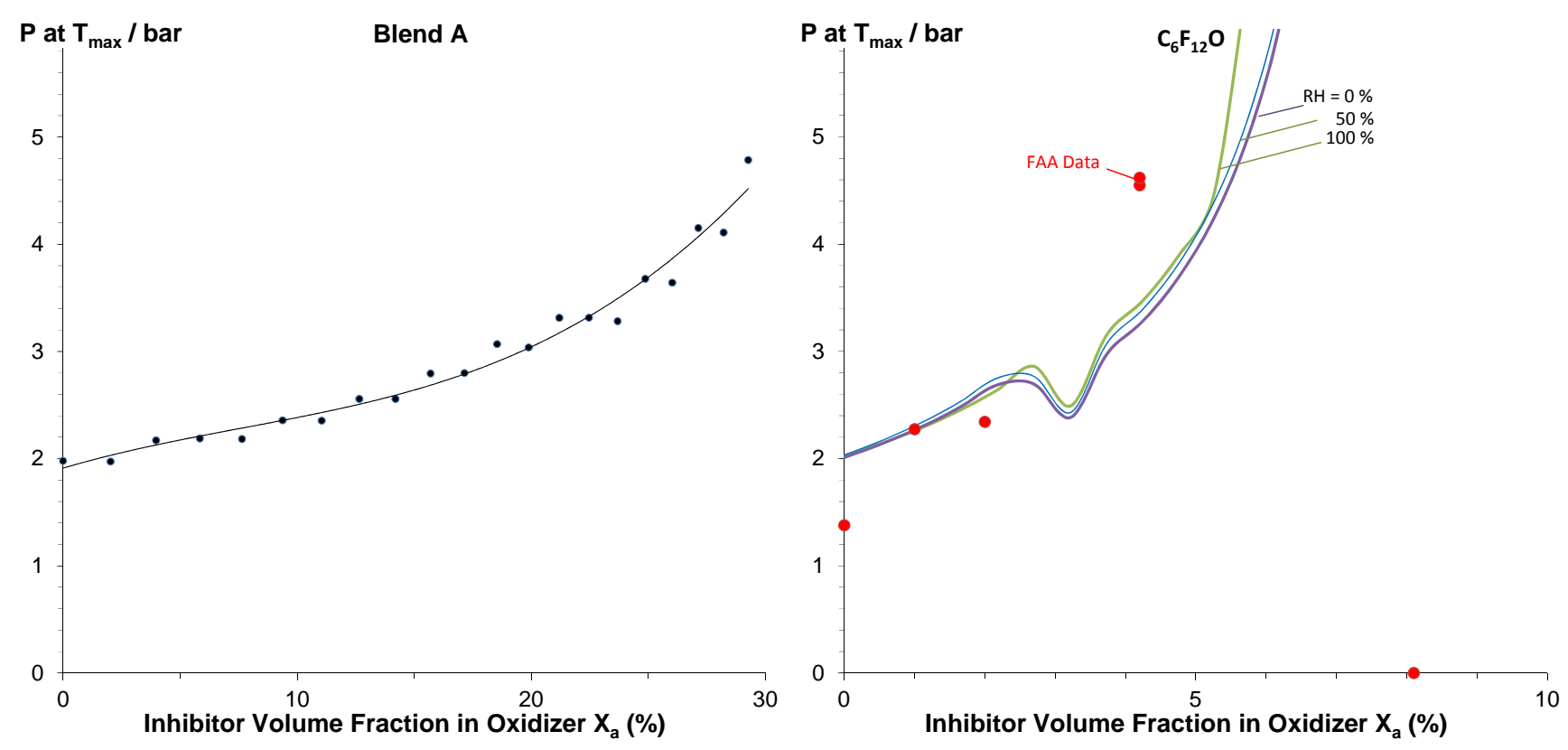

Figure 20 - Predicted pressure rise in the FAA-ACT as a function of the volume fraction of added inhibitor (left frame: Blend $\mathrm{A}$; right frame, $\mathrm{C}_{6} \mathrm{~F}_{12} \mathrm{O}[4]$ ).

\subsubsection{Blend D}

For Blend $\mathrm{D}$ (or $\mathrm{C}_{3} \mathrm{H}_{2} \mathrm{~F}_{3} \mathrm{Br}$ ) addition to the FAA-ACT, Figure 21 shows in similar format $T_{a d}$ as a function of $\eta$ and $X_{a}$, and Figure 22 shows the peak values of $T_{a d}$, and the values of $\eta$ at which they occur. As the figures show, $T_{a d}$ decreases steadily with Blend D addition, but is constant (around $2150 \mathrm{~K}$ ) with $\mathrm{C}_{3} \mathrm{H}_{2} \mathrm{~F}_{3} \mathrm{Br}$ addition. Based on these equilibrium simulations, the maximum pressure rise in the FAA-ACT for Blend $\mathrm{D}$ and $\mathrm{C}_{3} \mathrm{H}_{2} \mathrm{~F}_{3} \mathrm{Br}$ are shown in Figure 23. The predicted pressure rise at the inertion point is about 4 bar with Blend $\mathrm{D}$ and about 8 bar with $\mathrm{C}_{3} \mathrm{H}_{2} \mathrm{~F}_{3} \mathrm{Br}$. Thus, even without kinetic limitations, the pressure rise just below the inertion point with the blends is expected to be about one half that of the pure agents just below their inertion point. The key question is whether with blend addition to the FAA-ACT, the reaction rate is slowed faster than the pressure rise increases. To examine this we turn to stirred-reactor simulations to determine the overall chemical rate as a function of mixing state and additive loading. 

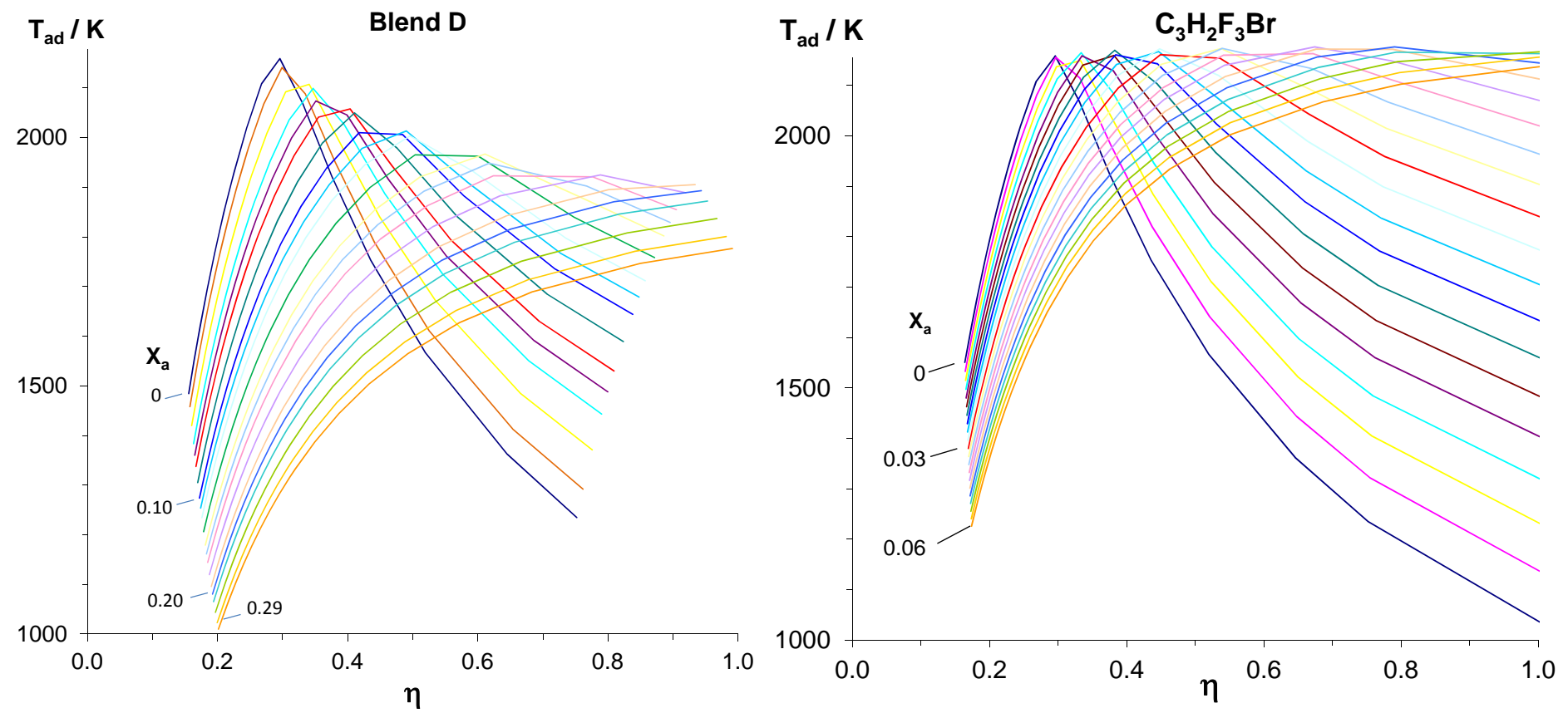

Figure 21 - Equilibrium adiabatic combustion temperature as a function of $\eta$, the fraction of chamber volume involved in combustion. Each curve refers to a different value of the agent volume fraction $X_{a}$ in the chamber (left frame: Blend $\mathrm{D}$; right frame, $\mathrm{C}_{3} \mathrm{H}_{2} \mathrm{~F}_{3} \mathrm{Br}$ [5])
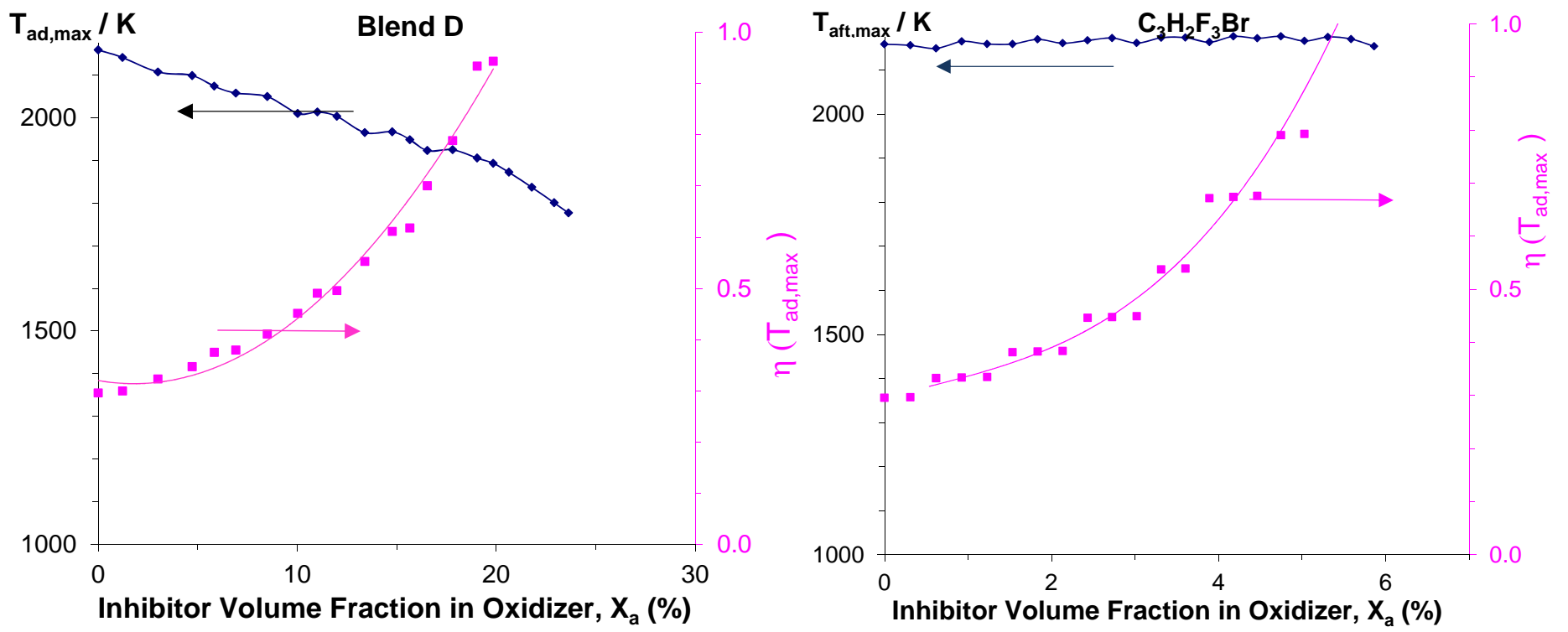

Figure 22 - Peak temperature (from Figure 21) and the value of $\eta$ at which the peak temperature occurs (left frame: Blend D; right frame, $\mathrm{C}_{3} \mathrm{H}_{2} \mathrm{~F}_{3} \mathrm{Br}$ [5]). 

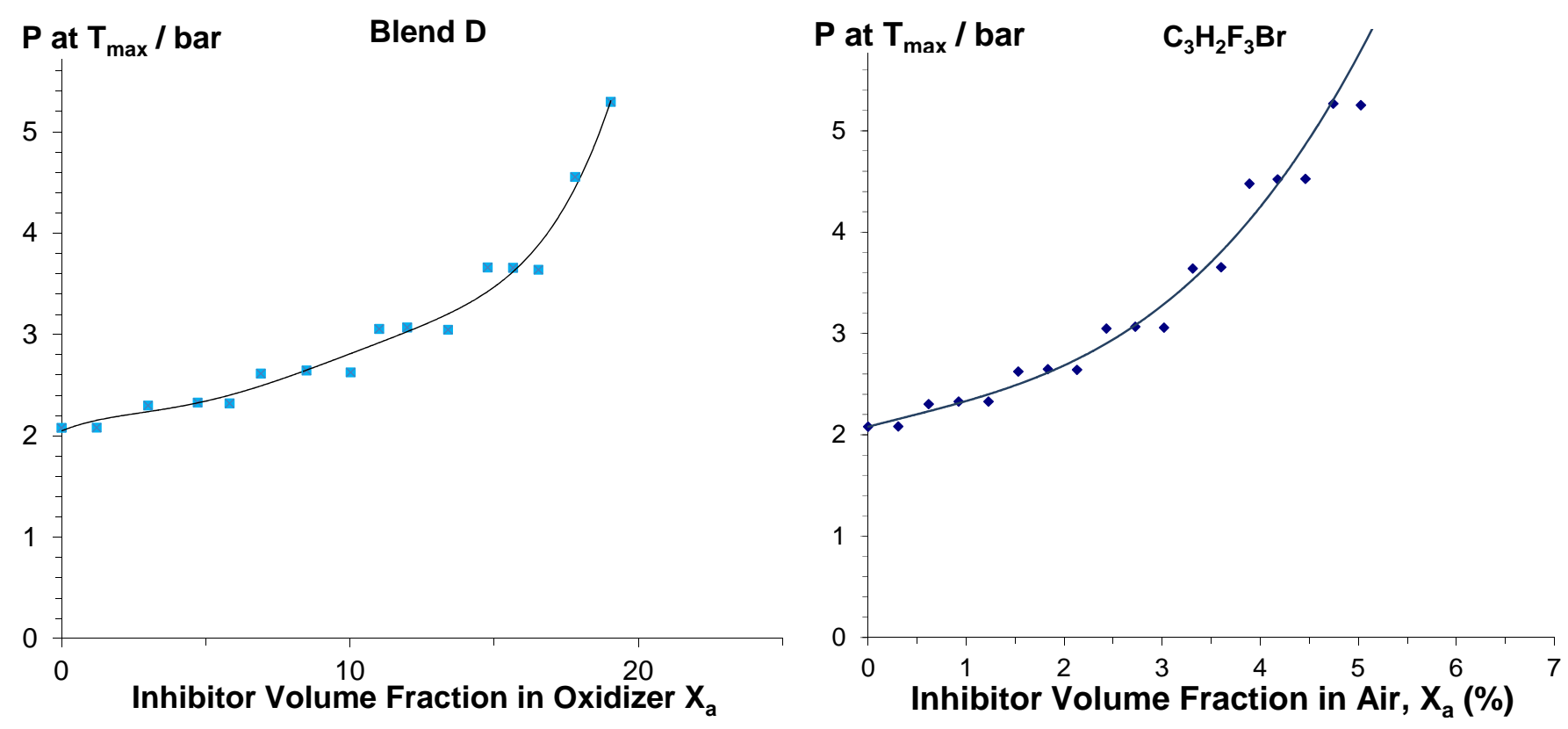

Figure 23 - Predicted pressure rise in the FAA-ACT as a function of the volume fraction $X_{a}$ of added inhibitor (left frame: Blend $\mathrm{D}$; right frame, $\mathrm{C}_{3} \mathrm{H}_{2} \mathrm{~F}_{3} \mathrm{Br}$ [5]).

\subsubsection{Perfectly Stirred Reactor Simulations}

Note that the assumptions that went into the calculation of the pressure rise as shown in Figure 20 and Figure 23 have been shown to reproduce the actual pressure rise in the FAA-ACT when there are no kinetic limitations. While the deviation of the experimental pressure rise in the 2-L experiments from the calculated equilibrium pressure rise illustrated the kinetic effects of the blends, it is of value to explore them in more detail for the FAA-ACT using perfectly stirred reactor simulations. In particular, the PSR simulations can: 1. determine the overall reaction rate of the mixtures for a wide range of $\phi$ and $X_{a} ; 2$. explore reaction rates with the actual FAA-ACT fuel (instead of the moist propane-air mixtures of the 2-L experiments), and 3. compare expected reaction rates for the blends with those of the pure agents, for which the extinction behavior in the FAA-ACT experiments is available for comparison.

The stirred-reactor overall chemical rate $\omega_{p s r}$ as a function of $\eta$ is shown in Figure 24 for Blend A (left frame) and $\mathrm{C}_{6} \mathrm{~F}_{12} \mathrm{O}$ (right frame) and in Figure 25 for Blend $\mathrm{B}$ and $\mathrm{C}_{3} \mathrm{H}_{2} \mathrm{~F}_{3} \mathrm{Br}$. The different curves refer to different values of $X_{a}$, as indicated. The green dots indicate the value of $\eta$ that provided the peak $T_{a d}$, and hence are expected to be the mixing condition at which the mixture in the FAA-ACT will burn (if possible). The black squares are the critical values of $\omega_{p s r}$ for extinguishment for the high-strain flame near the fuel release, or in the low-strain regions at the end-gases of the chamber. That is, near the explosive release of the aerosol can simulator and high-voltage igniter, the reaction rate must only be lowered (from about $\omega_{p s r}=9000 \mathrm{~s}^{-1}$ for the uninhibited mixture) to about $\omega_{p s r}=$ $1700 \mathrm{~s}^{-1}$, whereas in the low-strain regions of the chamber, if flammable mixtures exist, their reaction rate much be lowered to about $\omega_{p s r}=20 \mathrm{~s}^{-1}$. The mixtures of pure $\mathrm{C}_{6} \mathrm{~F}_{12} \mathrm{O}$ or $\mathrm{C}_{3} \mathrm{H}_{2} \mathrm{~F}_{3} \mathrm{Br}$ create overpressures in the FAA-ACT because the green dots for $\eta>0.7$ (shown in the right frames of Figure 24 and Figure 25) have higher reactivity than both the value necessary for inertion $\left(\omega_{p s r}=20 \mathrm{~s}^{-1}\right)$, and the value of the uninhibited flames (the blue curve marked $X_{a}=0$ ). That is, addition of this agent to the lean mixtures enhances flammability. Unfortunately, for Blend $A$, there is a region near $\eta=0.7$ for which the green dots also meet these criteria (the reactivity of the system at its desired stoichiometry is higher than for the uninhibited reactants). That higher reactivity, coupled with the increase in $\eta$ as 
$X_{a}$ increases, is likely to lead to overpressure at sub-inerting concentrations. In contrast, in Figure 25 for Blend $\mathrm{D}$, the reactivity at the conditions of the thermodynamically favorable reactant mixtures (i.e., the green dots) is always lower than that of the uninhibited system (curve for $X_{a}=0$ ). That is, adding the suppressant always lowers the reactivity for any initial fuel-air stoichiometry.
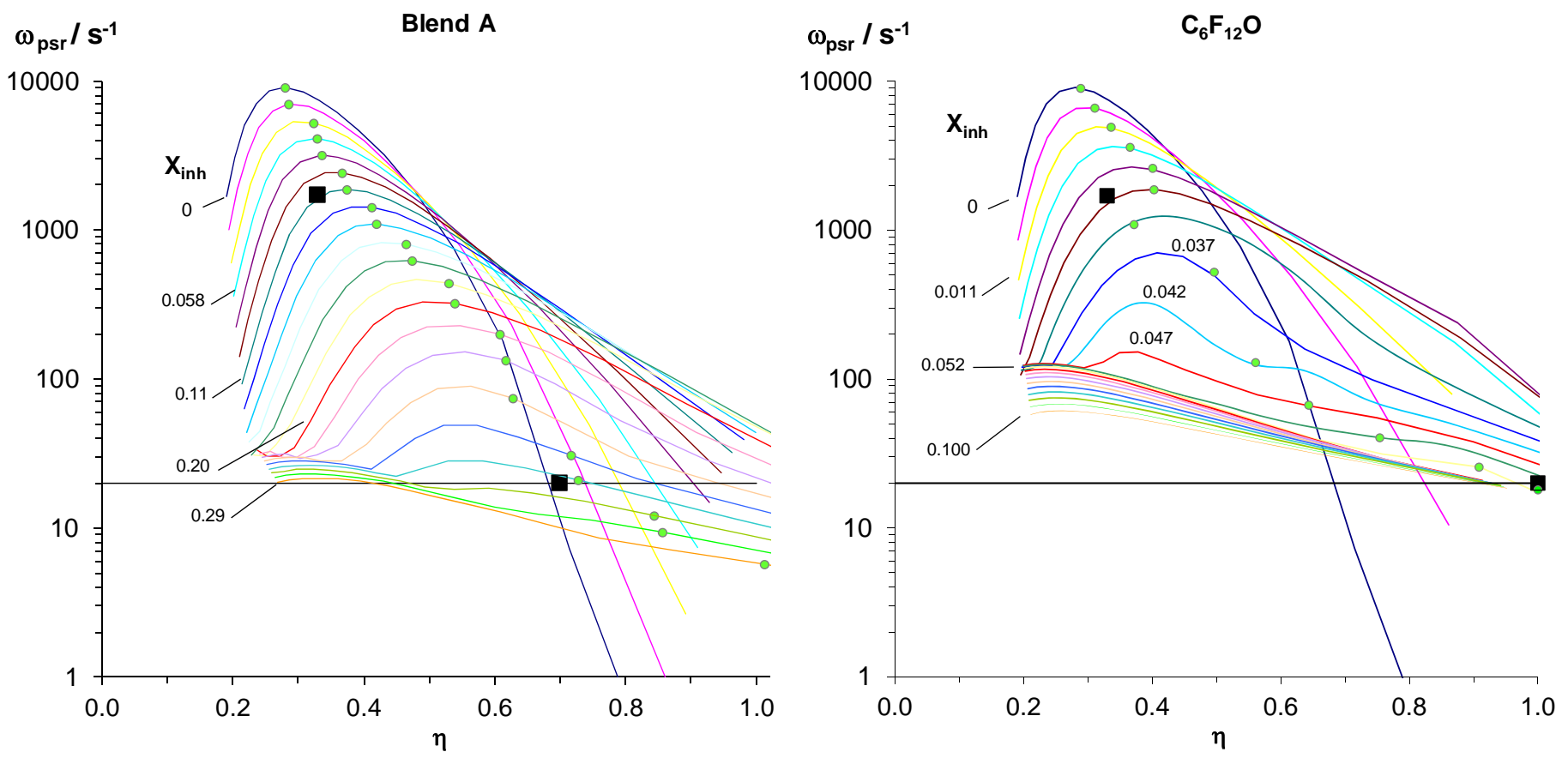

Figure 24 - Calculated stirred-reactor overall reaction rate $\omega_{p s r}$ as a function of $\eta$, the fraction of chamber volume involved in combustion. Each curve refers to a different value of the agent volume fraction $X_{a}$ in the chamber (left frame: Blend $A$; right frame, $\mathrm{C}_{6} \mathrm{~F}_{12} \mathrm{O}$ [4]).
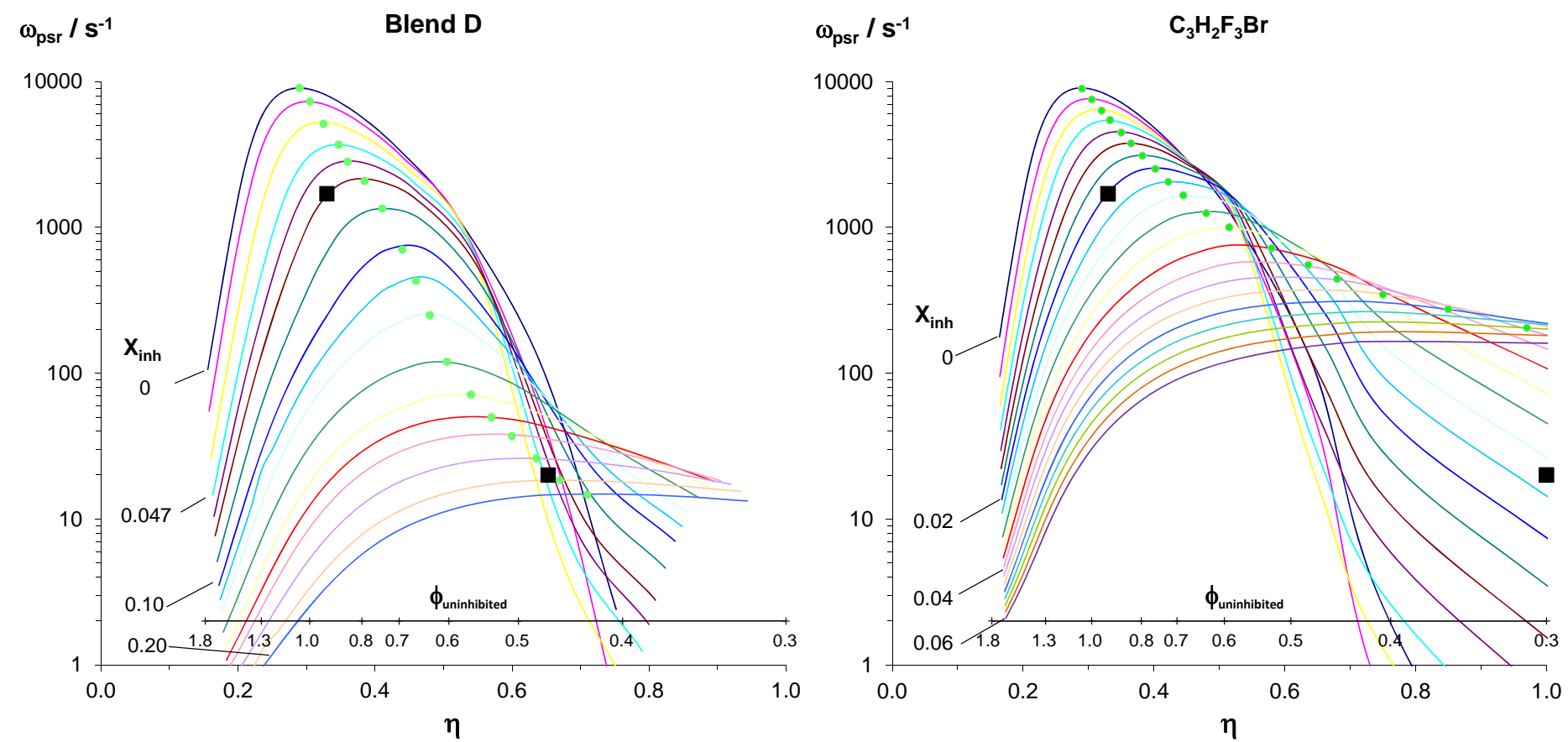

Figure 25 - Calculated stirred-reactor overall reaction rate $\omega_{p s r}$ as a function of $\eta$, the fraction of chamber volume involved in combustion. Each curve refers to a different value of the agent volume fraction $X_{a}$ in the chamber (left frame: Blend $\mathrm{D}$; right frame, $\mathrm{C}_{3} \mathrm{H}_{2} \mathrm{~F}_{3} \mathrm{Br}$ [5]). 
The effect of agent addition on overall reactivity can be shown more clearly by replotting the data of Figure 24 and Figure 25 in alternative format. Figure 26 shows $\omega_{p s r}$ as a function of $X_{a}$ (top frames: left $\mathrm{C}_{6} \mathrm{~F}_{12} \mathrm{O}$; right $\mathrm{C}_{3} \mathrm{H}_{2} \mathrm{~F}_{3} \mathrm{Br}$; bottom frames: left Blend $\mathrm{A}$, right Blend $\mathrm{D}$ ). In these frames, each curve refers to a specific value of $\eta$ (or equivalently, the equivalence ratio of the uninhibited mixtures $\phi_{\text {uninhibited }}=0.29 / \eta$, as listed on the labeled curves). The horizontal line at $\omega_{p s r}=20 \mathrm{~s}^{-1}$ indicates the value of $\omega_{p s r}$ at which no reaction is expected anywhere in the FAA-ACT chamber (i.e., this is the overall rate necessary for inertion of all reaction, even at very low strain). For $\mathrm{C}_{6} \mathrm{~F}_{12} \mathrm{O}$ (top left frame) with little fuel (i.e., high eta), the curve for $\eta / \phi=0.90 / 0.32$ indicates that at low agent loadings, adding agent increases the reactivity, while for $X_{a}>0.025$, it drops, so that at $X_{a}=0.06$, the mixture is predicted to be inert, even for low-strain flames in the FAA-ACT. The reactivity is relatively constant (and close to the inerting value) for $0.06 \leq X_{a} \leq 0.10$ (note that the FAA-ACT experiments were only conducted at $X_{a}=0.042$ and 0.081 , with no inertion and inertion, respectively, consistent with the prediction from Figure 26). For $\mathrm{C}_{3} \mathrm{H}_{2} \mathrm{~F}_{3} \mathrm{Br}$ (top right frame in Figure 26), the curve for $\eta / \phi=1.06 / 0.27$ indicates that the reactivity of the mixture is also increased with agent addition at low loading, such that the mixture is predicted to burn for low-strain conditions of $0.028 \leq X_{a} \leq 0.06$ (i.e., mixtures with $X_{a}=0.06$ will not be inerted, as was experienced in the FAA-ACT experiments).

For Blend A (bottom left frame in Figure 26) the curve for fuel-lean condtions $(\eta=1.0 / \phi=0.28)$ indicates that increasing $X_{a}$ makes the system more flammable, and brings it above the threshold for reactivity in the FAA-ACT $\left(\omega_{p s r}=20 \mathrm{~s}^{-1}\right)$; indeed, this is generally true for $\phi_{\text {uninhibited }}=>0.65$ : adding Blend A increases the reactivity of the system, and brings it above the overall reaction rate for inertion $\left(\omega_{p s r}=20 \mathrm{~s}^{-1}\right)$. In contrast, adding Blend $\mathrm{D}$ at the most dilute condition simulated (with regard to fuel from the aerosol can, $\eta=0.87 / \phi=0.48$ ), does not bring $\omega_{p s r}$, above the overall reactivity necessary for burning of the low-strain flames $\left(\omega_{p s r}=20 \mathrm{~s}^{-1}\right)$. Hence, Blend D is not expected to cause overpressure in the FAA-ACT.

Using Figure 24 and Figure 25, the expected inertion values for Blend A and Blend D in the FAA-ACT can be estimated. For example, in the figures, the curves (i.e., the value of $X_{a}$ ) for which $\omega_{p s r}$ is lower than that for inertion $\left(\omega_{p s t}=<=20 \mathrm{~s}^{-1}\right)$ at the expected mixing condition (i.e., the green dots) provides the inertion value. For Blend $\mathrm{A}$ and Blend $\mathrm{D}$, these are $X_{a}=0.27$ and $X_{a}=0.19$. These values are very close to the estimates from the 2-L explosion vessel (0.27 and 0.18), which is remarkable since: 1 . the overall PSR rate for inertion $\left(\omega_{p s r}=20 \mathrm{~s}^{-1}\right)$ is a rough estimate based on previous calculations [3-5] and experimental results in the FAA-ACT [1,63], and 2. the inerting volume fraction of Blend A and Blend $\mathrm{D}$ determined from the 2-L chamber are not resolved very well in the experiments, but rather, read from extrapolations of the curves in Figure 13 and Figure 14.

It is also possible that Blend D will inert the FAA-ACT at a lower volume fraction than $X_{a}=0.19$. In Figure 25, the volume fraction of Blend D estimated to extinguish the turbulent flame near the location of the fuel release and igniter (the upper black square in the figure) is estimated to be $X_{a}=0.11$. Physical locations away from this region have two differences: more diluted reactants (i.e., less fuel from the aerosol can), and lower strain (lower velocity gases). Further from the region of peak reactivity near ACT fuel release, the ACT fuel is diluted by the air/agent mixture, lowering the reactivity of the mixture; however, further from that region of explosive fuel release, the strain rate is lower, so that more agent is required to extinguish flames at that flow condition. See, for example, Figure 27 [64] which show the calculated agent volume fraction for extinction of a counterflow diffusion flame of methane-air, as a function of the strain rate. As indicated, the low-strain flames 
require more agent for extinction. It is not possible to know the complex way in which these two effects act, but if reaction rate is lowered (due to slower kinetics) faster than the agent requirement increases (because the lower strain flames require more agent), then the flames will extinguish at the lower value of $X_{a}=0.11$.
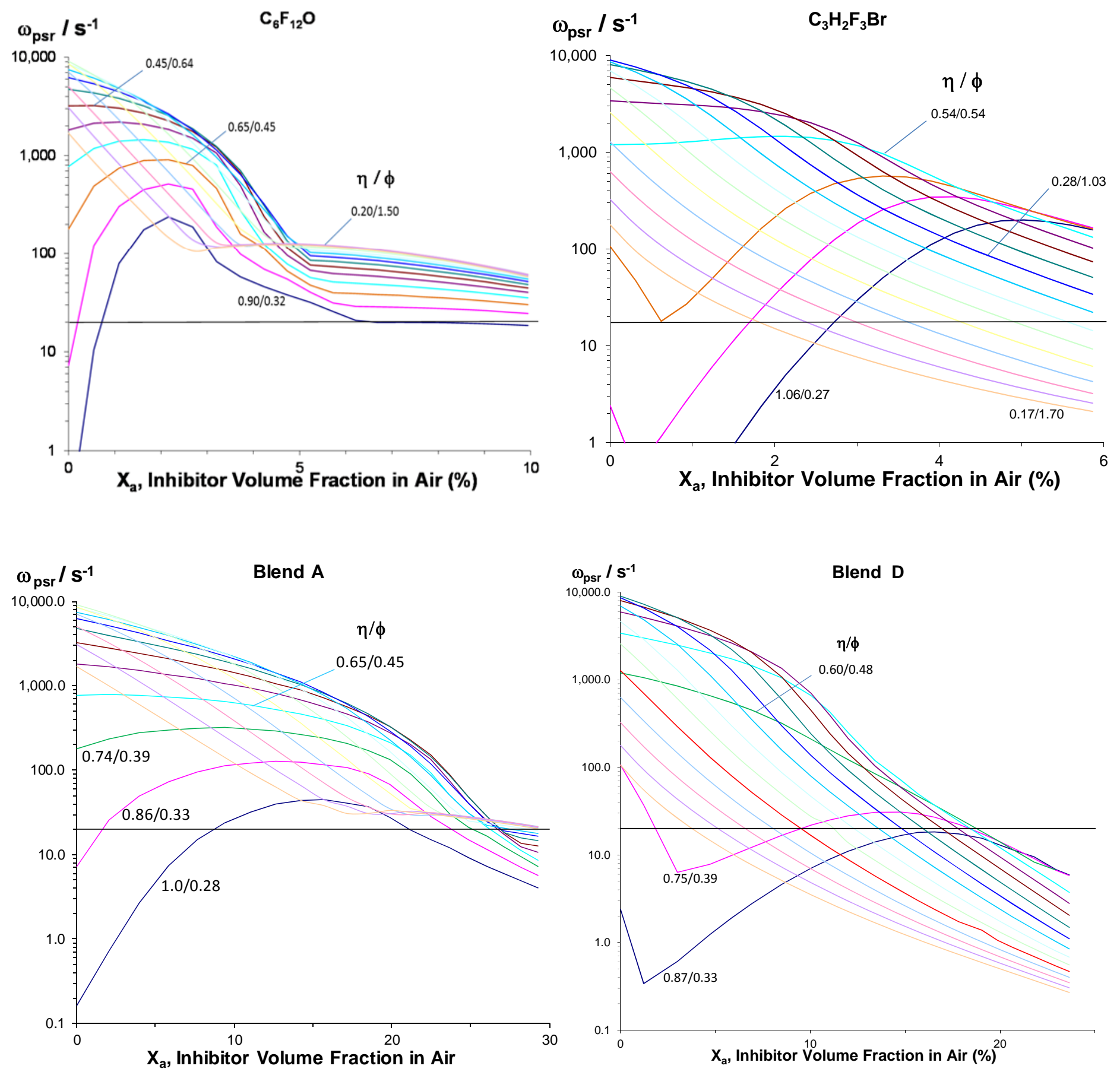

Figure 26 - Stirred reactor overall reaction rate as a function of inhibitor volume fraction in the FAA-ACT. Each curve refers to a different value of the fraction of chamber volume allowed to react with the fixed quantity of aerosol can test fuel (i.e., a different initial equivalence ratio of the uninhibited mixture) (top frames: left, $\mathrm{C}_{6} \mathrm{~F}_{12} \mathrm{O}$, right, $\mathrm{C}_{3} \mathrm{H}_{2} \mathrm{~F}_{3} \mathrm{Br}$; bottom frames: left, Blend $\mathrm{A}$, right Blend D). 


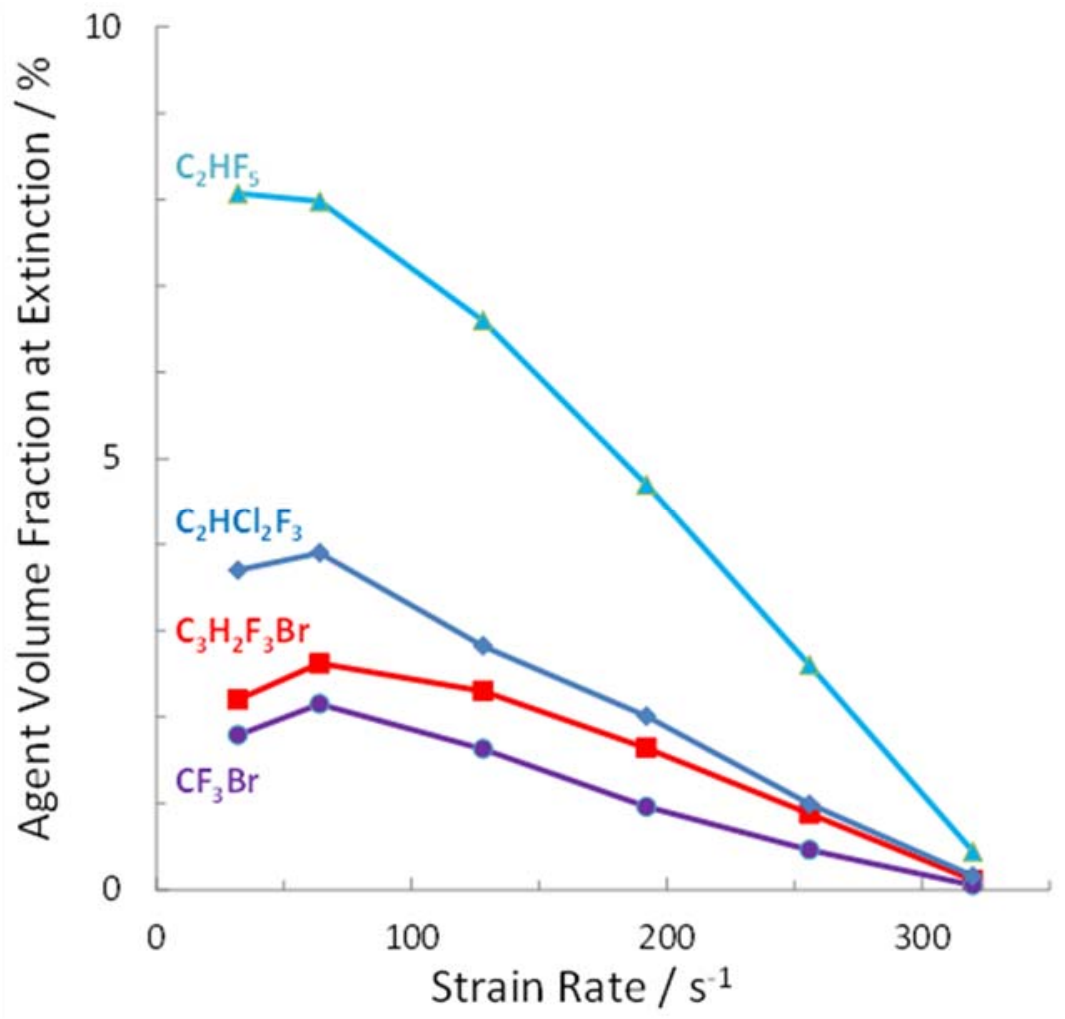

Figure 27 - Agent volume fraction at extinction vs. strain rate for a methane-air flame [64].

The potential for combustion enhancement by Blend A and Blend D has been explored above via experimental measurements of the explosion pressure in the 2-L combustion chamber, and via simulations of the equilibrium flame temperature and pressure and the stirred reactor overall reaction rate. In the section below, premixed burning velocity calculations and measurements are used to obtain additional insight, and further validate the kinetic mechanisms used for the simulations.

\subsection{Premixed Flame Burning Velocities}

\subsubsection{Inhibited Hydrocarbon-air Flames}

Figure 28 shows the calculated 1-D, laminar, unstretched burning velocity of premixed $\mathrm{C}_{3} \mathrm{H}_{8}$-air flames (initial conditions: 1 bar, 298 K, 100 \% r.h.) with added Blend A (left fame) or Blend D (right frame). Results are shown for equivalence ratios of the mixture (before addition of agent) of 1.0, 0.6, 0.55 , and 0.5. As described above, the accurate performance of the kinetic mechanisms for $\mathrm{C}_{6} \mathrm{~F}_{12} \mathrm{O}$ and $\mathrm{C}_{3} \mathrm{H}_{2} \mathrm{~F}_{3} \mathrm{Br}$ flame inhibition has been demonstrated in previous work [11,62]. As additional illustration of the accuracy in the present work, their effect on the burning velocity of premixed, moist, $\mathrm{C}_{3} \mathrm{H}_{8}$-air flames was determined using the 2-L chamber (as described above). Figure 29 shows the calculated (lines) and measured (points) burning velocity for addition of Blend A (left frame) and Blend D (right frame). As indicated, for the stoichiometric flames, the agreement is excellent, while for the lean $(\phi=0.6)$ flames, the experiments provide a slower burning velocity (by about $3 \mathrm{~cm} / \mathrm{s}$ ), for both neat mixtures and with a Blend A loading of $X_{a}=0.10$. As has been discussed [11, 62], this is likely due to radiative heat losses, which are a large fraction of the total heat release for slow burning flames. Nonetheless, the relative reduction in burning velocity caused by addition of Blend A is accurately predicted, as shown in Figure 30, which shows the data of Figure 29 as the normalized 
burning velocity (in which the burning velocity is normalized by the burning velocity of the uninhibited mixture at the same stoichiometry). As indicted, the effect of adding either agent is well captured in the simulations performed. Note that for Blend D in the lean flame $(\phi=0.6)$, the available spark ignition energy (estimated to be $500 \mathrm{MJ}$ ) was not powerful enough to initiate reaction (as observed when pure $\mathrm{C}_{3} \mathrm{H}_{2} \mathrm{~F}_{3} \mathrm{Br}$ was added to lean propane-air flames [11]).

As indicted in Figure 28, Figure 29, and Figure 30, Blend A is about half as effective on a molar basis as Blend D when added to stoichiometric flames; moreover, Blend $\mathrm{A}$ is predicted to increase the burning velocity when added to flames of $\phi<=0.6$. This may lead to overpressure in the FAA-ACT. In contrast, addition of Blend $\mathrm{D}$ is predicted to lower the reaction rate at all initial mixture stoichiometries (i.e., it never increases the reaction rate of the mixtures). These results reinforce the results found above in the experimental tests for explosion pressure and flammability limits, as well as the simulations for equilibrium temperature and pressure, and the stirred-reactor overall rates.

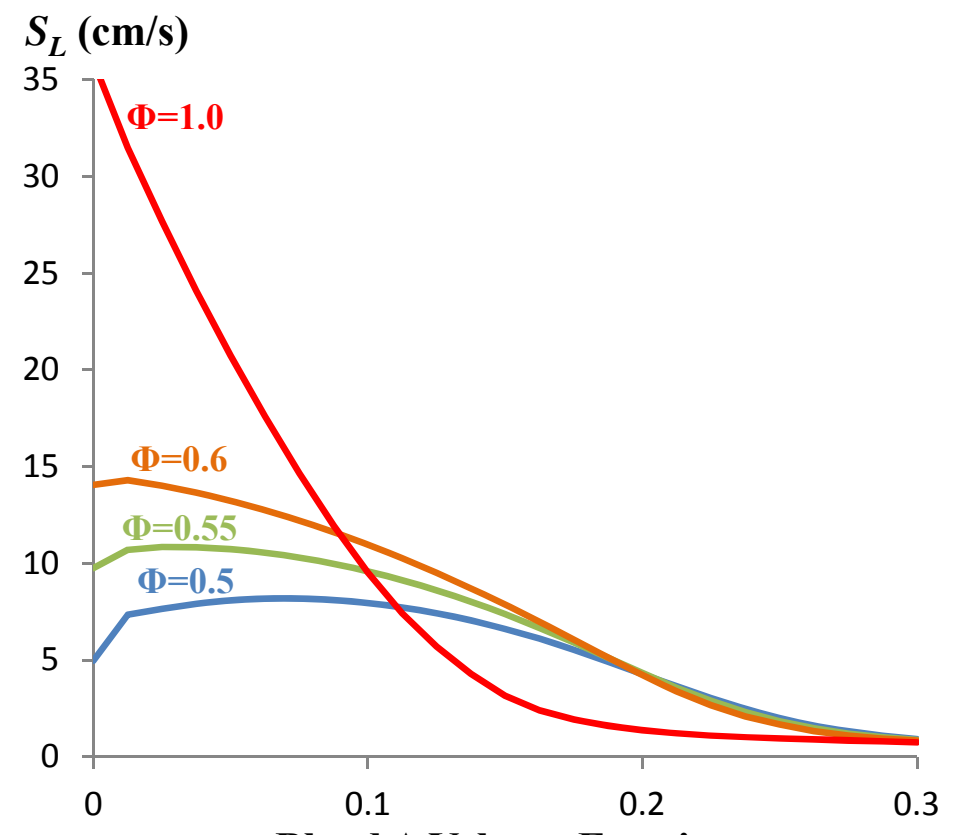

Blend A Volume Fraction

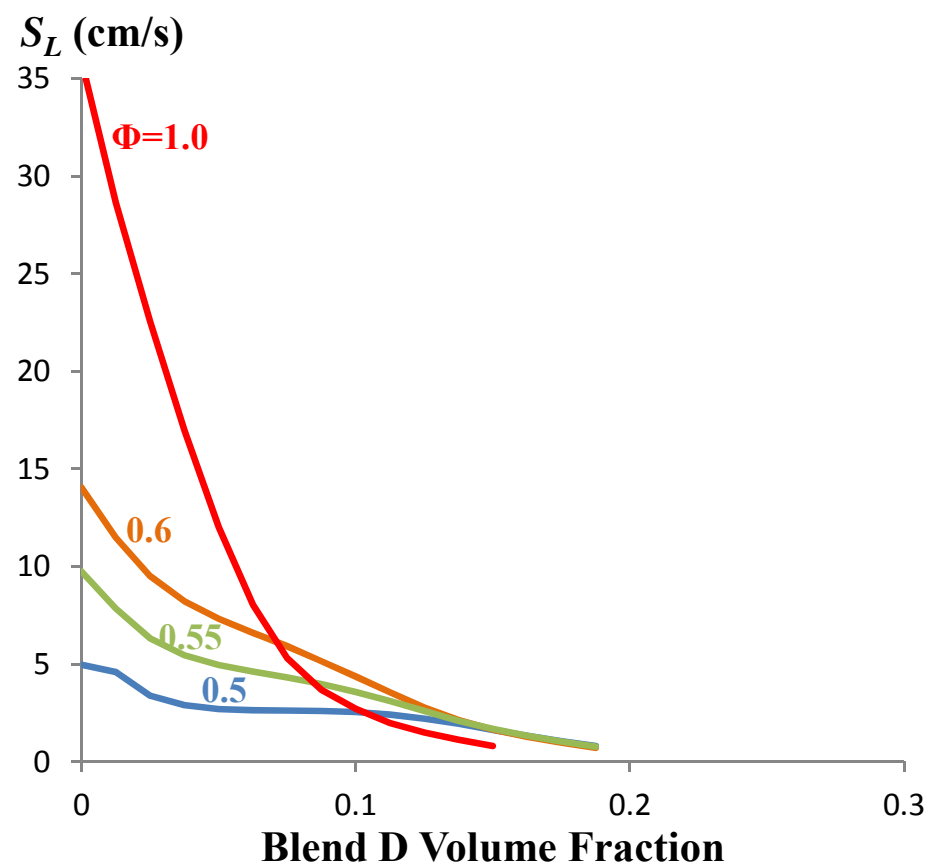

Figure 28 - Calculated unstretched laminar burning velocity of premixed, moist $\mathrm{C}_{3} \mathrm{H}_{8}$-air flames (of initial equivalence ratio $\phi$ of 1.0, 0.6, 0.55, and 0.5) with added suppressant (left frame: Blend A; right frame, Blend D). 

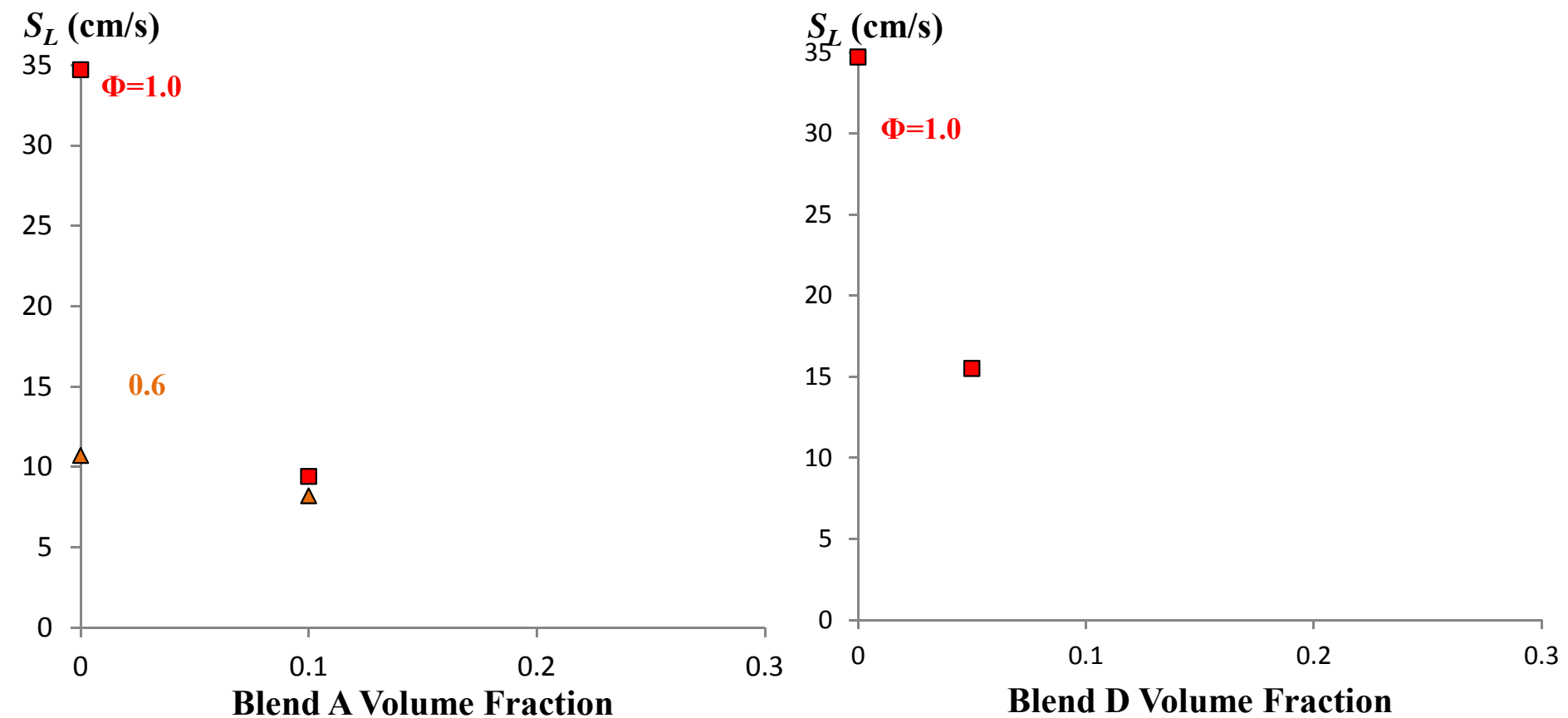

Blend A Volume Fraction

Blend D Volume Fraction

Figure 29 - Calculated (lines) unstretched and measured (points: $\square, \phi=1.0 ; \Delta, \phi=0.6$ ) laminar burning velocity of premixed, moist $\mathrm{C}_{3} \mathrm{H}_{8}$-air flames (of initial equivalence ratio $\phi$ of 1.0 and 0.6 ) with added suppressant (left frame: Blend $A$; right frame, Blend D).

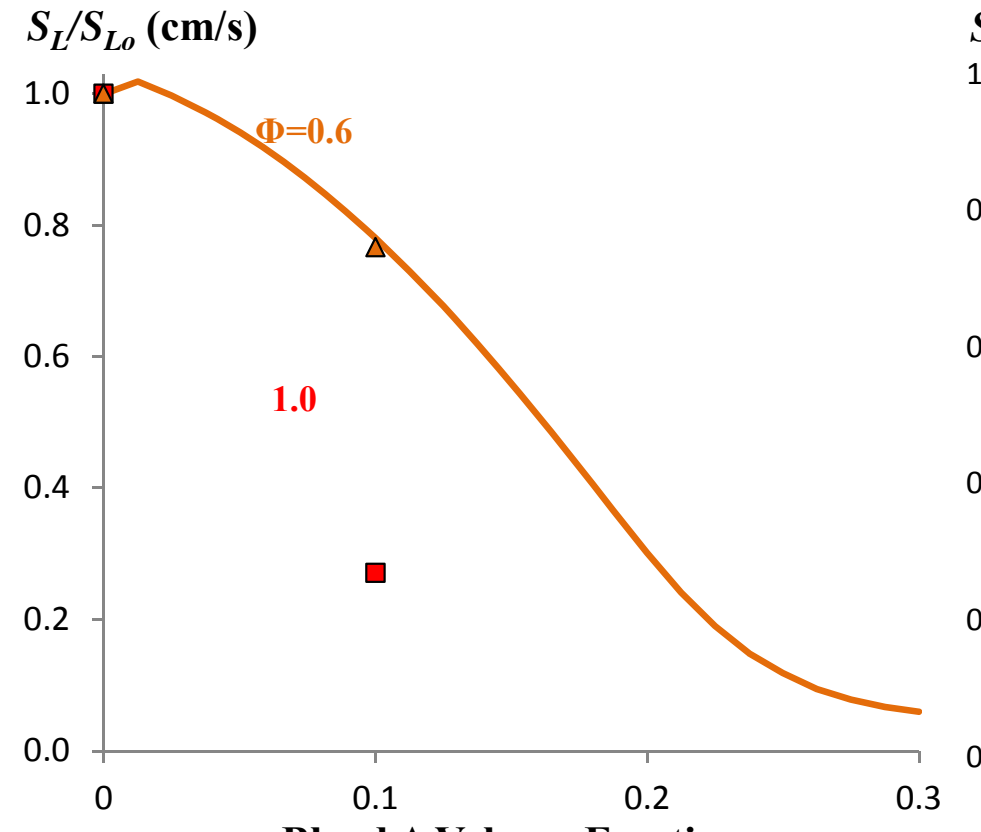

Blend A Volume Fraction

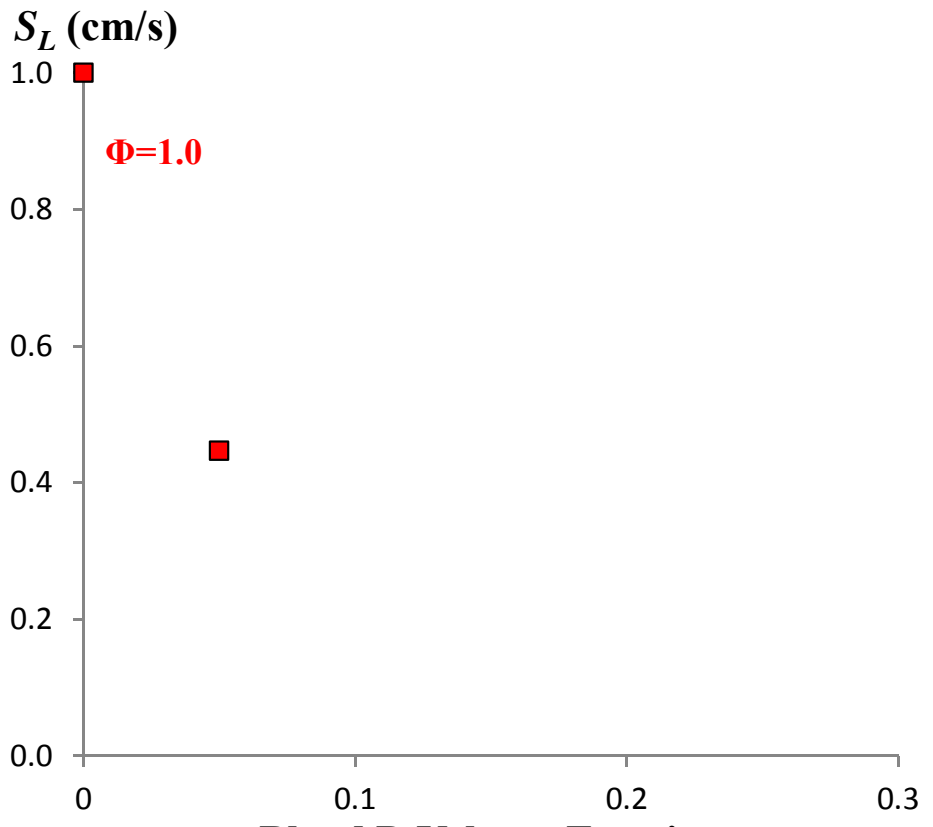

Blend D Volume Fraction

Figure 30 - Calculated (lines) unstretched and measured (points: $\square, \phi=1.0 ; \Delta, \phi=0.6$ ) laminar burning velocity, normalized by the uninhibited value, for premixed, moist $\mathrm{C}_{3} \mathrm{H}_{8}$-air flames (of initial equivalence ratio $\phi$ of 1.0 and 0.6) with added suppressant (left frame: Blend A; right frame, Blend D). 
The pure compounds $\mathrm{C}_{6} \mathrm{~F}_{12} \mathrm{O}$ and $\mathrm{C}_{3} \mathrm{H}_{2} \mathrm{~F}_{3} \mathrm{Br}$ and their blends (Blend $\mathrm{A}$ and Blend $\mathrm{D}$ ) were found to be non-flammable in the 2-L tests described above. The present simulations predict a peak burning velocity of $0.14 \mathrm{~cm} / \mathrm{s}$ for pure $\mathrm{C}_{6} \mathrm{~F}_{12} \mathrm{O}$-air at $308 \mathrm{~K}$ and $100 \%$ r.h. and $1.4 \mathrm{~cm} / \mathrm{s}$ for pure and $\mathrm{C}_{3} \mathrm{H}_{2} \mathrm{~F}_{3} \mathrm{Br}-$ air at $300 \mathrm{~K}$ and $100 \%$ r.h. (note that the high values of r.h. are selected because these are the most flammable conditions for pure agent-air mixtures). These low calculated burning velocities for pure $\mathrm{C}_{6} \mathrm{~F}_{12} \mathrm{O}$ - and $\mathrm{C}_{3} \mathrm{H}_{2} \mathrm{~F}_{3} \mathrm{Br}$-air flames are consistent with the non-ignition in the 2- $\mathrm{L}$ chamber tests with the platinum igniter. It is not necessary to calculate the burning velocities of Blend A-air and Blend D-air mixtures at near-room temperature conditions: if the pure agents had very low values of $S_{L}{ }^{0}$ at these conditions, the agents diluted with $\mathrm{CO}_{2}$ will have even lower burning velocities. Again, the predicted burning velocities are consistent with the lack of ignition of the mixtures in the 2-L chamber at $295 \mathrm{~K}$. Nonetheless, the flammability of the pure agent-air mixtures must be considered at higher temperature.

In the FAA-ACT, the end-gases are compressed by combustion of the earlier-burning reactants, thus increasing the temperature of the end-gases. For example, Figure 31 shows the calculated temperature from an adiabatic compression of the gases in the FAA-ACT (air or air and fuel) to the indicated final pressure [64]. The arrows illustrate the final pressure which would be experienced in the chamber at a value of $X_{a}$ just below the measured inertion point for each agent. As shown, for addition of HFC-125, Novec, or 2-BTP, the compressed end-gases can have initial temperatures of around $455 \mathrm{~K}, 480 \mathrm{~K}$, or $515 \mathrm{~K}$, respectively.

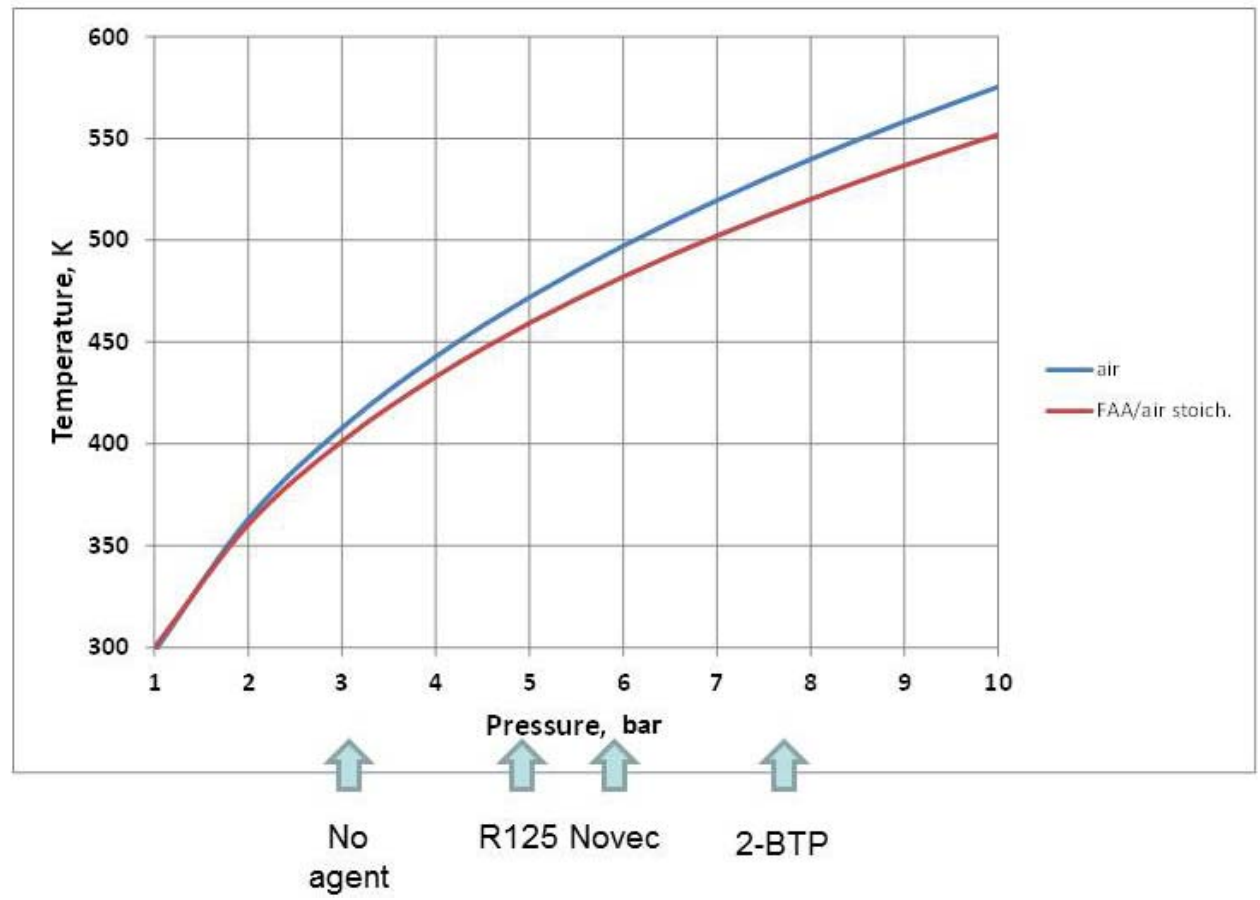

Figure 31 - Temperature of gases in the FAA-ACT after adiabatic compression to the indicated final pressure, for air or FAA-ACT fuel with air (as noted).

In previous work, Babushok et al. [60] calculated the burning velocity for pure $\mathrm{C}_{6} \mathrm{~F}_{12} \mathrm{O}$-air and $\mathrm{C}_{3} \mathrm{H}_{2} \mathrm{~F}_{3} \mathrm{Br}$-air flames at elevated temperatures and with added water vapor, as shown in Figure 32 . 
All of these mixtures are well above $1 \mathrm{~cm} / \mathrm{s}$, and would be expected to burn in the moist, compressively heated end-gasses of the FAA-ACT. The $\mathrm{C}_{6} \mathrm{~F}_{12} \mathrm{O}$-air burning velocity has a strong temperature dependence. In previous work, Babushok et al. [60] calculated the burning velocity for pure dry $\mathrm{C}_{6} \mathrm{~F}_{12} \mathrm{O}$-air flames, and the peak calculated burning velocity was found to be $0.367 \mathrm{~cm} / \mathrm{s}$ at $400 \mathrm{~K}$ and $1.6 \mathrm{~cm} / \mathrm{s}$ at $500 \mathrm{~K}$ with dry air [60]. With water vapor, the burning velocity is higher, for example (from Figure 32) at $500 \mathrm{~K}$, increasing to about $2 \mathrm{~cm} / \mathrm{s}$ at $7 \%$ water vapor. For both of these pure agents with air, the predicted burning velocity behavior is consistent with the overpressures obtained in the FAA-ACT at high agent loadings, for which both $\mathrm{C}_{6} \mathrm{~F}_{12} \mathrm{O}$ and $\mathrm{C}_{3} \mathrm{H}_{2} \mathrm{~F}_{3} \mathrm{Br}$ in the endgasses clearly burned.

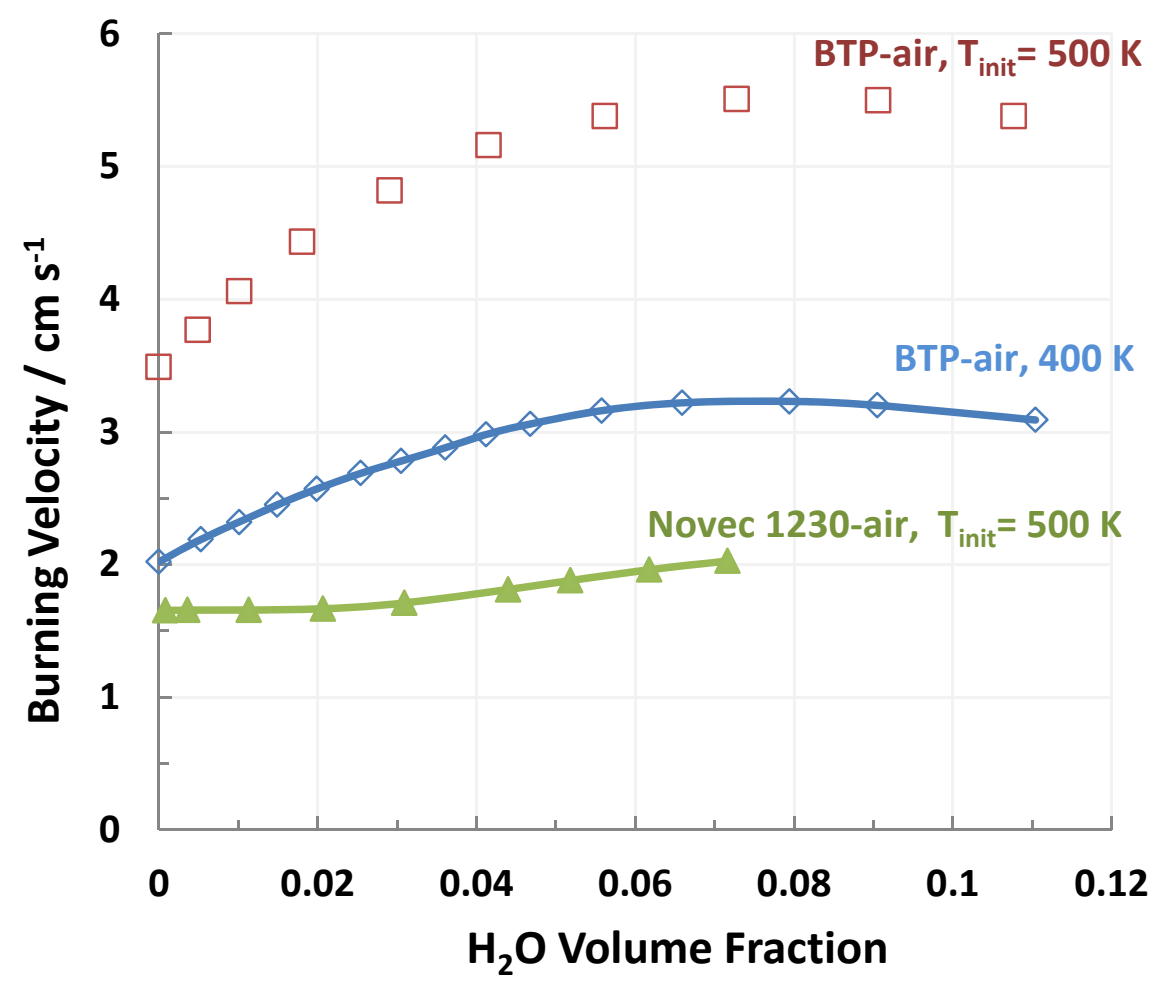

Figure 32 - Calculated burning velocity of pure $\mathrm{C}_{3} \mathrm{H}_{2} \mathrm{~F}_{3} \mathrm{Br}$-air and $\mathrm{C}_{6} \mathrm{~F}_{12} \mathrm{O}$-air flames as a function of initial temperature and water vapor content.

For Blend A and Blend D, however, the maximum overpressure (if there are no kinetic limitations) will only be 3.5 bar to 4 bar, leading to initial temperatures of about $430 \mathrm{~K}$ or $460 \mathrm{~K}$, respectively. It is useful to know the burning velocities of pure flames of Blend A or Blend D with air at the elevated initial temperatures corresponding to their potential overpressure. This will provide an assessment of the combustion propensity of the mixtures at the potential end-gas condition. Although these burning velocities could be measured (if they are high enough), our devices are not equipped for measurements at elevated temperature. Since the numerical predictions of burning velocity accurately reproduce measured values, the simulations are used to estimate the burning velocities at the heated conditions.

For the blends of these agents with $\mathrm{CO}_{2}$, the reactivities (i.e., burning velocities) in the end gases will be much lower than for the pure agents. The $\mathrm{CO}_{2}$ in the agent has two effects: lowering the temperature and reactivity at any initial temperature, and providing dilution, which reduces the compressive heating in the FAA-ACT - again lowering the reactivity. 
Figure 33 shows the calculated laminar premixed 1-D planar unstretched burning velocity $S_{L}{ }^{0}$ of Blend $\mathrm{A}$ and Blend D as a function of initial reactant temperature (at $100 \%$ r.h.). (In the figure the data points are the result of the calculations at the indicated initial temperature, while the lines are smooth curve fits to the data.) For Blend A at $430 \mathrm{~K}$, the calculated value of $S_{L}{ }^{0}$ is interpolated to be approximately $0.09 \mathrm{~cm} / \mathrm{s}$ while for Blend $\mathrm{D}$ at $460 \mathrm{~K}$, it is $0.82 \mathrm{~cm} / \mathrm{s}$. Both of these values are below the $1 \mathrm{~cm} / \mathrm{s}$ value which appeared to be the lower limit of flame propagation in the endgasses of the FAA-ACT [65]

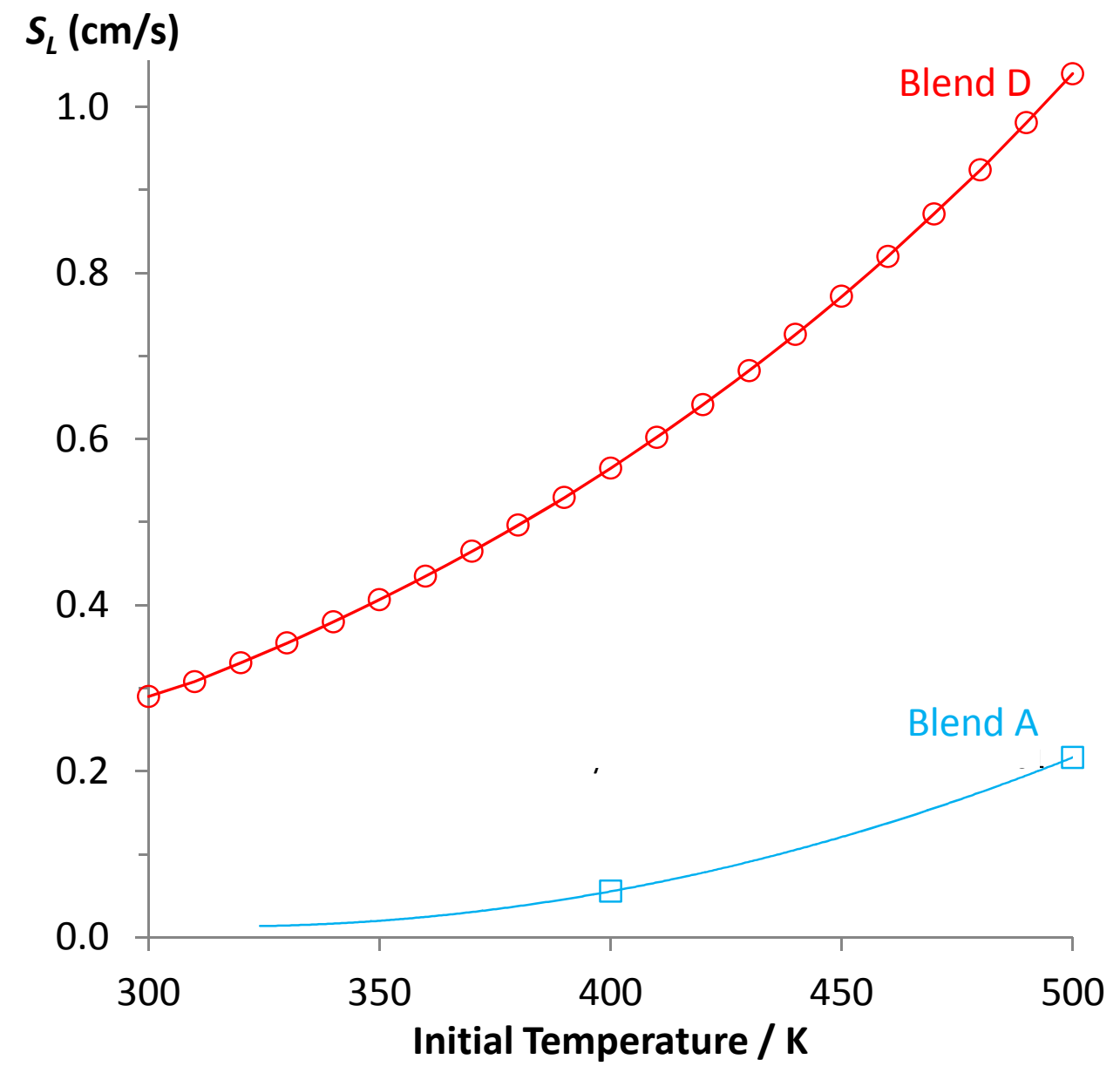

Figure 33 - Calculated laminar premixed 1-D planar unstretched burning velocity $S_{L}{ }^{o}$ of Blend D as a function of initial gas temperature. 


\section{Conclusions}

In order to understand the potential for overpressure in the FAA-ACT, experimental measurements and numerical simulations have been made. The following main points have been elucidated, and the tests or calculations leading to them are explained.

\section{The endgases of pure Blend $A$ or Blend $D$ in the FAA-ACT are not likely to combust.}

Explosion pressure tests indicate that pure $\mathrm{C}_{6} \mathrm{~F}_{12} \mathrm{O}$ or $\mathrm{C}_{3} \mathrm{H}_{2} \mathrm{~F}_{3} \mathrm{Br}$, and Blend $\mathrm{A}$ and Blend $\mathrm{D}$ in moist air are not flammable (at their most reactive stoichiometry), at $295 \mathrm{~K}$. Numerically calculated burning velocities indicate that the pure agents are flammable at temperatures expected in the compressed endgases of the FAA-ACT, and this behavior is consistent with their large overpressures in the FAAACT. For the Blends A and B, however, predicted burning velocities indicate that the blends are not flammable at the possible compressed conditions of the FAA-ACT for these agent. Hence, while the combustion of the endgases containing nearly pure agent and air will occur for the FAA-ACT, this will not happen with the blends. This characteristic will help reduce the overpressure tendency of the agents.

\section{The inerting concentrations of Blend $A$ and Blend $D$ have been determined.}

Blend $\mathrm{A}$ is predicted to inert the FAA-ACT at a volume fraction $X_{a}$ of 0.27 , and Blend $\mathrm{D}$ at $X_{a}=0.18$. This is based on the inerting concentrations in the 2-L chamber tests with the conservative Platinum igniter with moist propane-air mixtures at a range of initial fuel-air stoichiometries. Also, stirred reactor simulations independently predict inerting values in the FAA-ACT of 0.27 and 0.19 (i.e., nearly the same values). There is some chance that Blend D will inert the FAA-ACT at $X_{a}=0.11$, but it is difficult to say for certain.

\section{Blend $A$ is much more likely to cause an overpressure in the FAA-ACT than Blend $D$ (which is predicted to be effective in the FAA-ACT).}

There are many reasons for this result. As they are added to the FAA-ACT, both agents increase $\eta$ (the fraction of chamber volume involved in combustion), so the mass of combustible fuel increases as $X_{a}$ goes up. This exacerbates the overpressure potential of both agents, although the magnitude of the potential pressure rise is only half of the neat agents $\mathrm{C}_{6} \mathrm{~F}_{12} \mathrm{O}$ and $\mathrm{C}_{3} \mathrm{H}_{2} \mathrm{~F}_{3} \mathrm{Br}$. Moreover, for Blend $\mathrm{A}$, the reactivity of the lean mixtures is enhanced with agent addition. This was shown in the explosion pressure tests, the overall reaction rates calculated by the PSR simulations, and in the premixed flame speed calculations. Hence, with Blend A, the potential for overpressure from the increase in $\eta$, together with the enhanced reactivity of many of its mixtures with fuel are likely to result in overpressure (although much lower than that with added $\mathrm{C}_{6} \mathrm{~F}_{12} \mathrm{O}$ ). In contrast, Blend $\mathrm{D}$ always reduces the reactivity of the fuel-air mixture (at any value of $\phi$ ), so it has a much better chance to not cause the overpressure. For this to happen, Blend D must reduce the combustion efficiency in the chamber, on average, more effectively than its addition causes $\eta$ to go up (and the pressure rise to go up). Based on the tests results and calculations described above, it is believed that Blend D will not cause an overpressure in the FAA-ACT. 


\section{References:}

1. J. W. Reinhardt, Aircraft cargo MPS test of FK-5-1-12, in: International Aircraft Systems Fire Protection Working Group, October 25-26, 2006, Atlantic City, NJ, 2006, Federal Aviation Administration, Atlantic City, NJ,

2. G. T. Linteris, F. Takahashi, V. R. Katta, H. K. Chelliah, O. Meier, Thermodynamic analysis of suppressant-enhanced overpressure in the FAA aerosol can simulator, in: Fire Safety Science -Proceedings of the Tenth International Symposium, M. Spearpoint, (Ed.) College Park, MD, 6/19/2011, International Association for Fire Safety Science, Boston, MA, 2011, 307-320.

3. G. T. Linteris, D. R. Burgess, V. R. Katta, F. Takahashi, H. K. Chelliah, O. Meier, Combustion and Flame 159 (2012) 1016-1025.

4. G. T. Linteris, V. I. Babushok, P. B. Sunderland, F. Takahashi, V. R. Katta, O. Meier, Proceedings of the Combustion Institute 34 (2013) 2683-2690.

5. G. T. Linteris, V. Babushok, J. L. Pagliaro, D. R. Burgess Jr, J. A. Manion, F. Takahashi, V. R. Katta, P. T. Baker, Combustion and Flame, Understanding Overpressure in the FAA Aerosol Can Test by C3H2F3Br (2-BTP), accepted (2015).

6. D. R. Burgess Jr, V. I. Babushok, G. T. Linteris, J. A. Manion, International Journal of Chemical Kinetics A chemical kinetic mechanism for 2-bromo-3,3,3,-trifluoropropene (2-BTP) flame inhibition, accepted (2015).

7. V. Babushok, G. T. Linteris, D. R. Burgess Jr, P. T. Baker, Combustion and Flame 162 (2015) 1104-1112.

8. V. I. Babushok, G. T. Linteris, P. T. Baker, Combustion and Flame 162 (5) (2015) 2307-2310.

9. F. Takahashi, V. R. Katta, G. T. Linteris, V. I. Babushok, Proceedings of the Combustion Institute 35 (2015) 2741-2748.

10. J. L. Pagliaro, G. T. Linteris, P. B. Sunderland, P. T. Baker, Combustion and Flame 162 (1) (2015) 41-49.

11. J. L. Pagliaro, N. Bouvet, G. T. Linteris, Combustion and Flame, Premixed flame inhibition by $\mathrm{CF} 3 \mathrm{Br}$ and $\mathrm{C} 3 \mathrm{H} 2 \mathrm{~F} 3 \mathrm{Br}$ (2-BTP), in preparation (2015).

12. M. Metghalchi, J. C. Keck, Combustion and Flame 38 (1980) 143-154.

13. K. Takizawa, A. Takahashi, K. Tokuhashi, S. Kondo, A. Sekiya, Combustion and Flame 141 (3) (2005) 298-307.

14. R. Stone, A. Clarke, P. Beckwith, Combust. Flame 114 (1998) 546-555.

15. T. Iijima, T. Takeno, Combustion and Flame 65 (1986) 35-43. 
16. G. T. Linteris, J. L. Pagliaro, Test results prepared for Honeywell: Flammability of refrigerants in the Japanese high pressure gas law test, NISTIR 7178, National Institute of Standards and Technology, Gaithersburg MD, 2011, p 48 p.

17. J. E. Shephard, J. C. Krok, J. J. Lee, Spark Ignition Energy Measurements in Jet A, Explos. Dyn. Lab. Rep. FM 99e7, California Institute of Technology, Pasedena, CA, 1999.

18. S. P. Marshall, S. Taylor, C. R. Stone, T. J. Davies, R. F. Cracknell, Combust. Flame 158 (10) (2011) 1920-1932.

19. M. Metghalchi, J. C. Keck, Combustion and Flame 48 (1982) 191-210.

20. P. G. Hill, J. Hung, Combust. Sci. Technol. 60 (1988) 7-30.

21. B. Lewis, G. von Elbe, Combustion, Flames and Explosions of Gases, Academic, New York, 1961.

22. K. Saeed, C. R. Stone, Combust. Flame 139 (1-2) (2004) 152-166.

23. K. Eisazadeh-Far, A. Moghaddas, J. Al-Mulki, H. Metghalchi, Proceedings of the Combustion Institute 33 (1) (2011) 1021-1027.

24. G. P. Smith, D. M. Golden, M. Frenklach, N. W. Moriarty, B. Eiteneer, M. Goldenberg, C. T. Bowman, R. K. Hanson, S. Song, J. W. C. Gardiner, V. V. Lissianski, Z. Qin, GRI Mech 3.0.

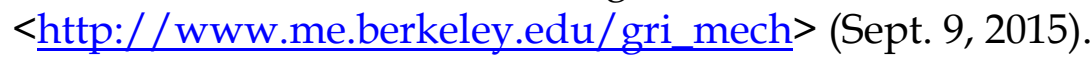

25. D. R. Burgess, M. R. Zachariah, W. Tsang, P. R. Westmoreland, Progress in Energy and Combustion Science 21 (6) (1995) 453-529.

26. D. Burgess, M. R. Zachariah, W. Tsang, P. R. Westmoreland, Thermochemical and Chemical Kinetic Data for Fluorinated Hydrocarbons, NIST Technical Note 1412, Gaithersburg, MD, 1995.

27. V. Babushok, T. Noto, D. R. F. Burgess, A. Hamins, W. Tsang, Combustion and Flame 107 (4) (1996) 351-367.

28. V. I. Babushok, D. R. F. Burgess, W. Tsang, A. W. Miziolek, Simulation studies on the effects of flame retardants on combustion processes in a plug reactor, in: Halon Replacements, W. Tsang; A. W. Miziolek, (Eds.), ACS Symposium Series 611, American Chemical Society, Washington, D.C., 1995, pp. 275-288.

29. S. Gordon, McBride, B.J., Computer program for calculation of complex chemical equilibrium compositions and applications, NASA Reference Publication 1311, Cleveland, OH, 1996.

30. F. A. Williams, A review of some theoretical considerations of turbulent flame structure, in: AGARD Conference Proceeding, AGARD-CP-164, NATO Science and Technology Organization, 1975,

31. M. Elia, M. Ulinski, M. Metghalchi, Journal of Engineering for Gas Turbines and Power 123 (1) (2001) 190. 
32. A. Moghaddas, K. Eisazadeh-Far, H. Metghalchi, Combustion and Flame 159 (4) (2012) 14371443.

33. D. Razus, V. Brinzea, M. Mitu, C. Movileanu, D. Oancea, Energy \& Fuels 26 (2) (2012) 901-909.

34. A. S. Huzayyin, H. A. Moneib, M. S. Shehatta, A. M. A. Attia, Fuel 87 (1) (2008) 39-57.

35. D. R. Dowdy, D. B. Smith, S. C. Taylor, A. Williams, Proceedings of the Combustion Institute 23 (1990) 325-332.

36. L. K. Tseng, M. A. Ismail, G. M. Faeth, Combustion and Flame 95 (4) (1993) 410-426.

37. U. J. Pfahl, M. C. Ross, J. E. Shepherd, K. O. Pasamehmetoglu, C. Unal, Combustion and Flame 123 (1-2) (2000) 140-158.

38. B. N. Taylor, C. E. Kuyatt, Guidelines for Evaluating and Expressing the Uncertainty of NIST Measurement Results, NIST Technical Note 1297, National Institute of Standards and Technology, Gaithersburg, MD, 1994.

39. I. Glassman, Combustion, Academic Press, San Diego, CA, 1996.

40. S. Kondo, Y. Urano, K. Takizawa, A. Takahashi, K. Tokuhashi, A. Sekiya, Fire Safety Journal 41 (1) (2006) 46-56.

41. M. I. Hassan, K. T. Aung, G. M. Faeth, Combustion and Flame 115 (4) (1998) 539-550.

42. G. Rozenchan, D. L. Zhu, C. K. Law, S. D. Tse, Proc. Combust. Inst. 20 (2002) 1461-1469.

43. C. H. Osorio, A. J. Vissotski, E. L. Petersen, M. S. Mannan, Combustion and Flame 160 (6) (2013) 1044-1059.

44. $\quad$ O. Park, P. S. Veloo, N. Liu, F. N. Egolfopoulos, Proc. Combust. Inst. 33 (1) (2011) 887-894.

45. C. M. Vagelopoulos, F. N. Egolfopoulos, Proceedings of the Combustion Institute 27 (1998) 513-519.

46. C. C. M. Luijten, E. Doosje, L. P. H. de Goey, International Journal of Thermal Sciences 48 (6) (2009) 1213-1222.

47. R. J. Kee, J. F. Grcar, M. D. Smooke, J. A. Miller, A fortran computer program for modeling steady laminar one-dimensional premixed flames, SAND85-8240, Sandia National Laboratories, Livermore, CA, USA, 1991.

48. P. Glarborg, R. J. Kee, J. F. Grcar, J. A. Miller, PSR: A FORTRAN program for modeling wellstirred reactors, SAND86-8209, Sandia National Laboratories, Albuquerque, NM, 1986, pp. 154 .

49. R. J. Kee, F. M. Rupley, J. A. Miller, CHEMKIN-II: A fortran chemical kinetics package for the analysis of gas phase chemical kinetics, SAND89-8009B, Sandia National Laboratories, Livermore, CA, 1989. 
50. R. J. Kee, G. Dixon-Lewis, J. Warnatz, R. E. Coltrin, J. A. Miller, A fortran computer package for the evaluation of gas-phase, multicomponent transport properties, SAND86-8246, Sandia National Laboratories, Livermore, CA, 1986.

51. S. R. Turns, An introduction to combustion : concepts and applications, WCB/McGraw-Hill, Boston, 2000.

52. F. A. Williams, Journal of Fire and Flammability 5 (1974) 54-63.

53. T. Marker, Initial development of an exploding aerosol can simulator, DOT/FAA/ARTN97/103, Federal Aviation Administration, Washington, D.C., 1998, pp. 1-16.

54. R. B. Barat, Chemical Engineering Science 56 (2001) 2761-2766.

55. S. Liu, M. C. Soteriou, M. B. Colket, J. A. Senecal, Fire Safety Journal 43 (8) (2008) 589-597.

56. H. Wang, X. You, K. W. Jucks, S. G. Davis, A. Laskin, F. Egolfopoulos, C. K. Law, USC Mech Version II. High-temperature combustion reaction model of $\mathrm{H} 2 / \mathrm{CO} / \mathrm{C} 1-\mathrm{C} 4$ compounds. $<$ http://ignis.usc.edu/USC_Mech_II.htm> (2015).

57. J. Li, A. Kazakov, F. L. Dryer, Journal of Physical Chemistry A 108 (38) (2004) 7671-7680.

58. D. L'Esperance, B. A. Williams, J. W. Fleming, Combustion and Flame 117 (4) (1999) 709-731.

59. Y. Saso, D. L. Zhu, H. Wang, C. K. Law, N. Saito, Combustion and Flame 114 (3-4) (1998) 457468.

60. V. I. Babushok, G. T. Linteris, O. Meier, Combust Flame 159 (2012) 3569-3575.

61. E. Goos, A. Burcat, B. Ruscic, Extended third millennium thermodynamic database for combustion and air-pollution use with updates from active thermochemical tables. <Ftp://ftp.technion.ac.il/pub/supported/aetdd/thermodynamics/BURCAT.THR > (August 2012).

62. J. L. Pagliaro, G. T. linteris, Fire Safety Journal, "Hydrocarbon flame inhibition by C6F12O (Novec 1230): Kinetic model validation and influence of water vapor," (2015) In Preparation.

63. J. W. Reinhardt, Behavior of bromotrifluoropropene and pentafluoroethane when subjected to a simulated aerosol can explosion, DOT/FAA/AR-TN04/4, Federal Aviation Administration, Washington, D.C., 2004, pp. 1-20.

64. G. T. Linteris, J. A. Manion, W. Tsang, D. R. Burgess Jr, V. Babushok, V. R. Katta, F. Takahashi, P. B. Sunderland, J. L. Pagliaro, Overpressure in the FAA aerosol can test with halon replacements, in: The Seventh Triennial International Fire \& Cabin Safety Research Conference, Dec. 3-5, 2013, Philadelphia, PA, 2013, Federal Aviation Administration, Atlantic City, NJ, 2013,

65. G. T. Linteris, J. A. Manion, D. R. Burgess, I. A. Awan, P. B. Sunderland, J. L. Pagliaro, Unwanted combustion enhancement by potential halon replacements: 2011 annual report, NIST Technical Note xxx, N. I. o. S. a. Technology, Gaithersburg, MD, 2011. 